\title{
MARGE TENÓRIO
}

\section{A gestão de redes de pesquisa científica, tecnológica e de inovação em saúde no Brasil}

Tese apresentada à Faculdade de Medicina da Universidade de São Paulo para obtenção do título de Doutora em Ciências

Programa de Medicina Preventiva

Orientadora: Prof ${ }^{\mathrm{a}}$. Dr ${ }^{\mathrm{a}}$. Ana Luiza D’Ávila Viana

Coorientador: Dr. Guilherme Arantes Mello

(Versão corrigida. Resolução CoPGr 6018/11, de 1 de novembro de 2011. A versão original está disponível na Biblioteca da FMUSP)

\section{São Paulo}




\section{MARGE TENÓRIO}

\section{A gestão de redes de pesquisa científica, tecnológica e de inovação em saúde no Brasil}

Tese apresentada à Faculdade de Medicina da Universidade de São Paulo para obtenção do título de Doutora em Ciências

Programa de Medicina Preventiva

Orientadora: Prof ${ }^{\mathrm{a}}$. Dr ${ }^{\mathrm{a}}$. Ana Luiza D’Ávila Viana Coorientador: Dr. Guilherme Arantes Mello

(Versão corrigida. Resolução CoPGr 6018/11, de 1 de novembro de 2011. A versão original está disponível na Biblioteca da FMUSP)

\section{São Paulo}




\section{Dados Internacionais de Catalogação na Publicação (CIP) \\ Preparada pela Biblioteca da}

Faculdade de Medicina da Universidade de São Paulo

Creprodução autorizada pelo autor para fins acadêmicos desde que citada a fonte.

\section{Tenório, Marge}

A gestão de redes de pesquisa científica, tecnológica e de inovação em saúde no Brasil / Marge Tenório. -- São Paulo, 2016.

Tese (doutorado)--Faculdade de Medicina da Universidade de São Paulo. Programa de Medicina preventiva.

Orientadora: Ana Luiza D'Avila Viana.

Coorientador: Guilherme Arantes Mello.

Descritores: 1.Políticas e cooperação em ciência, tecnologia e inovação 2.Inovação organizacional 3.Estudo multicêntrico 4.Ensaio clínico 5.Indicadores de ciência, tecnologia e inovação 6.Sistema Único de Saúde 


\section{DEDICATÓRIA}

À minha mãe Maria José, pelo incondicional amor;

Às minhas netas Mariana e Marina por rechearem minha vida de gratidão;

Aos meus filhos Juninho, Tutu e Guto, pelo permanente desejo de vê-los felizes;

Aos meus irmãos Marcos, Jabes e Jabemy eternos portos seguros. 


\section{AGRADECIMENTOS}

Além de agradecer, quero aqui festejar a amizade, a solidariedade, a cooperação e o apoio que cada amigo e colaborador me disponibilizaram durante essa jornada. A construção desta tese deriva de um percurso atravessado por adversidades, mas principalmente pautado por um desafio maior que justificou todo o esforço depreendido, devidamente superado especialmente por eu ter contado com essa grande rede de interlocução, apoio e solidariedade, presente nessa trajetória.

Foram muitas as pessoas que me incentivaram a concluir esse grande desafio, mas aqui deixo minha deferência a algumas, em especial agradecendo a:

Minha orientadora Dra. Ana Luiza D’Ávila Viana, pelo acolhimento acompanhado da contumaz disponibilidade em apontar os rumos desta pesquisa e, acima de tudo, pela confiança em me aceitar - e me acolher - como orientanda.

Ao meu coorientador Dr. Guilherme Arantes Mello, pelas variadas e providenciais intervenções para o enriquecimento da tese.

Aos grandes mestres Dr. Antônio Carlos Campos de Carvalho, Dr. Jesús P. MenaChalco e Dr. Moisés Goldbaum pelas valiosas colaborações no exame de qualificação e a sempre disponibilidade em diversos outros momentos que muito abrilhantaram este estudo.

Aos pesquisadores e gestores que aceitaram participar do estudo, fornecendo informações preciosas para o êxito deste trabalho.

Aos membros Titulares da Banca de Defesa, Dr. Antônio Carlos Campos de Carvalho, Dr. Moisés Goldbaum, Dr. Octávio Pontes Neto, e Dr. Paulo Roberto Brofman pelas reflexões e contribuições realizadas.

À minha queridíssima prima-irmã Claudinha, por tanto amor e cumplicidade. 
À Amiga Shirlene Holanda, pelas tantas acolhidas em São Paulo, pelo carinho e confiança.

Às amigas da Medicina Preventiva, pelos muitos momentos de descontração, companheirismo e incentivo: Ana Luiza Chieffi, Andréa Tenório, Camila Monteiro, Catarina Azeredo, Gina Paola e Liza Uchimura.

À Lílian Prado, pelo profissionalismo, disponibilidade e apoio às questões burocráticas da pós-graduação.

À equipe da Coordenação Geral de Pesquisa Clínica do Decit, com quem pude contar em cada momento: Camile Giaretta, Carlos Almeida, Felipe Bonifácio, Juliana Mendes, Lílian Bressan, Marcela Tibaes, Osmar Oliveira, Patrícia Boaventura, Patrícia Couto e Sérgio Nishioka.

À Faculdade de Medicina da USP, pela oportunidade de realização do doutorado.

Ao Departamento de Medicina Preventiva e ao Conselho Nacional de Desenvolvimento Científico e Tecnológico (CNPq) pela concessão de bolsa de doutorado, Processo No140687/2013-0.

Ao Departamento de Ciência e Tecnologia da Secretaria de Ciência, Tecnologia e Insumos Estratégicos do Ministério da Saúde por disponibilizar toda documentação referente à Rede Nacional de Pesquisa Clínica.

Aos familiares e amigos pela compreensão da minha ausência, bem como pelo incondicional apoio em todos os momentos que integraram este percurso.

Os meus mais profundos e sinceros agradecimentos. 


\section{EPÍGRAFE}

"Existem momentos na vida onde a questão de saber se se pode pensar diferentemente do que se pensa, $e$ perceber diferentemente do que se vê, é indispensável para continuar a olhar ou a refletir."

Michel Foucault. 
Esta tese está de acordo com as seguintes normas, em vigor no momento desta publicação:

Referências: adaptado de International Committee of Medical Journals Editors (Vancouver). Universidade de São Paulo. Faculdade de Medicina. Divisão de Biblioteca e Documentação. Guia de apresentação de dissertações, teses e monografias.

Elaborado por Anneliese Carneiro da Cunha, Maria Julia de A. L. Freddi, Maria F. Crestana, Marinalva de Souza Aragão, Suely Campos Cardoso, Valéria Vilhena. 3a ed. São Paulo: Divisão de Biblioteca e Documentação; 2011.

Abreviaturas dos títulos dos periódicos de acordo com List of Journals Indexed in Index Medicus. 


\section{SUMÁRIO}

Resumo.

Abstract. iii

Lista de abreviaturas e siglas.

Lista de figura

Lista de quadros ix

Lista de tabelas. $\mathrm{X}$

Lista de gráficos. $\mathrm{xi}$ xii

INTRODUÇÃO.

\section{CAPÍTULO 1. PESQUISA CLÍNICA NO FOMENTO À CIÊNCIA,} TECNOLOGIA E INOVAÇÃO EM SAÚDE NO BRASIL.

1.1. Introdução.

1.2. O Sistema Nacional de Inovação em Saúde.

1.3. Políticas e ações: a construção dos marcos regulatório e de incentivo à Ciência e Tecnologia

1.4. O Departamento de Ciência e Tecnologia e o fomento à pesquisa

1.5. Investimentos em Pesquisa e Desenvolvimento.

1.6. Particularidades da pesquisa clínica........................................................................ 34

1.7. Considerações finais

CAPÍTULO 2. A PESQUISA CLÍNICAS NO BRASIL: possíveis arranjos................ 42

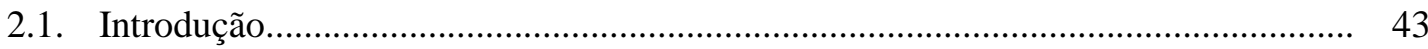

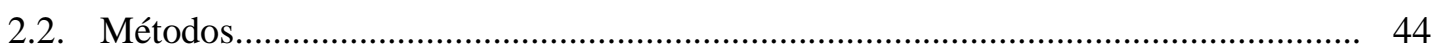

2.3. Resultados e discussão...................................................................................... 45

2.3.1. O processo regulatório e ético da pesquisa clínica no Brasil: Agência Nacional de Vigilância Sanitária - Anvisa e Comissão Nacional de Ética em Pesquisas - Conep......

2.3.2. Os ensaios clínicos na academia.

2.3.3. Ensaios Clínicos e Grupos de Pesquisas.

2.3.4. Registro de ensaios clínicos brasileiros no banco de dados ClinicalTrials.gov

2.3.5. Ensaios clínicos na base gerencial de dados do Departamento de Ciência e Tecnologia do (Decit) do Ministério da Saúde 'PesquisaSaude'. 
CAPÍTULO 3. ESTRUTURA DE PESQUISA EM REDE: o caso da Rede Nacional de Pesquisa Clínica em Hospitais de Ensino - RNPC.

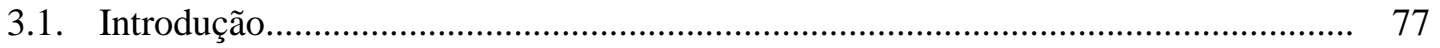

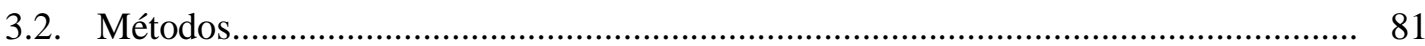

3.2.1. Tabulação e caracterização dos dados............................................................. 81

3.2.2. Métodos de análise dos dados................................................................... 82

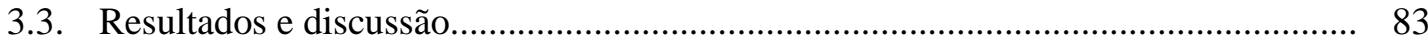

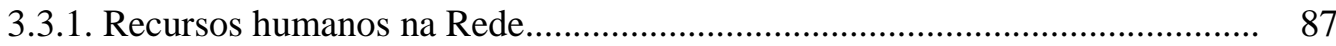

3.3.2. Especialidades e conexões............................................................................. 88

3.3.3. O fomento à pesquisa para a Rede.................................................................. 91

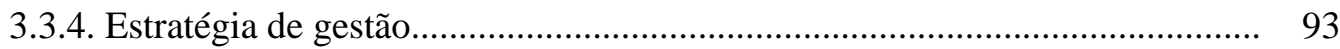

3.3.5. Desenvolvimento institucional.................................................................. 94

3.4. Considerações Finais........................................................................................... 95

CAPÍTULO 4. GESTÃO E PERCEPÇÃO DE PESQUISA EM REDE: uma visão a partir da Rede Nacional de Pesquisa Clínica em Hospitais de

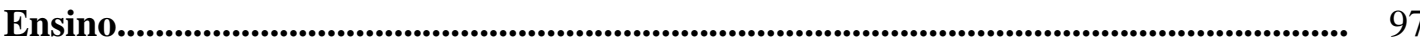

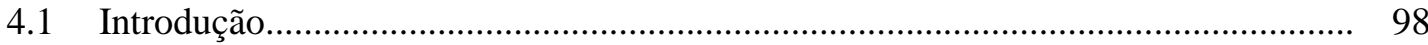

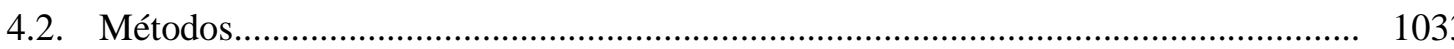

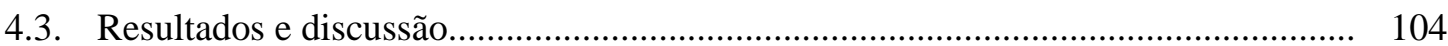

4.3.1. O valor heurístico do estudo de caso da RNPC e do arranjo multicêntrico... 104

4.3.2. Análise do caso no ambiente organizacional................................................. 105

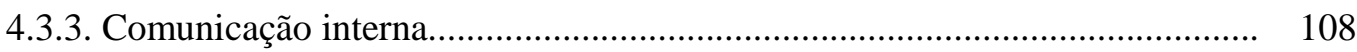

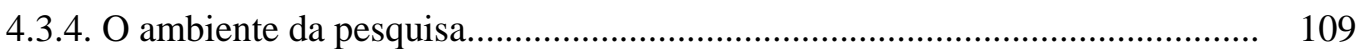

4.3.5. Fluxo organizacional da pesquisa multicêntrica e proposta de modelo........ 110

4.4. Considerações finais............................................................................................ 113

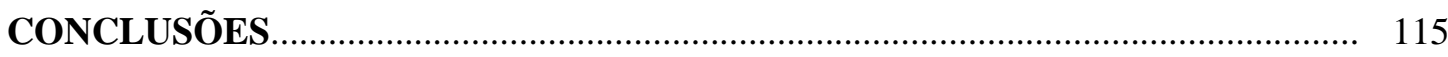

APÊNDICES

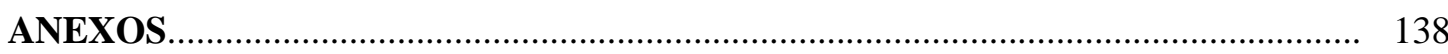

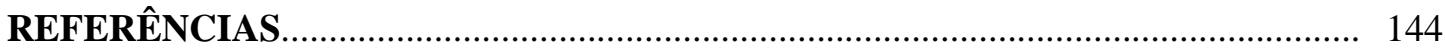


RESUMO

$\longrightarrow$ 


\section{RESUMO}

Tenório, Marge. A Gestão de Redes de Pesquisa Científica, Tecnológica e de Inovação em Saúde no Brasil [tese]. São Paulo: Faculdade de Medicina, Universidade de São Paulo; 2016.

Esta tese se pautou nas interfaces entre a estrutura do Sistema Nacional de Inovação em Saúde e o Sistema Nacional de Saúde - componentes estratégicos para os setores econômico e social do país. Abordou-se o marco jurídico institucional que dá sustentação à Ciência e Tecnologia em Saúde, envolvendo o arcabouço político que ampara a inovação tecnológica no país e os sistemas de regulação voltados a garantir sua sustentabilidade. O propósito desta pesquisa foi o de investigar as relações e os padrões que possibilitam o estabelecimento de vínculos entre os atores e ainda favorecem a formação de redes de pesquisas, buscando identificar quais os elementos que necessitam de maior foco dos gestores de forma que as conexões estabelecidas sejam fortalecidas e facilitem o monitoramento e a avaliação das redes. Caracteriza-se por ser uma pesquisa qualitativa elaborada a partir da teoria crítica, de abordagem quantitativa, incluindo um estudo de caso exploratório e analítico sobre a Rede Nacional de Pesquisa Clínica em Hospitais de Ensino, envolvendo a triangulação de métodos, baseada na observação, na análise de conteúdo e na vertente bibliográfica. Apoiou-se nas bases da Teoria Ator-Rede, ao investigar as relações e os padrões, que acabam por se configurar como vínculos entre pesquisadores e instituições. Os resultados depreendidos do estudo acrescentam novas compreensões sobre a gestão de redes de pesquisas, cuja análise se encontra hoje permeada por uma literatura centrada em atributos individuais. Ao se perceber a pesquisa clínica multicêntrica como estratégica fomentadora de inovação para saúde, esta tese delineou alternativas de gestão para expandir as conexões relacionais passíveis de fomentar, ampliar e fortalecer o Sistema Nacional de Ciência, Tecnologia e Inovação em Saúde e suas associações com as necessidades do Sistema Único de Saúde.

Palavras-chave: Políticas e Cooperação em Ciência, Tecnologia e Inovação; Inovação Organizacional; Estudo Multicêntrico; Ensaio Clínico; Indicadores de Ciência, Tecnologia e Inovação; Sistema Único de Saúde. 
ABSTRACT 


\begin{abstract}
Tenório, Marge. Managing Science, Technology and Innovation in Health Research Networks in Brazil (Thesis). São Paulo, School of Medicine, University of São Paulo; 2016.

This thesis is based on the interfaces between the Brazilian National System for Innovation in Health's structure and the Brazilian National Health System - strategic components for the economic and social sectors in the country. The institutional legal framework that gives support to Science and Technology in Health was referred to, considering the policies that sustain technological innovation in the country and the regulatory systems aimed at guaranteeing its sustainability. The goal of this study was to investigate the relationships and the patterns that make it possible to establish ties between actors and that also favor the formation of research networks, seeking to identify which elements require a greater focus from managers in order to strengthen the established ties and to facilitate network monitoring and evaluation. This study is a qualitative one that is elaborated upon critical theory, upon a quantitative approach, and includes an exploratory and analytical case study on the Brazilian National Network of Clinical Research in Teaching Hospitals, comprising a triangulation of methods, based on observation, on content analysis and on bibliographic lines. Upon investigating relationships or patterns, this study relied upon the bases of ActorNetwork Theory, which result in ties formed between researchers and institutions. The results gathered from the study added new insight into the management of research networks, whose analysis is currently permeated by literature centered on individual attributes. Upon perceiving multicenter clinical trials as a strategy that fortifies innovation in health, this thesis outlined management alternatives that may expand the relational connections believed to foment, increase and strengthen the Brazilian National Science, Technology and Innovation System and its associations with Brazilian Public Health System needs.
\end{abstract}

Key words: Policies and Cooperation in Science, Technology and Innovation; Organizational Innovation; Multicenter Study; Clinical Trial; Science, Technology and Innovation Indicators; Unified Health System. 


\section{LISTA DE ABREVIATURAS E SIGLAS}

ANPPS Agenda Nacional de Prioridades de Pesquisa em Saúde

Anvisa $\quad$ Agencia de Vigilância em Saúde

$A R O$

Academic Research Organization

ATS

Avaliação de Tecnologias em Saúde

BNDES Banco Nacional de Desenvolvimento Econômico e Social

BRICS Brasil, Russa, Índia, China e África do Sul

CAED Centro de Apoio de Educação à Distância

Capes Coordenação de Aperfeiçoamento de Pessoal de Nível Superior

CEIS Complexo Econômico-Industrial da Saúde

CEP Comitês de Ética em Pesquisas

CIDE Contribuição de Intervenção no Domínio Econômico

CNCTIS Conferência Nacional de Ciência e Tecnologia e Inovação em

Saúde

CNPq Conselho Nacional de Desenvolvimento Científico e Tecnológico

CNS Conselho Nacional de Saúde

$\mathrm{CO} \quad$ Centro Oeste

Conep Comissão Nacional de Ética em Pesquisas

Conitec Comissão Nacional de Incorporação de Tecnologias no SUS

Conjur/MS Consultoria Jurídica do Ministério da Saúde

CPqAM Centro de Pesquisas Ageu Magalhães

CPqRR Centro de Pesquisas René Rachou

CRO Contract Research Organization

CT\&I Ciência, Tecnologia e Inovação

CT\&I/S Ciência, Tecnologia e Inovação para Saúde

CTA Comitê Técnico Assessor

CT-Saúde Fundos Setoriais de Saúde

DALY Disability Adjusted Life Years

DDCM Dossiês de Desenvolvimento Clínico de Medicamento

Decit Departamento de Ciência e Tecnologia

ECRIN The European Clinical Research Infrastructures Network 
et al. e colaboradores

EUA Estados Unidos da América

FAP Fundações de Amparo à Pesquisa

FAP Fundação de Amparo à Pesquisa

Fapesp Fundação de Amparo à Pesquisa do Estado de São Paulo

FDA Food and Drug Administration

Finep Financiadora de Estudos e Projetos

Fiocruz Fundação Oswaldo Cruz

FMTA Fundação de Medicina Tropical do Amazonas

FNDCT Fundo Nacional de Desenvolvimento de Ciência e Tecnologia

FNS Fundo Nacional da Saúde

FUC Fundação Universitária de Cardiologia

Funasa Secretarias de Saúde dos Estados; Fundação Nacional do Índio.

FVA Fundo Verde-Amarelo

Gecis Grupo Executivo do Complexo Industrial da Saúde

GM/MS Gabinete do Ministro, Ministério da Saúde

HC Hospital de Clínicas

HCPA Hospital de Clínicas de Porto Alegre

IBGE Instituto Brasileiro de Geografia e Estatística

ICT Institutos de Ciência e Tecnologia

IFF Instituto Fernandes Figueira.

IGM Instituto Gonçalo Moniz

IMIP Instituto Materno Infantil Professor Fernando Figueira

INC Instituto Nacional de Cardiologia Laranjeiras

INCA Instituto Nacional do Câncer

INCT Instituto Nacional de Ciência e Tecnologia

INI Instituto Nacional de Infectologia Evandro Chagas

INTO Instituto Nacional de Traumatologia e Ortopedia

IOC Instituto Oswaldo Cruz

IPEA Instituto de Pesquisa Econômica Aplicada

MCTI Ministério da Ciência, Tecnologia e Inovação

MEC Ministério da Educação 


\begin{tabular}{|c|c|}
\hline MP & Medida Provisória \\
\hline MS & Ministério da Saúde \\
\hline $\mathrm{N}$ & Norte \\
\hline $\mathrm{NE}$ & Nordeste \\
\hline $\mathrm{NIH}$ & National Institutes of Health \\
\hline NLM & National Library of Medicine \\
\hline OGM & Organismo Geneticamente Modificado \\
\hline OPAS & Organização Panamericana de Saúde \\
\hline $\mathrm{P} \& \mathrm{D}$ & Pesquisa e Desenvolvimento \\
\hline $\mathrm{P} \& \mathrm{D} / \mathrm{S}$ & Pesquisa e Desenvolvimento em Saúde \\
\hline PACTI & Plano de Ação de Ciência, Tecnologia e Inovação \\
\hline PDP & Política de Desenvolvimento Produtivo \\
\hline PIB & Produto Interno Bruto \\
\hline PITCE & Política Industrial, Tecnológica e de Comércio Exterior \\
\hline PNCTIS & Política Nacional de Ciência e Tecnologia e Inovação em Saúde \\
\hline PNGTS & Política Nacional de Gestão de Tecnologias em Saúde \\
\hline PNPC & Programa Nacional das Plataformas do Conhecimento \\
\hline PNS & Política Nacional de Saúde \\
\hline PPA & Plano Plurianual \\
\hline PPSUS & Programa de Pesquisa para o SUS \\
\hline $\begin{array}{l}\text { Proadi- } \\
\text { SUS }\end{array}$ & Programa de Apoio ao Desenvolvimento Institucional do SUS \\
\hline Pronas/ & Programa Nacional de Apoio à Atenção da Saúde da Pessoa com \\
\hline PCD & Deficiência \\
\hline Pronon & Programa Nacional de Apoio à Atenção Oncológica \\
\hline PUC/RS & Pontifícia Universidade Católica do Rio Grande do Sul \\
\hline RDC & Resolução de Diretoria Colegiada \\
\hline Rebrats & Rede Brasileira de Avaliação de Tecnologia em Saúde \\
\hline Rede RUTE & Rede Universitária de Telemedicina \\
\hline RNPAVC & Rede Nacional de Pesquisas em Acidente Vascular Cerebral \\
\hline RNPC & Rede Nacional de Pesquisa Clínica em Hospitais de Ensino \\
\hline RNPCC & Rede Nacional de Pesquisa Clínica em Câncer \\
\hline
\end{tabular}


RNPDC Rede Nacional de Pesquisa em Doenças Cardiovasculares

RNPDN Rede Nacional de Pesquisas em Doenças Negligenciadas

RNPPS Rede Nacional de Pesquisa sobre Políticas de Saúde

RNTC Rede Nacional de Terapia Celular

SCTIE Secretaria de Ciência, Tecnologia e Insumos Estratégicos

SE Sudeste

SES Secretaria Estadual de Saúde

SNI Sistema Nacional de Inovação

SUS Sistema Único de Saúde

TCLE Termos de Consentimento Livre e Esclarecido

UEC Universidade Estadual do Ceará

UEM Universidade Estadual de Maringá

UF Unidade Federativa

UFBA Universidade Federal da Bahia

UFC Universidade Federal do Ceará

UFF Universidade Federal Fluminense

UFG Universidade Federal de Goiás

UFMA Universidade Federal do Maranhão

UFMG Universidade Federal de Minas Gerais

UFPA Universidade Federal do Pará

UFRGS Universidade Federal do Rio Grande do Sul

UFRJ Universidade Federal do Rio de Janeiro

UFRN Universidade Federal do Rio Grande do Norte

UnB Universidade de Brasília

Unesco Organização das Nações Unidas para o Desenvolvimento da

Educação, Ciência e Cultura.

Unesp Universidade Estadual Paulista

Unicamp Universidade Estadual de Campinas

Unisul Universidade do Sul de Santa Catarina

UPC Unidades de Pesquisas Clínicas

UPE Universidade de Pernambuco

USP Universidade de São Paulo

USP/RP Universidade de São Paulo - Ribeirão Preto 


\section{LISTA DE FIGURAS}

Figura 1 Cronologia das redes de colaborações científicas.

Figura 2 Sistema Nacional de Inovação em Saúde: Contexto políticoinstitucional e produtivo.

Figura 3 Organograma do Departamento de Ciência e Tecnologia (Decit)

Figura 4 Fases do Processo de Pesquisa e Desenvolvimento 37

Figura 5 Rede de coautoria formada a partir dos coordenadores das UPC da Rede Nacional de Pesquisa Clínica em Hospitais de Ensino.

Figura 6 Distribuição do número de ensaios clínicos, por países da América do Sul e por países BRICS, registrados no ClinicalTrials.gov.

Figura 7 Layout da base de dados gerencial do Decit 'PesquisaSaude'

Figura 8 Sociograma das Unidades de Pesquisa Clínica da Rede Nacional de Pesquisa Clínica em Hospitais de Ensino.

Figura 9 Sociograma das áreas médicas disponíveis nas Unidades de Pesquisas Clínicas segundo relatos dos integrantes.....................................................................

Figura 10 Organograma da atual estrutura de gestão da Rede Nacional de Pesquisa Clínica em Hospitais de Ensino 106

Figura 11 Modelo de fluxo das etapas para institucionalização organizacional de estudos em rede 


\section{LISTA DE QUADROS}

Quadro 1 Distribuição dos principais instrumentos políticos relacionados ao desenvolvimento científico, à pesquisa, à capacitação científica e tecnológica e à inovação, por ordem cronológica......

Quadro 2 Áreas temáticas sob análise da Comissão Nacional de Ética em Pesquisas (Conep)

Quadro 3 Distribuição das Unidades de Pesquisa Clínicas integrantes da Rede Nacional de Pesquisa Clínica ampliada, segundo instituição, cidade e região a que pertencem.

Quadro 4 Especialidades médicas disponíveis nas Unidades de Pesquisas Clínicas, segundo reportado pelos seus integrantes. 


\section{LISTA DE TABELAS}

Tabela 1 Evolução orçamentária dos gastos com medicamentos no Ministério da Saúde.

Tabela 2 Evolução situacional dos protocolos clínicos submetidos à análise da Comissão Nacional de Ética em Pesquisa - Conep, no período de 2012 a 2015

Tabela 3 Distribuição das especialidades dos grupos de pesquisas de ensaios clínicos por instituição, registrados na Plataforma Lattes.

Tabela 4 Distribuição do número de projetos fomentados pelo Ministério da Saúde e parceiros, por modalidade de fomento, no período de 2002 a 2014

Tabela 5 Distribuição de recursos por número de projetos e percentual, segundo as regiões brasileiras - Editais 2007, 2008, 2010 e 2013...... 


\section{LISTA DE GRÁFICOS}

Gráfico 1 Representação dos percentuais de investimentos em Pesquisa e Desenvolvimento nos países, frente aos aportes públicos e privados, em relação aos seus Produtos Internos Brutos.

Gráfico 2 Distribuição das dez principais áreas terapêuticas projetadas para 2016, segundo participação no mercado e crescimento de vendas (2010-2016)

Gráfico 3 Distribuição da capacidade científica e de infraestrutura para realização de ensaios clínicos, por Unidade de Pesquisa Clínica da Rede.

Gráfico 4 Distribuição de ensaios clínicos com participação do Brasil, por tamanho amostral, registrados no ClinicalTrials.

Gráfico 5 Distribuição dos estudos ao longo dos anos com participação do Brasil, registrados no ClinicalTrials.

Gráfico 6 Distribuição de estudos com participação do Brasil por tipo de financiamento considerando-se a fonte principal, registrados no ClinicalTrials.

Gráfico 7 Distribuição de estudos por tipo de fase clínica, registrados no ClinicalTrials

Gráfico 8 Distribuição do número de ensaios clínicos fomentados pelo Ministério da Saúde e parceiros, no período de 2002 a 2014 registrados no 'PesquisaSaude'.

Gráfico 9 Distribuição do número de ensaios clínicos fomentados pelo Ministério da Saúde e parceiros, segundo região do país, no período de 2002 a 2014, registrados no 'PesquisaSaude'. 
INTRODUÇÃO 


\section{INTRODUÇÃO}

O tema Ciência e Tecnologia e Inovação (CT\&I) continua provocando os mais variados questionamentos e especulações, carregando consigo questões antigas e recorrentes. Esta tese assume o propósito de conferir relevo a algumas questões de base que podem ser úteis a um amplo processo de revisão do tema para a gestão das políticas de Ciência, Tecnologia e Inovação em Saúde (CT\&I/S), bem como as suas estratégias e prioridades.

A maioria dos países, desde muito, reconhece que CT\&I constituem a base do crescimento econômico (GUIMARÃES \& VIANNA, 1994). As influências mútuas entre o sistema de inovação em saúde, os sistemas de bem-estar social e os produtos, gerados por essas conexões, que correspondem à saúde e ao desenvolvimento, ocupam um singular lócus nas políticas e nos debates políticos, fundamentando-se no conhecimento científico e ainda cooperando para que o Estado se transforme predominantemente em um consumidor dos resultados da atividade científica (QUENTAL et al., 2013); (VARGAS et al., 2015).

Entretanto, é compreensível que, durante o processo de tomada de decisões, não se analise exclusivamente o aparato científico, sendo este um dos elementos do processo, e que alguns, entre os demais aspectos, não sejam - e, possivelmente, nunca serão - cientificamente fundamentados. A explicação é que especialmente em alguns casos, a tomada de decisão pode identificar a necessidade de novos conhecimentos, demandando novas pesquisas (BARRETO, 2004); (VARGAS et al., 2015). 
Nesse sentido, algumas políticas direcionadas à Ciência e Tecnologia $(\mathrm{C} \& \mathrm{~T})$ e à Pesquisa e Desenvolvimento $(\mathrm{P} \& \mathrm{D})$ para saúde, como poderemos atestar no desenvolvimento da tese, têm-se consolidado graças ao forte estímulo à criação de estruturas organizacionais de natureza coletiva, as quais corroboram para que os diferentes atores passem a interagir e também fomentam, além de ações para formação e capacitação de recursos humanos, a execução compartilhada de projetos de pesquisa, configurando, assim, a conformação de redes com potencial para intensificar a produção de insumos estratégicos para o Sistema Único de Saúde (SUS) (CASSIOLATO \& LASTRES, 2005); (MARTINS et al., 2012).

A análise do perfil epidemiológico da população brasileira, realizada por meio do estudo carga de doenças no Brasil, permite constatar que o país vive uma transição peculiar com preponderância das doenças crônicas não transmissíveis em todas as regiões, em particular as doenças cardiovasculares, os transtornos mentais, o diabetes e a doença pulmonar obstrutiva crônica (DA COSTA LEITE et al., (2015). Tal perfil epidemiológico encadeia uma sequência de questões de saúde pública, que demandam, entre outras medidas, avaliações e pesquisas de grande porte, sugerindose, portanto, estudos em rede (COSTA, 2014).

Este trabalho assume a relevância de acrescentar abordagens importantes acerca da compreensão da gestão de redes de pesquisas, cuja análise se encontra hoje permeada por uma literatura que, segundo Marques (2007a), está centrada em atributos individuais. Recai justamente na possibilidade de identificar alternativas de gestão que incrementem as conexões relacionais que resultam em oportunidades passíveis de fomentar, expandir e fortalecer o Sistema Nacional de Ciência, Tecnologia e Inovação em Saúde e suas relações com as necessidades do SUS e o desenvolvimento do país. 
Tanto quanto as ciências, o registro sobre parcerias colaborativas na literatura é bastante antigo, segundo avalia Velho (2001). Um resgate histórico sobre esse surgimento, remetendo às redes de colaboração científica, é apresentado por Balaciere et al. (2005). Os autores expõem uma cronologia ao longo de quatro décadas (Figura 1), demarcando esse período como o de principal registro evolutivo das colaborações científicas, antecedendo à era das Tecnologias da Informação e Comunicação (TIC).

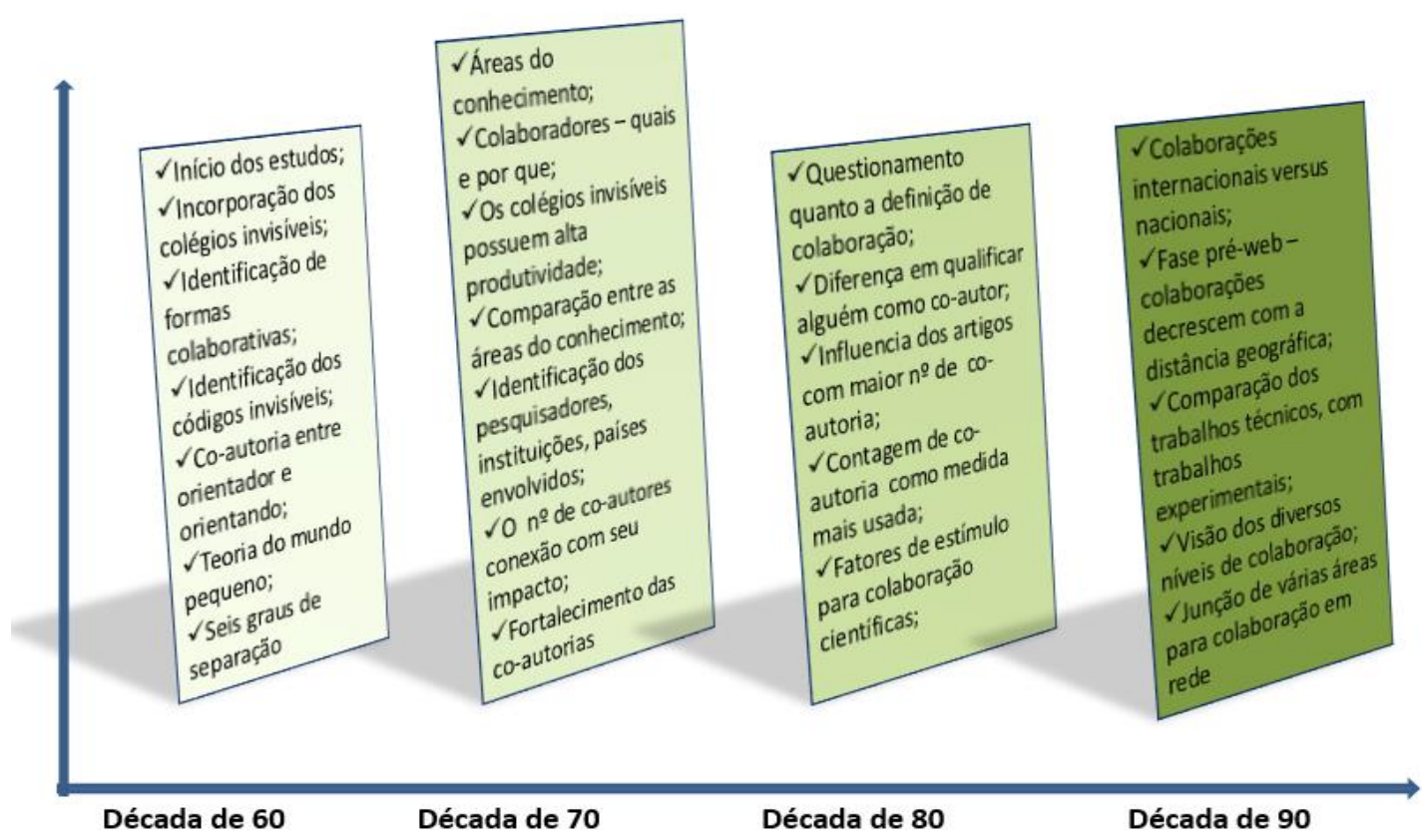

FONTE: Balaciere et al. 2005, com adaptações próprias.

\section{Figura 1 - Cronologia das redes de colaborações científicas}

Conforme ilustra a Figura 1, a década de 60 é tomada, nesta tese, como o marco referencial para o registro das coautorias e compartilhamento comum, observando-se que os primeiros estudos realizados em coautoria, apesar de registros anteriores, começam a ser de fato adotados publicamente entre os pesquisadores, os quais, por sua vez, passam também a assumir que os seus orientandos fazem parte da 
equipe, reconhecendo-os como parceiros legítimos nas produções. Nessa década também, percebe-se maior aproximação de grupos de pesquisas de instituições diferentes, bem como os primeiros ensaios métricos com relação às conexões entre autores.

Na década de 70, surge a definiçãa de cooperação como o conjunto de trabalhos desenvolvidos por dois ou mais pesquisadores, que registram, além de seus nomes, o nome de suas instituições e países. Nesse período, também, ocorreu a intensificação das atividades dos 'colégios invisíveis'" por meio das colaborações acadêmicas que possibilitavam o intercâmbio de estudantes para treinamentos em grandes centros.

Ainda na década de 70, iniciam-se os estudos de métricas cuja análise se debruçava no número de coautores em trabalhos de diferentes áreas. As publicações das ciências básicas e naturais apresentavam um número maior de autores do que as ciências aplicadas, formando uma rede de coautoria maior, enquanto o número de artigos não correspondia à mesma lógica.

Caracterizando os anos 80, a evidência de que publicar com grandes grupos promove maior visibilidade ao pesquisador perante a comunidade científica, podendo, assim, agregar maior capital social no meio acadêmico. Soma-se a isso o fato de que as colaborações passam a ser encaradas como forma de maior promoção da visibilidade entre os próprios pares. Ademais, nessa década, passaram-se a ser estabelecidos o grau e a abrangência de colaboração, se técnico ou científico e em que proporção.

\footnotetext{
1 "Colégios invisíveis" identificados nos anos 60, citado por De Solla et al. (1966), eram comunidades informais de pesquisadores que, reunindo-se periodicamente para compartilhamento de conhecimentos, experiências e informações, fomentavam a publicação formal e a disseminação dos avanços científicos.
} 
Na década de 90, evidenciou-se que as publicações internacionais são duas vezes mais citadas do que as nacionais. Outra forma de colaboração evidenciada nessa época foi o compartilhamento de equipamentos caros e de uso comum. Surge, então, um novo conceito para rede como uma associação de vínculos delicados, formada por indivíduos ou grupos ligados entre si por motivos diversos. Verificou-se ainda que, nessa época, o aparecimento de diferentes níveis de colaborações entre áreas diversas, porém complementares, sugerindo as colaborações multidisciplinares e os novos conceitos de redes de colaboração.

Nas últimas duas décadas, porém, os estudos que adotaram o modelo de redes colaborativas entre instituições vêm prosperando em quantidade e padrão. Essa evolução pode ser explicada pelo crescente número de iniciativas em fomentar esse estilo de parceria (CAMARGO, et al. (2013). No entanto, ainda não há um conceito universal sobre redes, conforme Fleury (2008:78) adverte:

Não há concordância entre os estudiosos em relação ao poder teórico do conceito de redes, visto por alguns como uma metáfora para demonstrar que as políticas públicas envolvem multiplicidade de atores diversos, já outros o aceitam como uma ferramenta analítica valiosa para o estudo das relações entre atores e poder público, enquanto um outro grupo de autores entende as redes de políticas como um método de análise da estrutura social.

O objeto desta tese não pretende ser descrito de forma rigorosa nem foi formulado a partir de uma hipótese pontual. O escopo derivou do reconhecimento de que há uma falta de entendimento sistêmico sobre a gestão de arranjos multicêntricos para execução de pesquisas e que esse hiato precisa ser superado.

Este estudo desenvolveu-se no âmbito do Departamento de Ciência e Tecnologia (Decit) da Secretaria de Ciência, Tecnologia e Insumos Estratégicos 
(SCTIE) do Ministério da Saúde e do Conselho Nacional de Desenvolvimento Científico e Tecnológico (CNPq), no período de 2012 a 2016.

O Decit, enquanto órgão fomentador de conhecimentos científicos, tecnológicos e de inovação, e também de indução à formação e capacitação de recursos humanos em Saúde, no âmbito do Sistema Único de Saúde (SUS), integra as estratégias da Política Nacional de Ciência, Tecnologia e Inovação em Saúde. É também o principal responsável por organizar a agenda de prioridades de pesquisas em saúde frente às necessidades do SUS.

Por sua vez, o CNPq é uma agência do Ministério da Ciência, Tecnologia e Inovação (MCTI), que tem por finalidade promover e fomentar o desenvolvimento científico e tecnológico do País e contribuir na formulação das políticas nacionais de ciência, tecnologia e inovação. É também de sua competência promover a realização de convênios e acordos de cooperação.

Esta tese caracteriza-se por ser uma pesquisa qualitativa fundamentalmente elaborada a partir da teoria crítica, incluindo um estudo de caso exploratório e analítico, de abordagem quantitativa (YIN, 2005). Utilizou-se o referencial teórico da gestão de ciência, tecnologia e inovação, da análise de políticas públicas (de Ciência Tecnologia e Inovação), pesquisa bibliográfica nacional e internacional, análise de dados secundários, análise documental e entrevistas com atores-chave sobre a estrutura e funcionamento de redes de pesquisas.

Aceita-se que as diversidades de fontes e de versões ou as diferenças de espaço e tempo se conformam em elementos de triangulação de pesquisa (MINAYO, 2010). A coleta de dados foi interrompida ao se observar sinais de saturação teórica (FONTANELLA et al., 2008). Realizou-se estudo-piloto para aprimorar a clareza e a 
concisão do questionário e do roteiro de entrevistas. Os dados foram transcritos e lidos exaustivamente, seguidos das devidas análises técnica e de conteúdo/enunciado (BAXTER \& JACK, 2008); (MINAYO, 2010); (BARDIN, 2011).

Apoiamo-nos nas bases da Teoria Ator-Rede ${ }^{2}$ ao investigar as relações e os padrões que se configuram como vínculos entre pesquisadores e instituições, quando estes se envolvem em atividades de pesquisa. Estudaram-se, a partir desta orientação, as relações dos atores, sendo eles humanos ou não humanos (infraestrutura física e organizacional, insumos, documentos, recursos, etc), para se compreender a dinâmica desse envolvimento (LATOUR, 2012).

A Teoria Ator-Rede exige que para se "rastrear relações mais sólidas e descobrir padrões mais reveladores [é preciso encontrar] um meio de registrar os vínculos entre quadros de referência instáveis e mutáveis” Latour (2012:45), visando “apenas" situá-las sem, no entanto, podá-las. O foco dessa teoria é direcionado ao processo "organizar" ao invés de assumir "organizações" (ALCADIPANI \& TURETA, 2009).

Ao tentar resolvê-las, no entanto, corre-se o risco de privar os atores de seus talentos. Dessa forma, as controvérsias não são obstáculos que devam ser retirados da ação, mas, sim o próprio meio pelo qual os novos arranjos possam emergir (GONZALES \& BAUM, 2013). Segundo Tureta \& Alcadipani (2009:57), um dos pressupostos dessa teoria "é o de que não há qualquer tipo de definição rígida que possa ser aplicada em todas as situações".

\footnotetext{
${ }^{2}$ Essa teoria possibilita identificar os atores que fazem parte do processo e perceber seu papel diante da interação. $\mathrm{O}$ ator nesse contexto não é a sustentação de uma ação, mas o alvo móvel de vários componentes associados. (GARCIA, 2015)
} 
A pesquisa foi registrada na Plataforma Brasil, cujo parecer consubstanciado encontra-se sob o $\mathrm{n}^{\circ}$. CAAE 15899213.0.0000.0065 (Anexo1), aprovada pelo Comitê de Ética da Faculdade de Medicina da Universidade de São Paulo em sessão do dia 29/05/2013 sob o protocolo de pesquisa número 199/13(Anexo 2), em atendimento à Resolução do Conselho Nacional de Saúde $n^{\circ} .196$, de 10/10/1996, posteriormente revogada para a Resolução CNS n. ${ }^{\circ}$ 466/2012.

Os participantes do estudo assinaram Termo de Consentimento Livre e Esclarecido (TCLE). Garantiram-se as totais confidencialidade e privacidade das informações prestadas fora do círculo da pesquisadora e orientadores. (Apêndice 1).

Os dados encontram-se armazenados em arquivos digitais e devem permanecer sob guarda por pelo menos cinco anos, conforme Resolução CNS 466/2012 e orientações do CEP/FMUSP.

Foram adquiridas autorizações formais das direções do Decit (Anexo 3) e do CNPq (Anexo 4) para assegurar o acesso aos documentos internos referentes à Rede Nacional de Pesquisa Clínica em Hospitais de Ensino (RNPC) que não estão publicados, gerados a partir do fluxo e rotina de trabalho, correspondendo a atas de reuniões, encontros científicos, memoriais, notas técnicas, pareceres.

Os documentos modelo de questionários aplicados (Apêndice 2), e roteiro de entrevistas (Apêndice 3), encontram-se disponíveis no final desta tese. Tendo em vista que foram utilizadas diferentes fontes e ferramentas na busca e análise dos dados, optou-se por detalhar as particularidades metodológicas em cada capítulo, aproximando, dessa forma, a percepção do leitor. Foram elaborados quatro capítulos, assim estruturados: 


\section{O Capítulo I: Pesquisa clínica no fomento à ciência, tecnologia e}

inovação em saúde no Brasil aborda as interfaces entre as estruturas do Sistema Nacional de Inovação em Saúde e o Sistema Nacional de Saúde como importantes componentes para os setores econômico e social do país.

Nessa direção, apresenta-se o arcabouço que promove a sustentabilidade das atividades de Ciência, Tecnologia e Inovação (CT\&I), ações regulatórias e as políticas públicas implantadas para o seu fortalecimento, além das janelas de oportunidades criadas a partir dos arranjos em rede proporcionados pela pesquisa clínica - uma das estratégias para a produção de bens e serviços de saúde.

Esse capítulo tem o objetivo de agregar relevo a algumas questões de base que podem ser úteis em um amplo processo de revisão do tema para a gestão das políticas de Ciência, Tecnologia e Inovação em Saúde (CT\&I/S), bem como suas estratégias e prioridades.

Para entender o contexto da pesquisa clínica como janela de oportunidade de fomento à inovação fez-se necessário, a priori, trazer o contexto histórico da criação do Decit no âmbito do Ministério da Saúde. Com esse intento, foi necessário demarcar determinados conceitos, ponderando-se que, enquanto estrutura formal promotora de atividades relevantes - pesquisas, disseminação de conhecimento, desenvolvimento de produtos e processos -, essa estrutura pode interagir e estabelecer vínculos, aportando conhecimento e competência específicos, em busca de um desempenho efetivamente inovador.

No capítulo 2, intitulado A pesquisa clínica no Brasil: possíveis arranjos, apresenta-se um panorama das características dos grupos de pesquisas que desenvolvem ensaios clínicos no Brasil, objetivando disponibilizar insumos para os 
gestores frente à tomada de decisão no fomento à $\mathrm{P \& D}$, além de serem identificadas possibilidades de estabelecimento de vínculos ou conexões entre as instituições e os grupos que se referenciam com capacidade para execução de ensaios clínicos, mapeados a partir da análise de três bancos de dados (Plataforma Lattes - Diretório dos Grupos de Pesquisas e Currículos Lattes; The ClinicalTrials.gov; e o PesquisaSaude).

Apresentam-se, complementarmente, dados referentes ao funcionamento e evolução do sistema ético e regulatório da pesquisa clínica no Brasil, realizados pelo Sistema CEP/ Conep e Anvisa.

Já no capítulo 3: Estrutura de pesquisa em rede: o caso da Rede Nacional de Pesquisa Clínica em Hospitais de Ensino - RNPC analisa-se a estrutura da RNPC, por meio de estudo de caso exploratório, abordando as suas características e identificando ainda o que dificulta ou possibilita empreender esforços para a execução de pesquisas clínicas bem-sucedidas.

Entre as razões pela escolha da RNPC para o estudo de caso, destaca-se principalmente o fato de se constituir um marco importante no reconhecimento institucional de caráter estratégico para o desenvolvimento do complexo produtivo da saúde nacional, além de ser uma iniciativa interministerial instituída há mais de dez $\operatorname{anos}(2005)$.

Confrontam-se relatos adquiridos por meio de questionários e entrevistas com documentos disponibilizados pelo Decit, devidamente amparados com os dados disponíveis na literatura. Apresenta-se também o posicionamento relacional entre as Unidades de Pesquisas Clínicas (UPC) componentes da Rede, bem como a capacidade de interação científica entre elas para o estabelecimento de parcerias. 
No capítulo 4: Gestão e percepção de pesquisa em rede: uma visão a partir da Rede Nacional de Pesquisa Clínica em Hospitais de Ensino procede-se a uma análise das implicações que permeiam as cooperações em rede a partir do caso da RNPC. Discute-se tanto a gestão de pesquisa associada ao nível de incremento no domínio estrutural como a necessidade de se incluir uma visão mais ampla, envolvendo os rumos e valores dos avanços tecnológicos e econômicos na percepção da pesquisa. Ambas as questões são raramente discutidas - situação que tende a prosseguir - frente ao desempenho organizacional e a disseminação do conhecimento. Nesse sentido, aborda-se o fluxo organizacional da pesquisa multicêntrica, apresentando-se uma proposta de modelo baseado na "Triplice Helix" (LEYDESDORFF \& ETZKOWITZ, 1996); (ETZKOWITZ \& LEYDESDORFF, 2000), reforçada pelo modelo II (GIBBONS et al., 2011).

Essa disposição teórica vem ao encontro dos objetivos desta tese, os quais pretenderam investigar as relações e os padrões que possibilitam o estabelecimento de vínculos entre os atores que favorecem a formação de redes de pesquisas clínicas, buscando identificar quais os elementos componentes de uma rede que necessitam de maior foco da gestão, de forma que as conexões e vínculos estabelecidos sejam fortalecidos e facilitem o monitoramento, avaliação e disseminação de conhecimentos.

Ao abordar o marco jurídico institucional que dá sustentação à P\&D e C\&T, este estudo permite que a análise seja feita a partir do nível macro, envolvendo o arcabouço político que sustenta a inovação tecnológica e os sistemas de regulação que se propõem a garantir sua sustentabilidade.

A pesquisa admite a relevância de aperfeiçoar o processo de monitoramento e avaliação do impacto da pesquisa em rede, para que os indicadores 
gerados se mostrem úteis para a melhoria da relação entre a produção científica, a produção tecnológica e a efetividade do modelo de gestão.

Ficam abertas as questões sobre a disponibilidade de infraestruturas comprovadamente adequadas para o desenvolvimento das diversas fases de ensaios clínicos, de modo a possibilitar o estabelecimento de uma rede de pesquisa clínica com capacidade efetiva para fomentar inovação e atender às necessidades do SUS.

Por fim, as discussões da tese sintetizam as análises elaboradas com base no objetivo proposto e apontam alguns desafios para novos estudos. 


\section{CAPÍTULO I}

PESQUISA CLÍNICA NO FOMENTO À CIÊNCIA, TECNOLOGIA

E INOVAÇÃO EM SAÚDE NO BRASIL 


\section{PESQUISA CLÍNICA NO FOMENTO À CIÊNCIA, TECNOLOGIA E INOVAÇÃO EM SAÚDE NO BRASIL}

\subsection{Introdução}

Este capítulo aborda a estrutura do Sistema Nacional de Inovação em Saúde (SNIS), considerando que este representa a sua interface com o Sistema Nacional de Saúde (SNS), bem como o fato de essa conexão configurar um componente importante para os setores econômico e social do país.

Para entender o argumento da pesquisa clínica como janela de oportunidade de fomento à inovação, faz-se necessário, a priori, trazer o contexto histórico da criação do Departamento de Ciência e Tecnologia no âmbito do Ministério da Saúde. Com esse intento, é imprescindível ainda demarcar determinados conceitos essenciais, ponderando-se que, enquanto estrutura formal promotora de diversas atividades relevantes - pesquisas, disseminação de conhecimento, desenvolvimento de produtos e processos -, essa estrutura interage e estabelece vínculos, aportando conhecimento e competência específicos, em busca de um desempenho efetivamente inovador (MARQUES, 1999).

Nessa direção desenha-se o arcabouço que promove a sustentabilidade das atividades de Ciência, Tecnologia e Inovação (CT\&I) e ações regulatórias instaladas no Brasil, as políticas públicas implantadas para o seu fortalecimento, além das janelas de oportunidades criadas a partir dos arranjos em rede proporcionados pela pesquisa clínica - uma das estratégias para a produção de bens e serviços de saúde. 
Sem dúvida, o tema CT\&I continua provocando as mais variadas especulações, carregando consigo questões muito antigas. Este capítulo assumiu o propósito de conferir relevo a algumas questões de base que podem ser úteis a um amplo processo de revisão do tema para a gestão das políticas de Ciência, Tecnologia e Inovação em Saúde (CT\&I/S), bem como suas estratégias e prioridades.

Em relação à abordagem acerca das possibilidades de rede, vínculo e colaborações, são apontados os atores protagonistas na indução de ações que suportam os processos. Nesse contexto, apresentam-se ainda possíveis arranjos entre os grupos que compõem a Rede Nacional de Pesquisa Clínica, demonstrando os fatores a serem considerados para o estabelecimento de parcerias que fomentem e fortaleçam o sistema de CT\&I/S no Brasil.

\subsection{O Sistema Nacional de Inovação em Saúde}

Foi no final da década de 1980 que surgiu o conceito de Sistema Nacional de Inovação (SNI) em estudos realizados por Freeman, com o propósito de explicar o desempenho econômico do Japão naquela época. Trata-se de um conjunto de diversas instituições voltadas à geração, incorporação, uso e difusão de conhecimento, tendo como fonte empresas, organizações e demais instituições envolvidas nesse processo (COSTA, 2013). Também é explorado para explicar como o conhecimento e a inovação determinam a competitividade dos países, especialmente pelo fato de esse novo conceito extrapolar o foco individualizado quando associado à análise das 
organizações. O surgimento desse conceito é atribuído aos estudos de (FREEMAN, 1987) ${ }^{3}$; (LUNDVALL, 1992) $)^{4}$ e (NELSON, 1993) ${ }^{5}$, apud (COSTA, 2013).

Para o SNIS ser devidamente fundamentado, desenvolveu-se um arcabouço teórico a partir do qual se deriva o conceito que compõe o Complexo Econômico-Industrial da Saúde (CEIS) que, por sua vez, se pauta em um projeto desenvolvimentista-social ao possibilitar a articulação entre inclusão social, consumo de massa, expansão do emprego e da renda, fortalecimento da estrutura produtiva, de processos de inovação e dos investimentos, culminando, assim, com a possibilidade de redução da dependência nacional (GADELHA et al., 2013); (GADELHA et al., 2015a).

Depreende-se de vasta literatura, portanto, que a inovação na área da saúde envolve um campo de estudos de excelência, uma vez que possui capacidade para mobilizar infraestrutura de CT\&I/S articulada com a base industrial, além de promover a sua consolidação. Ademais, é vista também como um processo político e social por fazer parte do planejamento estratégico do país, que visa à redução nacional da dependência de insumos para saúde produzidos no exterior, reforçando a economia política do país (LASTRES \& CASSIOLATO, 2007); (BOTELHO \& ALVES, 2015).

A (Figura 2) representa o Sistema Nacional de Inovação em Saúde, criada por Gadelha \& Maldonado Apud (GADELHA et al., 2013). Nela se identifica a estrutura

\footnotetext{
${ }^{3}$ FREEMAN C. Technology policy and economic performance: lessons from Japan. London: Pinter. 1987.

${ }^{4}$ LUNDVAL, Bengt-Åke. National Systems of Innovation: towards a theory of innovation and interactive learning. Pinter, London, 1992.

${ }^{5}$ NELSON, Richard R. National innovation systems: comparative analysis. New York: Oxford University Press. 1993.
} 
socioinstitucional e política de que é formada, com foco específico para o contexto produtivo da área da saúde. Segundo COSTA, 2013,

...o arcabouço político-institucional do CEIS é influenciado pela atuação do Estado (relações de poder, estrutura decisória e formulação de políticas implícitas e explícitas), instituições (desde as instituições formais de C\&T e de educação, agências de fomento e órgãos de financiamento, por exemplo, até as de normas de conduta institucionalizada na sociedade), sociedade civil organizada (órgãos e associações de classe, por exemplo) e a população em geral. (COSTA, 2013:79)

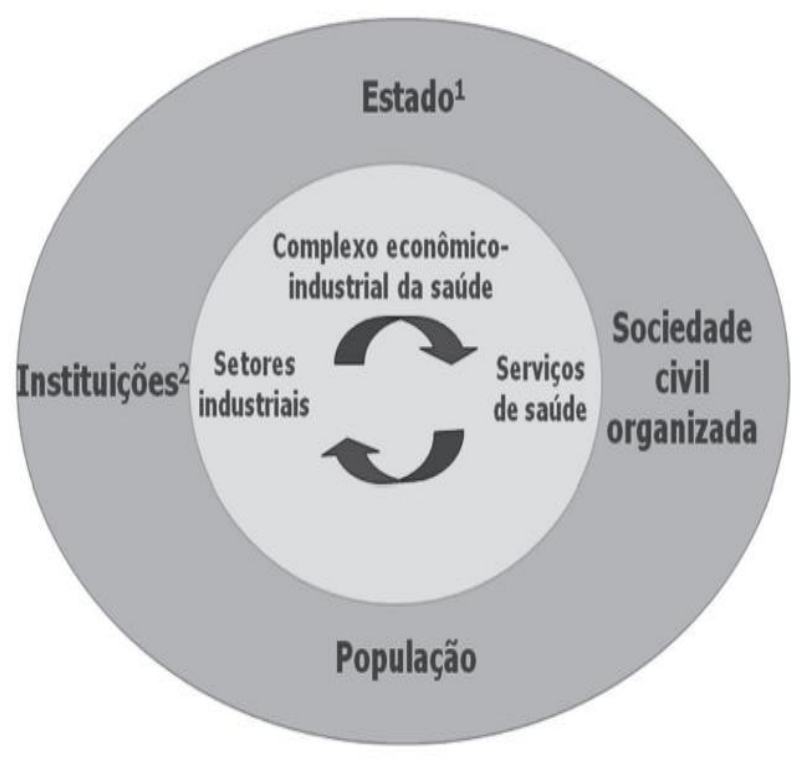

FONTE: Gadelha e Maldonado (2007). Apud Gadelha et al. (2013).

Figura 2 - Sistema Nacional de Inovação em Saúde: Contexto políticoinstitucional e produtivo

\section{Legenda:}

1. Incorpora as relações de poder, a estrutura decisória e a formulação e implementação de políticas implícitas e explícitas.

2. Desde instituições formais de C\&T e de educação, agências de fomento, órgãos de financiamento, entre outras, até de normas de conduta institucionalizadas na sociedade. 


\subsection{Políticas e ações: a construção dos marcos regulatório e de incentivo à Ciência e Tecnologia}

Entre os instrumentos e políticas que visam à sustentação das ações de CT\&I/S, neste capítulo será conferida maior ênfase à Política Nacional de Ciência Tecnologia e Inovação para a Saúde (PNCTIS), em articulação com a Política Nacional de Saúde (PNS) e com a Política Nacional de Ciência, Tecnologia e Inovação (PNCTI), por se entender que seus eixos ${ }^{6}$ e estratégias ${ }^{7}$ são instrumentos facilitadores na interface entre as ações do Estado, do mercado e da comunidade científica, em prol do Sistema Único de Saúde (SUS) (BRASIL, 2007a; 2008).

A Agenda Nacional de Prioridades de Pesquisa em Saúde (ANPPS) compreende uma das estratégias da PNCTIS e assume o relevante papel de direcionar as ações de fomento à pesquisa e à formação de recursos humanos voltados para o SUS, de forma a potencializar esforços em direção às áreas que efetivamente integram o elenco estratégico do enfrentamento aos agravos da saúde pública local e nacionalmente.

A construção da ANPPS contou com significativas contribuições da comunidade científica, gestores do setor de saúde, bem como representantes do

${ }^{6}$ Os eixos da PNCTIS são: (1) extensividade; (2) inclusividade; (3) seletividade; (4) complementaridade; (5) competitividade; (6) mérito técnico, científico e ético; (7) relevância social e econômica; (8) responsabilidade gestora; e (9) controle social, (BRASIL, 2008:19).

\footnotetext{
${ }^{7}$ As estratégias da PNCTIS são: (a) sustentação e fortalecimento do esforço nacional em ciência, tecnologia e inovação em saúde; (b) criação do sistema nacional de inovação em saúde; (c) construção da agenda nacional de prioridades de pesquisa em saúde; (d) criação de mecanismos para superação das desigualdades regionais; (e) aprimoramento da capacidade regulatória do Estado e criação de rede nacional de avaliação tecnológica; (f) difusão dos avanços científicos e tecnológicos; (g) formação, capacitação e absorção de recursos humanos no sistema nacional de ciência, tecnologia e inovação em saúde, incentivando a produção científica e tecnológica em todas as regiões do País, considerando as características e as questões culturais regionais; (h) participação e fortalecimento do controle social, BRASIL (2008:21).
} 
controle social nos segmentos da Saúde, Educação, Ciência e Tecnologia, além da área de Serviços Sociais em seminários em nível municipal, estadual, regional, e nacional, sendo finalizada na $2^{\mathrm{a}}$ Conferência Nacional de Ciência e Tecnologia e Inovação para Saúde (CNCTIS) em 2004 (BRASIL, 2006; 2007b; 2011a).

Trata-se de um instrumento político-democrático, o qual considerou em sua construção: i) a situação de Saúde e condições de vida da população brasileira sistematizado na publicação Saúde no Brasil: contribuições para a Agenda de Prioridades de Pesquisa (BRASIL, 2007a; 2007b); ii) a definição de subagendas em pesquisa - realizada por um Comitê Técnico Assessor (CTA), composto por especialistas e gestores; iii) a definição de temas de pesquisa ${ }^{8}$ elencados por grupos de trabalho para discussão em cada subagenda.

Dessa forma, a ANPPS e a PNCTIS são os instrumentos norteadores para as ações de CT\&I/S no âmbito da Secretaria de Ciência, Tecnologia e Insumos Estratégicos do Ministério da Saúde.

\footnotetext{
${ }^{8}$ A definição de temas de pesquisa ocorreu no Seminário para Construção da Agenda, realizado em 6 e 7 de novembro de 2003, em Brasília. Com base em diversas experiências internacionais, foram adotados os seguintes critérios para a definição de prioridades de pesquisa: a) carga de doença, medida por DALY (Disability Adjusted Life Years - Anos de Vida Perdidos Ajustados por Incapacidade) ou outros indicadores; b) análise dos determinantes da carga de doenças segundo os diferentes níveis de intervenção: individual, familiar, comunitário; ministério, sistema e serviços de saúde; instituições de pesquisa; políticas governamentais e outros setores com impacto na saúde; c) estado da arte do conhecimento científico e tecnológico disponível; d) custo-efetividade das possíveis intervenções e a possibilidade de sucesso; e) efeito na equidade e justiça social; f) aceitabilidade ética, política, social e cultural; g) possibilidade de encontrar soluções; h) qualidade científica das pesquisas propostas; i) factibilidade de recursos humanos e financeiros (BRASIL, 2011a: 6).
} 
Outra iniciativa que tem contribuído para mudança positiva no cenário de

C\&T no país, foi a criação dos Fundos Setoriais ${ }^{9}$ em 1999, sob gestão da Financiadora de Estudos e Projetos (Finep) do Ministério da Ciência, Tecnologia e Inovação (MCTI). Esse empreendimento assumiu mais ritmo a partir da disponibilização de um conjunto de instrumentos, políticas, programas e leis que são favoráveis ao SNI (GUIMARÃES, 2011).

Selecionou-se uma síntese cronológica dos principais instrumentos e políticas que contribuem para o fortalecimento da CT\&I/S (Quadro 1), os quais se configuram como fortes aliados para o fomento à inovação na área de saúde.

Quadro 1 - Distribuição dos principais instrumentos políticos relacionados ao desenvolvimento científico, à pesquisa, à capacitação científica e tecnológica e à inovação, por ordem cronológica

\begin{tabular}{|lll|}
\hline Ano & Instrumento & \multicolumn{1}{c|}{ Comentário } \\
\hline 1990 & $\begin{array}{l}\text { Lei no }{ }^{\circ} \mathbf{8 . 0 8 0 / 1 9 9 0} \\
\text { (Art. 15 § XIX) }\end{array}$ & $\begin{array}{l}\text { Define que cabe ao SUS fomentar pesquisas e estudos na área de } \\
\text { saúde. }\end{array}$ \\
\hline 1994 & $\mathbf{1}^{\text {a }}$ CNCTIS & $\begin{array}{l}1^{\text {a }} \text { Conferência Nacional de Ciência Tecnologia e Inovação em Saúde } \\
\text { promoveu a institucionalização do debate político sobre as } \\
\text { atribuições do SUS no fomento à P\&D/S. }\end{array}$ \\
\hline 1999 & Fundos Setoriais & $\begin{array}{l}\text { Instrumentos de financiamento de projetos de pesquisa, } \\
\text { desenvolvimento e inovação. Cabe à área de Saúde: CT-Saúde, CT- } \\
\text { infra, CT-Biotec, CT-verde/amarelo, e ainda, as denominadas "ações } \\
\text { transversais" que envolvem mais de um fundo. }\end{array}$ \\
\hline
\end{tabular}

\footnotetext{
${ }^{9}$ Há 16 Fundos Setoriais, sendo 14 relativos a setores específicos e dois transversais. Destes, um é voltado à interação universidade-empresa (FVA - Fundo Verde-Amarelo), enquanto o outro (CT-infra) é destinado a apoiar a melhoria da infraestrutura de Institutos de Ciência e Tecnologia (ICT).

As receitas dos Fundos são oriundas de contribuições incidentes sobre o resultado da exploração de recursos naturais pertencentes à União, parcelas do Imposto sobre Produtos Industrializados de certos setores e de Contribuição de Intervenção no Domínio Econômico (CIDE) incidente sobre os valores que remuneram o uso ou aquisição de conhecimentos tecnológicos/transferência de tecnologia do exterior. Constituem ainda valioso instrumento da política de integração nacional, pois pelo menos $30 \%$ dos seus recursos são obrigatoriamente dirigidos às Regiões Norte, Nordeste e Centro-Oeste, promovendo a desconcentração das atividades de $C \& T$ e a consequente disseminação de seus benefícios. Disponível em: http://www.finep.gov.br/a-finep-externo/fontes-de-recurso/fundossetoriais/o-que-sao-fundos-setoriais.
} 


\begin{tabular}{|c|c|c|}
\hline 2001 & $\begin{array}{l}\text { Programa } \\
\text { Institutos do } \\
\text { Milênio }\end{array}$ & $\begin{array}{l}\text { Estimula a formação de redes de pesquisa entre laboratórios, de modo } \\
\text { a potencializar a infraestrutura física existente. }\end{array}$ \\
\hline \multirow{6}{*}{2004} & $2^{\text {a }}$ CNCTIS & $\begin{array}{l}2^{\text {a }} \text { Conferência Nacional de Ciência Tecnologia e Inovação em Saúde } \\
\text { - aproximou os objetivos da Política Nacional de Saúde (PNS) com } \\
\text { os da Política Nacional de Ciência e Tecnologia (PNCT) } \\
\text { incrementando a articulação entre os setores da Saúde, Educação e } \\
\text { Ciência e Tecnologia. }\end{array}$ \\
\hline & PNCTIS & $\begin{array}{l}\text { Política Nacional de Ciência, Tecnologia e Inovação em Saúde - } \\
\text { orienta para que o desenvolvimento nacional em CT\&I/S se faça de } \\
\text { modo sustentável, e com apoio na produção de conhecimentos } \\
\text { técnicos e científicos ajustados às necessidades econômicas, sociais, } \\
\text { culturais e políticas do País. }\end{array}$ \\
\hline & ANPPS & $\begin{array}{l}\text { Agenda Nacional de Prioridades de Pesquisas em Saúde - orienta as } \\
\text { prioridades de pesquisa a serem fomentadas, em consonância com os } \\
\text { princípios do SUS. }\end{array}$ \\
\hline & $\begin{array}{l}\text { Lei }{ }^{\circ} .10 .973 / 2004 \\
\text { - Lei da Inovação }\end{array}$ & $\begin{array}{l}\text { Estabelece medidas de incentivo à CT\&I no ambiente produtivo, } \\
\text { visando à habilitação e alcance da autonomia tecnológica e ao } \\
\text { desenvolvimento industrial do país. }\end{array}$ \\
\hline & PITCE & $\begin{array}{l}\text { Política Industrial, Tecnológica e de Comércio Exterior - define a } \\
\text { inovação como eixo central da política produtiva e de comércio } \\
\text { exterior. }\end{array}$ \\
\hline & $\begin{array}{l}\text { Lei } n^{\circ} \cdot 11.105 / 2004 \\
\text { Lei de } \\
\text { Biossegurança }\end{array}$ & $\begin{array}{l}\text { Estabelece normas de segurança e mecanismos de fiscalização de } \\
\text { atividades que envolvam Organismos Geneticamente Modificados - } \\
\text { (OGM) e seus derivados. }\end{array}$ \\
\hline 2005 & $\begin{array}{l}\text { Lei } n^{0} .11 .196 / 2005 \\
\text { Lei do Bem }\end{array}$ & Dispõe sobre incentivos fiscais para a inovação tecnológica. \\
\hline 2006 & $\begin{array}{l}\text { Programa de } \\
\text { Subvenção } \\
\text { Econômica }\end{array}$ & $\begin{array}{l}\text { Promove ascensão das atividades de inovação e o incremento da } \\
\text { competitividade das empresas e da economia do País. }\end{array}$ \\
\hline 2007 & $\begin{array}{l}\text { PACTI } \\
(2007-2010)\end{array}$ & $\begin{array}{l}\text { Plano de Ação de Ciência, Tecnologia e Inovação - buscou } \\
\text { incrementar a produção científica e tecnológica do país. }\end{array}$ \\
\hline \multirow{4}{*}{2008} & PDP & $\begin{array}{l}\text { Política de Desenvolvimento Produtivo - incrementa o Complexo } \\
\text { Econômico Industrial (CEI) em seus diversos setores, entre eles as } \\
\text { parcerias universidade/empresas. }\end{array}$ \\
\hline & $\begin{array}{l}\text { Portaria GM/MS } \\
\mathbf{n}^{\circ} .1 .942 / 2008 \\
\text { GECIS }\end{array}$ & $\begin{array}{l}\text { Cria o Grupo Executivo do Complexo Industrial da Saúde para a } \\
\text { implementação do marco regulatório brasileiro que dispõe sobre as } \\
\text { estratégias para o fortalecimento do Complexo Produtivo e de } \\
\text { Inovação em Saúde (CEIS). }\end{array}$ \\
\hline & Programa INCT & $\begin{array}{l}\text { Programa dos Institutos Nacionais de Ciência e Tecnologia. } 82 \text { INCT } \\
\text { são da área da Saúde, dentre os } 252 \text { fomentados em } 2016 .\end{array}$ \\
\hline & $\begin{array}{l}\text { Portaria GM/MS } \\
\mathbf{n}^{\circ} .978 / 2008\end{array}$ & $\begin{array}{l}\text { Define produtos estratégicos para o SUS. Prioriza o fomento à PD\&I } \\
\text { e a fabricação de vacinas, hemoderivados e produtos para doenças } \\
\text { negligenciadas. }\end{array}$ \\
\hline \multirow{2}{*}{2009} & PNGTS & $\begin{array}{l}\text { Política Nacional de Gestão de Tecnologias em Saúde - promove } \\
\text { atividades gestoras relacionadas aos processos de avaliação, } \\
\text { incorporação, difusão, gerenciamento da utilização e retirada de } \\
\text { tecnologias do sistema de saúde. }\end{array}$ \\
\hline & $\begin{array}{l}\text { Lei } n^{\circ} .12 .101 / 2009 \\
\text { Proadi - SUS }\end{array}$ & $\begin{array}{l}\text { Cria o Programa de Apoio de Desenvolvimento Institucional para o } \\
\text { SUS (Proadi-SUS), apoiando pesquisas estratégicas para o SUS, por } \\
\text { meio de recursos de isenção fiscal. Fazem parte desse programa os } \\
\text { hospitais de excelência. }\end{array}$ \\
\hline
\end{tabular}




\begin{tabular}{|c|c|c|}
\hline 2010 & $\begin{array}{l}\text { Lei } n^{0} .12 .349 / 2010 \\
\text { - Lei de Compras } \\
\text { Públicas }\end{array}$ & $\begin{array}{l}\text { Promove a substituição de importações de produtos manufaturados e } \\
\text { serviços nacionais resultantes de desenvolvimento e inovações } \\
\text { tecnológicas realizadas no país. }\end{array}$ \\
\hline 2010 & $\begin{array}{l}\text { Plano Nacional de } \\
\text { Pós-Graduação } \\
\text { (2011-2020) }\end{array}$ & $\begin{array}{l}\text { Prioriza as ações de P\&D em saúde, dentre elas: promover pesquisa } \\
\text { agregando ensino de pós-graduação - empresa - sociedade; estimular } \\
\text { a parceria universidade - empresa; promover cooperação } \\
\text { internacional; contribuir para o fortalecimento dos INCT e dos } \\
\text { Centros de Pesquisa, de Difusão e de Inovação; apoiar o } \\
\text { fortalecimento da Rede Nacional de Pesquisa Clínica (RNPC). }\end{array}$ \\
\hline \multirow{3}{*}{2011} & Agenda PESS & $\begin{array}{l}\text { Agenda de Pesquisa Estratégica para o Sistema de Saúde - define as } \\
\text { linhas de pesquisa do SUS, para atender aos objetivos estratégicos } \\
\text { definidos no Plano Plurianual (PPA) 2012-2015. }\end{array}$ \\
\hline & $\begin{array}{l}\text { Plano Brasil Maior } \\
\text { 2011-2014 }\end{array}$ & $\begin{array}{l}\text { Fortalece a cadeia produtiva, de inovação e de competitividade } \\
\text { nacional seguindo as linhas de ação das PDP e da PITCE com vistas } \\
\text { ao apoio, e ao desenvolvimento e execução de portfólios tecnológicos } \\
\text { nas empresas. }\end{array}$ \\
\hline & Lei $n^{0} .12 .401 / 2012$ & $\begin{array}{l}\text { Cria a Comissão Nacional de Incorporação de Tecnologias (Conitec) } \\
\text { no SUS. Responsável por assessorar o MS na incorporação, exclusão } \\
\text { ou alteração pelo SUS de novas tecnologias em saúde. }\end{array}$ \\
\hline \multirow{4}{*}{2012} & $\begin{array}{l}\text { Estratégia Nacional } \\
\text { de CTI 2012-2015 }\end{array}$ & $\begin{array}{l}\text { Incrementa a inovação nas empresas e consolida o Sistema nacional } \\
\text { de Inovação (SNI). }\end{array}$ \\
\hline & $\begin{array}{l}\text { Portaria GM/MS } \\
\mathbf{n}^{\circ} .837 / 2012\end{array}$ & $\begin{array}{l}\text { Define as diretrizes e os critérios para o estabelecimento das parcerias } \\
\text { para o desenvolvimento produtivo, fomenta a parceria entre } \\
\text { instituições públicas e privadas, estimulando a transferência } \\
\text { tecnológica para o país. }\end{array}$ \\
\hline & $\begin{array}{l}\text { Resolução CNS } \\
\text { 466/2012 }\end{array}$ & $\begin{array}{l}\text { Regulamenta as diretrizes e normas de pesquisas envolvendo seres } \\
\text { humanos. }\end{array}$ \\
\hline & $\begin{array}{l}\text { Lei } \mathrm{n}^{0} .12 .715 / 2012 \\
- \\
\text { Pronon e Pronas/ } \\
\text { PCD }\end{array}$ & $\begin{array}{l}\text { Cria o Programa Nacional de Apoio à Atenção Oncológica (Pronon) } \\
\text { e o Programa Nacional de Apoio à Atenção da Saúde da Pessoa com } \\
\text { Deficiência (Pronas/PCD) que visa a incentivar ações e serviços } \\
\text { desenvolvidos por entidades, associações e fundações privadas sem } \\
\text { fins lucrativos no campo da oncologia e da pessoa com deficiência, } \\
\text { respectivamente, com recursos provenientes de deduções fiscais no } \\
\text { Imposto de Renda. }\end{array}$ \\
\hline \multirow{4}{*}{2013} & $\begin{array}{l}\text { INOVA-SAÚDE } \\
(\text { 2013-2017) }\end{array}$ & $\begin{array}{l}\text { Apoia atividades de PD\&I em projetos de instituições públicas e } \\
\text { privadas que atuam no CEIS permitindo a continuidade do } \\
\text { financiamento a projetos com potencial para a diminuição da } \\
\text { dependência tecnológica do País frente aos insumos utilizados no } \\
\text { campo da saúde. }\end{array}$ \\
\hline & $\begin{array}{l}\text { Portaria GM/MS } \\
\mathbf{n}^{\circ} . \mathbf{3 . 0 8 9}\end{array}$ & $\begin{array}{l}\text { Prioriza o fomento científico e tecnológico para os biomateriais e } \\
\text { produtos relacionados à oncologia, às doenças crônicas não } \\
\text { transmissíveis, às doenças negligenciadas, às enfermidades virais, às } \\
\text { doenças sexualmente transmissíveis e à Aids. }\end{array}$ \\
\hline & $\begin{array}{l}\text { Decreto } \mathrm{n}^{\circ} \\
8.065 / 2013 \\
\S 31\end{array}$ & $\begin{array}{l}\text { Atribui ao Departamento de Ciência e Tecnologia (Decit) a } \\
\text { participação na formulação, implementação e avaliação da PNCTIS } \\
\text { tendo como pressupostos as necessidades demandadas pela PNS e a } \\
\text { observância dos princípios e diretrizes do SUS; coordenar e executar } \\
\text { as ações do MS no campo da P\&D em saúde, e promover a articulação } \\
\text { intersetorial no âmbito do Sistema Nacional de Ciência e Tecnologia. }\end{array}$ \\
\hline & $\begin{array}{l}\text { Portaria GM/MS } \\
\mathrm{n}^{\circ} .2 .531 / 2013\end{array}$ & $\begin{array}{l}\text { Redefine a lista de produtos prioritários para o investimento do SUS } \\
\text { em P\&D, produção e estabelecimento de PDP. }\end{array}$ \\
\hline
\end{tabular}




\begin{tabular}{|lll|}
\hline PNPC & $\begin{array}{l}\text { Programa Nacional das Plataformas do Conhecimento - apoia as parcerias } \\
\text { entre empresas e instituições de pesquisa científica e tenológica, } \\
\text { nacionais e internacionais, para a realização de encomendas } \\
\text { tecnológicas e para obtenção de produtos ou processos inovadores, de } \\
\text { bens ou serviços, que envolvam risco tecnológico. }\end{array}$ \\
\hline $\mathbf{2 0 1 5}$ & $\begin{array}{l}\text { Regulamenta o processo de acreditação dos Comitês de Ética em } \\
\text { Resolução CNS } \\
\mathbf{n}^{\mathbf{0}} . \mathbf{5 0 6} / \mathbf{2 0 1 6}\end{array}$ & $\begin{array}{l}\text { Pesquisa (CEP) que compõem o Sistema CEP/Conep e dá outras } \\
\text { orientações }\end{array}$ \\
\hline $\begin{array}{l}\text { Emenda } \\
\text { Constitucional } \\
\mathbf{n}^{\circ} . \mathbf{8 5 / 2 0 1 5}\end{array}$ & $\begin{array}{l}\text { Código Nacional de C\&T - altera e adiciona dispositivos na na } \\
\text { Constituição Federal para atualizar o tratamento das atividades de } \\
\text { Ciência, Tecnologia e Inovação. }\end{array}$ \\
\hline $\mathbf{2 0 1 6}$ & Lei no 13.243/2016 & $\begin{array}{l}\text { Marco legal de CT\&I - Dispõe sobre o estimulo ao desenvolvimento } \\
\text { científico, a pesquisa a capacitação científica tecnológica e a } \\
\text { inovação. }\end{array}$ \\
\hline
\end{tabular}

FONTE: Adaptado de (IOZZI, 2012); (BOTELHO \& ALVES, 2015); (ALMEIDAANDRADE, 2015); (VARGAS et al., 2015).

Os instrumentos apresentados nesse quadro não se esgotam por si mesmo. Diversos outros instrumentos, a exemplo dos termos de cooperação firmados entre MS e o MCTI, permitiram e têm facilitado a implementação de um conjunto de ações que favorecem o fortalecimento e colaboram para a intensificação das demandas de $\mathrm{P} \& \mathrm{D} / \mathrm{S}$ e de CT\&I/S, inclusive por promover maior confiabilidade para os atores envolvidos, tanto na geração de produtos e processos - as universidades, os centros de pesquisa e as empresas públicas ou privadas - quanto para os investidores e consumidores (ALMEIDA-ANDRADE, 2015).

Por meio dessa análise, é possível inferir que vem sendo construído, no Brasil, um arcabouço de marcos institucionais que fortalece, orienta e incentiva as atividades $\mathrm{P} \& \mathrm{D} / \mathrm{S}$ e de $\mathrm{CT} \& \mathrm{I} / \mathrm{S}$ no país, além de fomentar a articulação com as iniciativas do setor produtivo. Entretanto, não se pode desprezar o importante incremento em C\&T proporcionado pelo Conselho Nacional de Desenvolvimento Científico e Tecnológico (CNPq), desde o início da década de 50, pela Fundação de 
Amparo à Pesquisa no Estado de São Paulo (Fapesp), iniciado em 1962, e pela Financiadora de Estudos e Projetos (Finep), a partir de 1971 (GUIMARÃES, 2002).

Acredita-se que a articulação real entre os atores que permeiam essas políticas pode facilitar o acesso a resultados; atrair C\&T estrangeiras para inovação no Brasil; bem como instrumentalizar o Estado para responder à crescente pressão social ${ }^{10}$ e do mercado por incorporação tecnológica de produtos de alto valor agregado no SUS (ALMEIDA-ANDRADE, 2015).

\subsection{O Departamento de Ciência e Tecnologia e o fomento à pesquisa ${ }^{11}$}

No âmbito do governo federal, as atribuições de fomentar, acompanhar e avaliar os projetos de pesquisas em saúde são prerrogativas do Departamento de Ciência e Tecnologia (Decit) da Secretaria de Ciência, Tecnologia e Insumos Estratégicos (SCTIE) do MS, sendo este o principal agente responsável por fazer cumprir a PNCTIS, promovendo a articulação intersetorial no Sistema Nacional de Ciência e Tecnologia em Saúde.

Após a $2^{\mathrm{a}}$ Conferência Nacional de Ciência, Tecnologia e Inovação em Saúde (CNCTIS), na qual foram aprovadas a PNCTIS e a ANPPS, o Decit passou a ser o protagonista na definição de prioridades para fomentar P\&D em saúde no país,

\footnotetext{
${ }^{10}$ Estudo realizado pela Consultoria Jurídica do Ministério da Saúde consolidou dados dos gastos durante o período de 2009 até 2012. Como resultado, observou-se que em 2009 existiram 10.486 novas ações e em 2012 esse número aumentou para 13.051. Em relação aos custos para aquisição de medicamentos, equipamentos e insumos concedidos em decisões judiciais. Em 2009 o MS gastou em torno de 87 milhões de reais e em 2012, o montante passou para 287,8 milhões de reais. http://u.saude.gov.br/images/pdf/2014/maio/29/Panorama-da-judicializa----o---2012---modificadoem-junho-de-2013.pdf

${ }^{11}$ A autora é consultora do Departamento de Ciência e Tecnologia desde o ano de 2004. Isso lhe possibilita abordar atividades inerentes ao Departamento a partir do conhecimento vivenciado em sua rotina de trabalho, alguns deles não publicados na literatura.
} 
incorporando um importante diferencial frente ao modelo praticado anteriormente pelas agências de fomento, ao incluir no processo de definição de linhas de pesquisa a serem fomentadas representantes da comunidade científica e de segmentos do mercado, além de gestores de saúde (GUIMARÃES et al., 2006); (GOLDBAUM \& SERRUYA, 2006).

Em 2004, a cerimônia da $2^{\mathrm{a}}$ CNCTIS - composta por conferências estaduais realizadas em todos estados, exceto Roraima, Tocantins e Goiás, e 307 conferências regionais e municipais - contou, em sua consolidação final, com 15 mil participantes, entre delegados, convidados e observadores. Além da aprovação da PNCTIS e da ANPPS, incluiu-se em sua pauta de discussões a necessidade de se refletir sobre as ferramentas que se detinha, à época, para operacionalizar o novo modelo de gestão da PNCTIS, sendo almejada a criação de um órgão de fomento para tal (BRASIL, 2005; 2006).

Frente a isso e sob o tema "Por que uma agência de fomento vinculada ao Ministério da Saúde?" ${ }^{12}$, o professor Reinaldo Guimarães apresentou um painel, defendendo a criação de um órgão de fomento que contribuísse efetivamente com a implantação e execução da PNCTIS e da ANPPS, de forma a garantir maior efetividade aos processos. Por motivos diversos, como os político-partidários e a incompreensão de alguns conselheiros, não houve consenso para aprovação da agência.

O Decit foi, então, criado na estrutura da Secretaria Executiva do Ministério da Saúde em 2000, tendo sido integrado à SCTIE, quando da sua criação

\footnotetext{
${ }^{12}$ As questões que fundamentaram a pergunta estavam relacionadas a: $1^{\circ}$ ) a dimensão da capacidade de pesquisa em saúde no Brasil; $2^{\circ}$ ) Necessidade de aumentar a presença de política de saúde no fomento à pesquisa; $3^{\circ}$ ) incrementar o orçamento do MS no fomento à pesquisa; $4^{\circ}$ ) aumentar a eficiência das ações de fomento à pesquisa pelo MS (BRASIL, 2005).
} 
em 2003. A atual estrutura funcional, conforme ilustra a (Figura 3), conta com 61 profissionais especializados na área finalística da coordenação a qual pertence, sendo destes $30 \%$ doutores, $29 \%$ mestres, $31 \%$ especialistas e os demais com graduação na área de saúde ou afim.

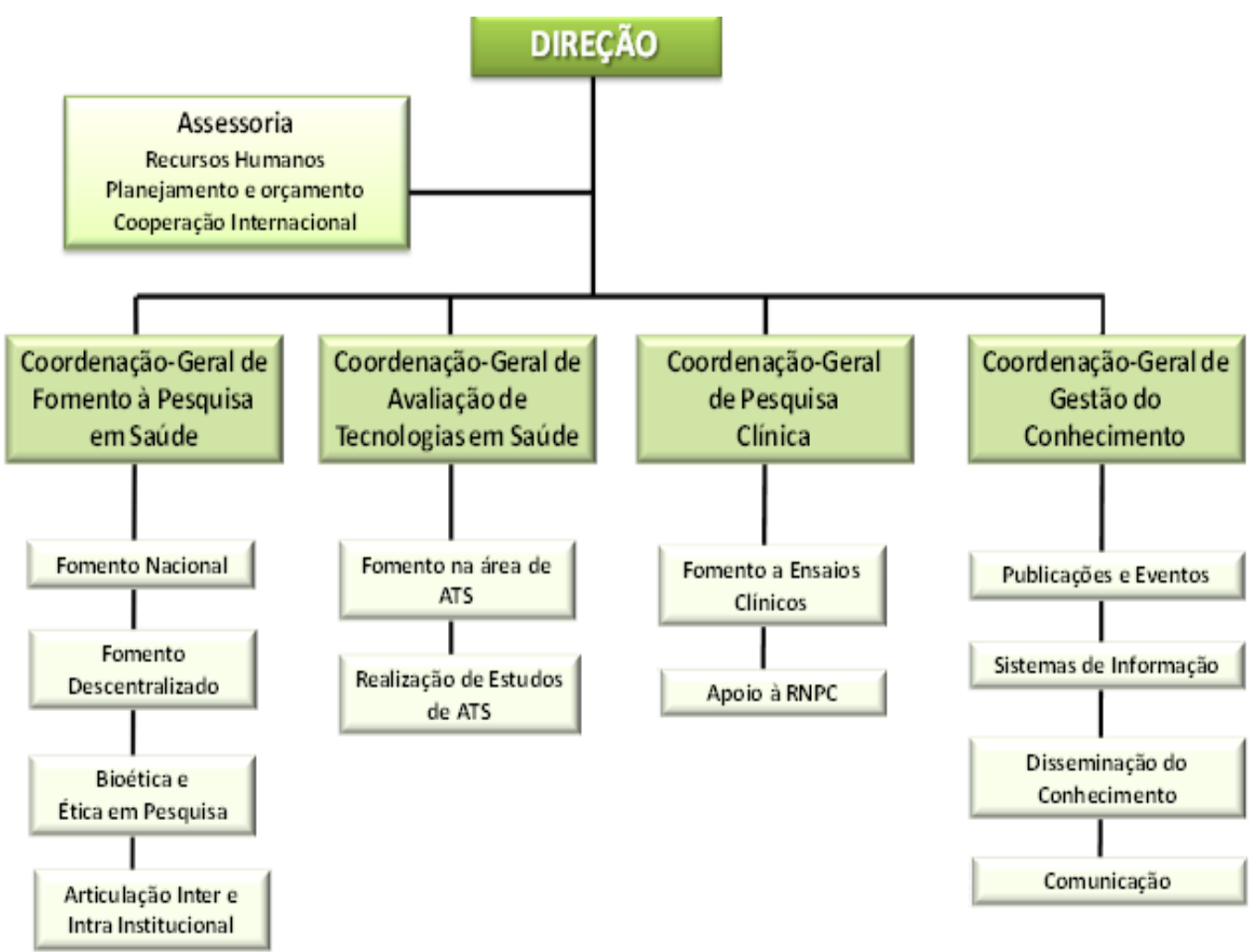

FONTE: Elaboração própria a partir de documentos do Decit.

Figura 3 - Organograma do Departamento de Ciência e Tecnologia (Decit)

Na figura 3, observa-se que cada coordenação tem objetivos que convergem com o consensuado e demarcado propósito de fomento à $\mathrm{C} \& \mathrm{~T}$ em Saúde.

O fomento no âmbito do Decit obteve sua efetividade e expansão, graças aos termos de cooperação firmados entre os Ministérios da Saúde e da Ciência, Tecnologia e Inovação. Esse ato tem possibilitado a transferência de 
recursos do Fundo Nacional da Saúde (FNS) para o Fundo Nacional de Desenvolvimento de Ciência e Tecnologia (FNDCT), permitindo, desse modo, que suas agências de fomento - CNPq e Finep - realizem todos procedimentos necessários à contratação de projetos induzidos pelo Decit.

É contumaz a menção sobre o "casamento perfeito", para se referir a essa parceria, uma vez que o volume de recursos empenhados versus projetos contratados, advindos dessa cooperação ao longo desses anos (2004-2015), seria impensável sem a expertise inerente a essas agências. As modalidades de fomento praticadas pelo Decit se dividem em três tipos:

Fomento Nacional: chamadas públicas que envolvem a concorrência livre de projetos de pesquisa temáticos, para as quais todas as instituições do país estão aptas a participar;

$\checkmark \quad$ Fomento Descentralizado: chamadas públicas multitemáticas lançadas nos estados, envolvem a concorrência exclusiva para pesquisas das instituições locais. Nessa modalidade está inserido o Programa de Pesquisa para o SUS (PPSUS), cujas chamadas são construídas a partir das necessidades locais e de temas de pesquisas elencados pela comunidade científica também local, em parceria com a Secretaria estadual de Saúde (SES). A gestão desse programa é compartilhada com o CNPq e as Fundações de Amparo a Pesquisas (FAP) de cada estado. O PPSUS tem forte apelo junto à comunidade científica por contribuir para a redução da desigualdade em C\&T, historicamente presente nas regiões do país; e 
Contratação Direta: modalidade de fomento que ocorre em casos de demandas de emergências de saúde pública ou especificidade, a exemplo da situação mais atual da contratação direta de projetos de pesquisa cujos objetos são o enfrentamento dos agravos pelo vírus Zika. As contratações de pesquisas fomentadas pelo Decit podem ser de duas formas: por meio de contratos e convênios ou descentralização de recursos aos parceiros administradores. No caso dos convênios, estes são operados pelo sistema de gestão de convênios do governo - Gescon e Siconv - com o Fundo Nacional de Saúde; ou por meio da descentralização de recursos, nos casos das parcerias com as agências do MCTI (CNPq e Finep), com a Coordenação de Aperfeiçoamento de Pessoal de Nível Superior (Capes) do Ministério da Educação (MEC), ou ainda com as Fundações de Amparo à Pesquisa (FAP) nos estados, por meio da descentralização de recursos ao CNPq que administra os convênios.

Nos últimos cinco anos (2011-2015), o Decit investiu recursos da ordem de 509 milhões de reais para a realização de 1.615 pesquisas, destas, 97\% foram contratadas a partir de chamadas públicas. Esse investimento possibilitou a expansão e consolidação das seguintes iniciativas: Rede Nacional Pesquisa Clínica (RNPC), Rede Brasileira de ATS (Rebrats), Rede Nacional de Terapia Celular (RNTC), Rede Nacional de Pesquisas em Doenças Negligenciadas (RNPDN), Rede Nacional de Pesquisa sobre Políticas de Saúde (RNPPS), Rede Nacional de Pesquisas em Acidente Vascular Cerebral (RNPAVC), Rede Nacional de Pesquisa Clínica em Câncer (RNPCC), e Rede Nacional de Pesquisa em Doenças Cardiovasculares (RNPDC), além da cooperação técnica nacional e internacional; e o fortalecimento da ética - 
valorização da Comissão Nacional de Ética em Pesquisa (Conep) e Comitês de Ética em Pesquisas (CEP).

\subsection{Investimentos em Pesquisa e Desenvolvimento}

O legado de Joseph Schumpeter constitui referencial primordial para abordar as relações que envolvem a inovação e o desenvolvimento econômico. De acordo com esse autor, o crescimento da economia transcorre como um processo dinâmico, sendo, antes de tudo, "um processo de destruição criadora ${ }^{13}$ ”, dependendo fundamentalmente da geração e uso de inovações associadas aos processos envolvidos em sua difusão, tais como exploração de novos mercados e novas dinâmicas de negócios (SCHUMPETER, 2005); (VIANA, et al., 2012a); (COSTA, 2013).

Em suma, depreende-se desse contexto que as atividades PD\&I/S geram oportunidades de investimento, emprego e renda, compondo, assim, um espaço ativo de desenvolvimento econômico surgido, segundo apontam Viana \& Silva (2012), a partir de adaptações entre os subsistemas em momentos históricos distintos, robustecido ainda por uma interligação específica com a produção de insumos, medicamentos, equipamentos e materiais médicos, que hoje se apresenta como o principal eixo para a definição dos rumos da política de saúde em todo mundo.

No Brasil, historicamente, o financiador mais significativo de P\&D tem sido o governo (QUENTAL et al., 2001); (IOZZI, 2012); (VIANA, et al., 2012a). Nos

\footnotetext{
${ }^{13}$ A expressão é originária da teoria econômica marxista, relacionada aos processos interligados de acumulação e destruição da riqueza no capitalismo. Entretanto, a partir de 1950, o termo vem sendo identificado a Schumpeter, que o adaptou e o popularizou no âmbito da economia da inovação (COSTA, 2013:29).
} 
países desenvolvidos, entretanto, o investimento privado na área continua crescendo em relação às taxas do investimento público que oscilam entre $2 \%$ a $4 \%$ do PIB, conforme apresentado no (Gráfico 1).

\section{Gráfico 1 - Representação dos percentuais de investimentos em Pesquisa e desenvolvimento nos países, frente aos aportes públicos e privados em relação aos seus Produtos Internos Brutos}

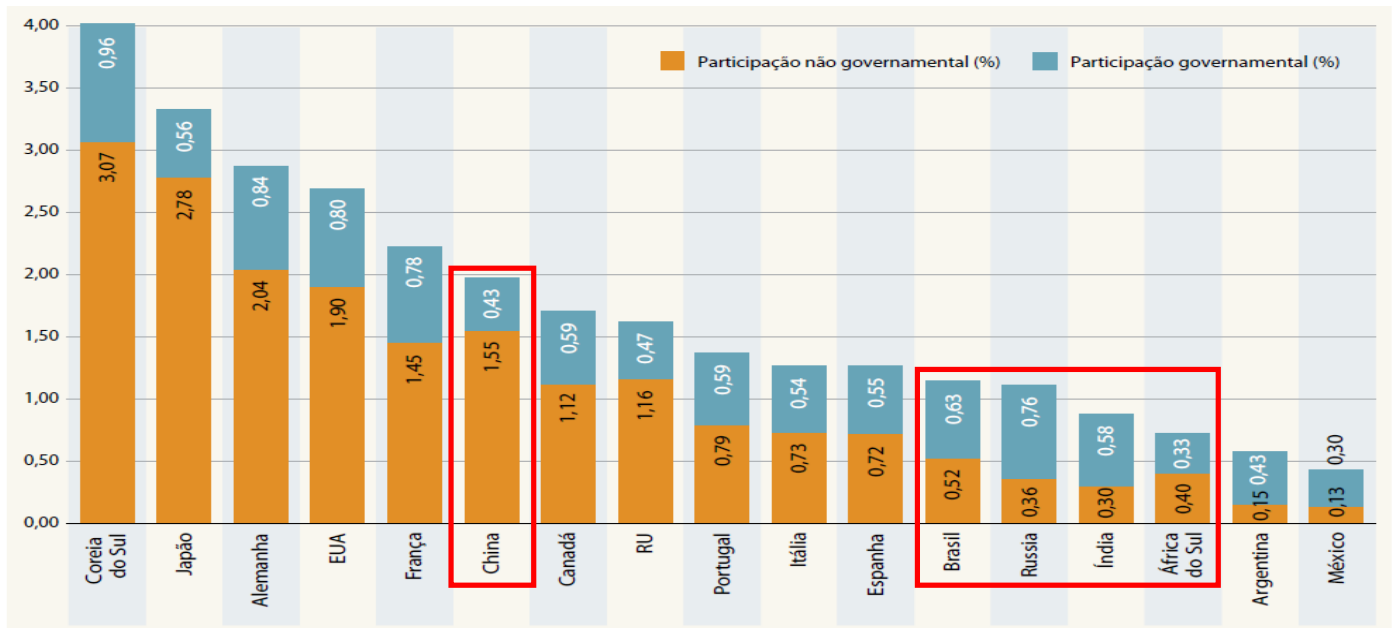

FONTE: Ministério de Ciência, Tecnologia e Inovação (2015), Apud Unesco (2015).

O investimento público brasileiro tem-se mantido mais ou menos estável desde 2008, enquanto o setor privado aumentou ligeiramente a sua contribuição (UNESCO, 2015). Quanto aos investimentos privados, percebe-se, ainda, que o Brasil frente aos BRICS ${ }^{14}$ se encontra em segunda posição, dos quais a China é o que mais recebe esse tipo de incentivo.

Segundo o relatório de Ciências da Unesco: Rumo a 2030:

Ao manter uma forte demanda por commodities para alimentar seu crescimento rápido, a China resguardou as economias exportadoras de recursos, desde 2008, da queda da demanda da América do Norte e da UE. Em última análise, no entanto, o "boom" cíclico em commodities chegou ao fim, revelando deficiências estruturais, particularmente no Brasil e na Federação Russa (UNESCO, 2015:45).

\footnotetext{
${ }^{14}$ BRICS - Bloco de países composto pelo Brasil, Russa, Índia, China e África do Sul, caracterizados como economias emergentes destinadas a ocupar posição de crescente relevância na economia mundial. < http://www.funag.gov.br/biblioteca/dmdocuments/OBrasileosBrics.pdf\#page=31>
} 
No Brasil, as despesas com medicamentos e similares são bastante importantes. Na (Tabela 1) é possível comparar o gasto total com medicamentos e investimentos em P\&D na área de Assistência Farmacêutica pelo Ministério da Saúde frente ao percentual do orçamento total do MS ao longo de cinco anos.

Tabela 1 - Evolução orçamentária dos gastos com medicamentos no Ministério da Saúde

\begin{tabular}{|c|c|c|c|c|c|}
\hline Ações & 2011 & 2012 & 2013 & 2014 & 2015 \\
\hline Med. Estratégicos & 162.000 .000 & 124.000 .000 & 134.834 .524 & 164.730 .448 & 340.000 .000 \\
\hline Med. Básico & 1.060 .000 .000 & 1.077 .448 .725 & 1.213 .500 .000 & 1.292 .642 .028 & 1.230 .000 .000 \\
\hline Med. Excepcionais & 3.521 .496 .999 & 4.082 .150 .000 & 4.977.534.000 & 4.890 .845 .854 & 5.867 .474 .795 \\
\hline Med. Aids & 804.802 .000 & 823.600 .000 & 770.200 .000 & 864.187 .200 & 1.101 .000 .000 \\
\hline Imunobiológicos & 1.613.204.809 & 1.676 .500 .000 & 2.181 .900 .000 & 2.296 .719 .000 & 3.300 .672 .000 \\
\hline Coagulopatia & 412.565 .000 & 552.300 .000 & 747.915 .000 & 583.432 .574 & 802.500 .000 \\
\hline Farmácia Popular & 774.605 .000 & 1.410 .000 .000 & 1.856 .600 .000 & 2.460 .838 .514 & 3.261 .328 .000 \\
\hline $\begin{array}{l}\text { SUBTOTAL } \\
\text { MEDICAM. }\end{array}$ & 8.348.673.808 & 9.745.998.725 & 11.882.483.524 & 12.553.395.618 & 15.902.974.795 \\
\hline Inovação e Produção & 56.860 .300 & 64.900 .000 & 72.720 .000 & 55.525 .381 & 50.160 .000 \\
\hline $\begin{array}{l}\text { Modernização de } \\
\text { Parque Produtivo }\end{array}$ & 0 & 130.000 .000 & 160.000 .000 & 106.400 .000 & 46.800 .000 \\
\hline Laboratórios Oficiais & 0 & 70.000 .000 & 0 & 0 & 0 \\
\hline Pesquisa & 77.337 .653 & 81.392 .000 & 93.685 .000 & 90.305 .000 & 84.128 .000 \\
\hline Estruturação - A. F. & 10.972 .576 & 25.000 .000 & 39.000 .000 & 69.399 .580 & 84.152 .000 \\
\hline TOTAL GERAL & 8.493.844.337 & 10.117 .290 .725 & 12.247.888.524 & 12.875.025.579 & 16.168.214.795 \\
\hline ORÇAMENTO - MS & 63.113 .634 .859 & 78.361 .160 .095 & 84.051 .839 .071 & 108.393 .354 .888 & 121.154 .205 .789 \\
\hline$\%$ & $13 \%$ & $12 \%$ & $14 \%$ & $12 \%$ & $13 \%$ \\
\hline
\end{tabular}

FONTE: SCTIE/MS

Acredita-se, a partir dos dados apresentados, que fomentar CT\&I na área de medicamentos, fármacos e insumos para saúde, vem ao encontro das políticas e instrumentos criados para fortalecimento da área, sendo que essa premissa é sustentada por Vargas et al. (2013) quando se manifestam sobre o envolvimento de vários atores em prol da retomada do crescimento da base produtiva nacional: 
[...] envolve a crescente articulação entre a política industrial e tecnológica e a área da saúde, associada ao processo de retomada de políticas de crescimento, refletindo o reconhecimento da forte interface da saúde com as novas plataformas tecnológicas ligadas à biotecnologia, nanotecnologia e química fina avançada, e de sua importância na base produtiva industrial [...] (VARGAS et al., 2013:68).

Nesse sentido uma das áreas estratégicas para fomentar uma inovação que resulte em novos medicamentos para a população, fazendo a ponte entre pesquisa biotecnológica e produção - a pesquisa clínica -, converge com o debate que engloba a produção de C\&T para geração de insumos voltados ao enfrentamento aos agravos à saúde, ou seja, cria-se uma interface entre inovação e produção com assistência. Nesse sentido, o Estado, com sua função de intermediador, formula e aplica ações que geram desenvolvimento para o aparato social (VIANA \& DA FONSECA, 2016).

Ao contrário de outros produtos do mercado, tais como eletrônicos, alimentos, etc, a saúde é um bem público, também sujeito à falha de mercado, mas que, entretanto, envolve a vida humana, o bem maior (VIANNA et al., 2015).

Partindo-se dessa premissa, justifica-se o compromisso do Estado de não abdicar do seu papel regulador, disponibilizando mecanismos de controle e vigilância que possam garantir a segurança dos produtos para saúde (medicamentos, fármacos e demais insumos) mesmo que o próprio Estado seja o fomentador da produção (VIANNA et al., 2015). Para manter o processo produtivo em saúde, considera-se, então, a necessidade de se envolver vários atores articulados em redes, construídas por intencionalidade nesse contexto, sem, no entanto, abrir mão da segurança e do cuidado a ser dedicado aos indivíduos. 
Nessa direção, Vianna et al. (2015:177) escreveram:

Ao longo do tempo, tanto as motivações produtivas quanto as sociais da saúde foram construídas sobre as discussões que envolviam de um lado a PD\&I, e do outro, a ética, os direitos e a garantia de acesso aos serviços de saúde de qualidade. Ao longo do tempo, a compreensão de como esses interesses se relacionavam foi decisiva para a construção de políticas ou de mecanismos para integrá-las.

\subsection{Particularidades da pesquisa clínica}

As prioridades em torno da pesquisa clínica podem ser contempladas em todas as 24 subagendas da ANPPS. Trata-se de uma estratégia que transversalmente perpassa todas as subagendas da ANPPS $^{15}$, como demonstra o (Gráfico 2), apresentada por Vargas et al. (2013). O demonstrativo ilustra o resumo das novas tendências tecnológicas associadas a diferentes áreas de conhecimento que servem de parâmetro inicial para ações de capacitação de tecnologias-chave, as quais podem sugerir ensaios clínicos contemplando, nesse caso, pelo menos dez possíveis subagendas da ANPPS.

Apesar da inquestionável relevância da ANPPS, enquanto estratégia para implantação da equidade na distribuição de recursos para a pesquisa faz-se igualmente fundamental considerar que, embora seja desejável, nem sempre os profissionais estão preparados para consumir resultados. Aproximar as atividades de quem faz pesquisa com as ações de quem faz política pode ser uma estratégia a ser considerada devido a sua relevante importância (CARVALHO et al., 2010); (SILVA \& CAETANO, 2011).

\footnotetext{
${ }^{15}$ Os nichos com potencial elevado de sucesso são: produção de vacinas, imunobiológicos e novas tecnologias para diagnóstico. Novos produtos para tratamento, prevenção e promoção, tais como fitoterápicos, fármacos e medicamentos, hemoderivados, medicamentos homeopáticos e insumos para práticas complementares de promoção e prevenção à saúde. (BRASIL, 2008:23)
} 
Gráfico 2 - Distribuição das dez principais áreas terapêuticas projetadas para 2016, segundo participação no mercado e crescimento de vendas (2010-2016)

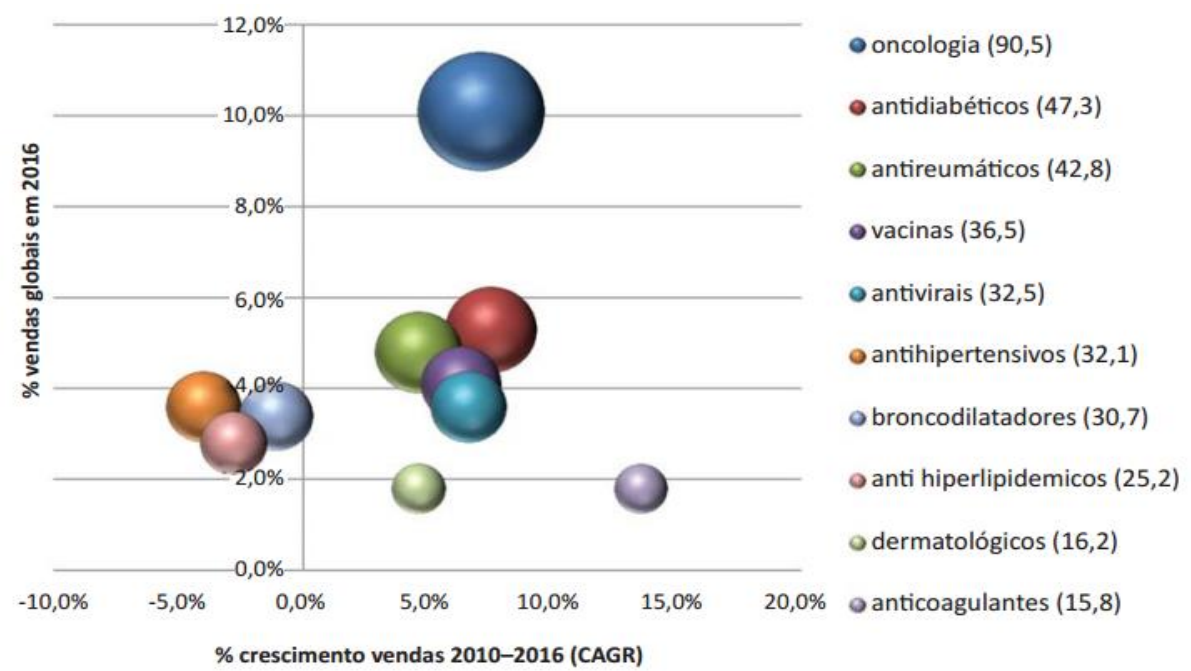

FONTE: Evaluete Pharma (2011) apud (VARGAS et al., 2013)

Nesse sentido, a prática da pesquisa clínica ${ }^{16}$ desenvolvida nas universidades e institutos de ensino e pesquisa disponibiliza nas instituições oportunidades de formação e capacitação aos profissionais da saúde, intercâmbio técnico e científico, desenvolvimento e aprimoramento dos métodos de ensino e pesquisa, além de novas opções terapêuticas aos pacientes, que podem ser usadas pelo gestor hospitalar para auxiliar na reorientação das atividades tanto de ensino e pesquisa quanto de assistência.

A pesquisa clínica é também usada pelo gestor de saúde para tomada de decisões, por meio da realização de estudos necessários, como complementação de evidências científicas para subsidiar a tomada de decisões comuns à prática de

\footnotetext{
${ }^{16}$ Pesquisa conduzida com participantes humanos (ou em materiais de origem humana como tecidos, espécimes ou fenômenos cognitivos), na qual um investigador (ou membros de equipe) interage diretamente com os participantes. Excluem-se dessa definição os estudos in vitro que utilizam tecidos humanos que não podem ser associados a um indivíduo vivo. A pesquisa clínica inclui: (a) mecanismos de doença humana; (b) intervenções terapêuticas; (c) ensaios clínicos; ou (d) desenvolvimento de novas tecnologias.

http://grants.nih.gov/grants/glossary.htm\#ClinicalResearch
} 
Avaliação de Tecnologias em Saúde (ATS), que tem como premissa o estabelecimento de diretrizes e protocolos clínicos, regulação de preços de medicamentos e política formal de avaliação, incorporação e gestão de tecnologias no âmbito do SUS (ELIAS, 2013).

Quanto aos ensaios clínicos, trata-se de uma das modalidades/tipos da pesquisa clínica que objetivam avaliar em humanos a eficácia e a segurança de produtos e procedimentos médicos, para que sejam passíveis de uso na prática médica. São, em sua maioria, estudos multicêntricos, multi-institucionais e algumas vezes multissetoriais, e até multinacionais, conforme o grau de complexidade envolvido nos processos em questão.

Envolvem ainda centros de excelência com profissionais altamente treinados, seguem protocolos de pesquisas elaborados sob rígidos critérios éticos, de boas práticas clínicas e bases sólidas de conhecimento respaldado por estudos anteriores, bem como de conhecimento associado à evolução da doença, que é o foco da pesquisa.

Todo o processo de um ensaio clínico, desde o planejamento até fechamento do estudo, possui uma regulamentação bem definida pelos órgãos de proteção dos direitos dos participantes (Conep e Anvisa), visando à obtenção de resultados com elevada qualidade científica (DAINESE \& GOLDBAUM, 2012); (QUENTAL \& SALLES-FILHO, 2006). Esses estudos são realizados por fases conforme ilustra a (Figura 4). À medida que os resultados gerados são positivos o estudo avança para fase seguinte. 


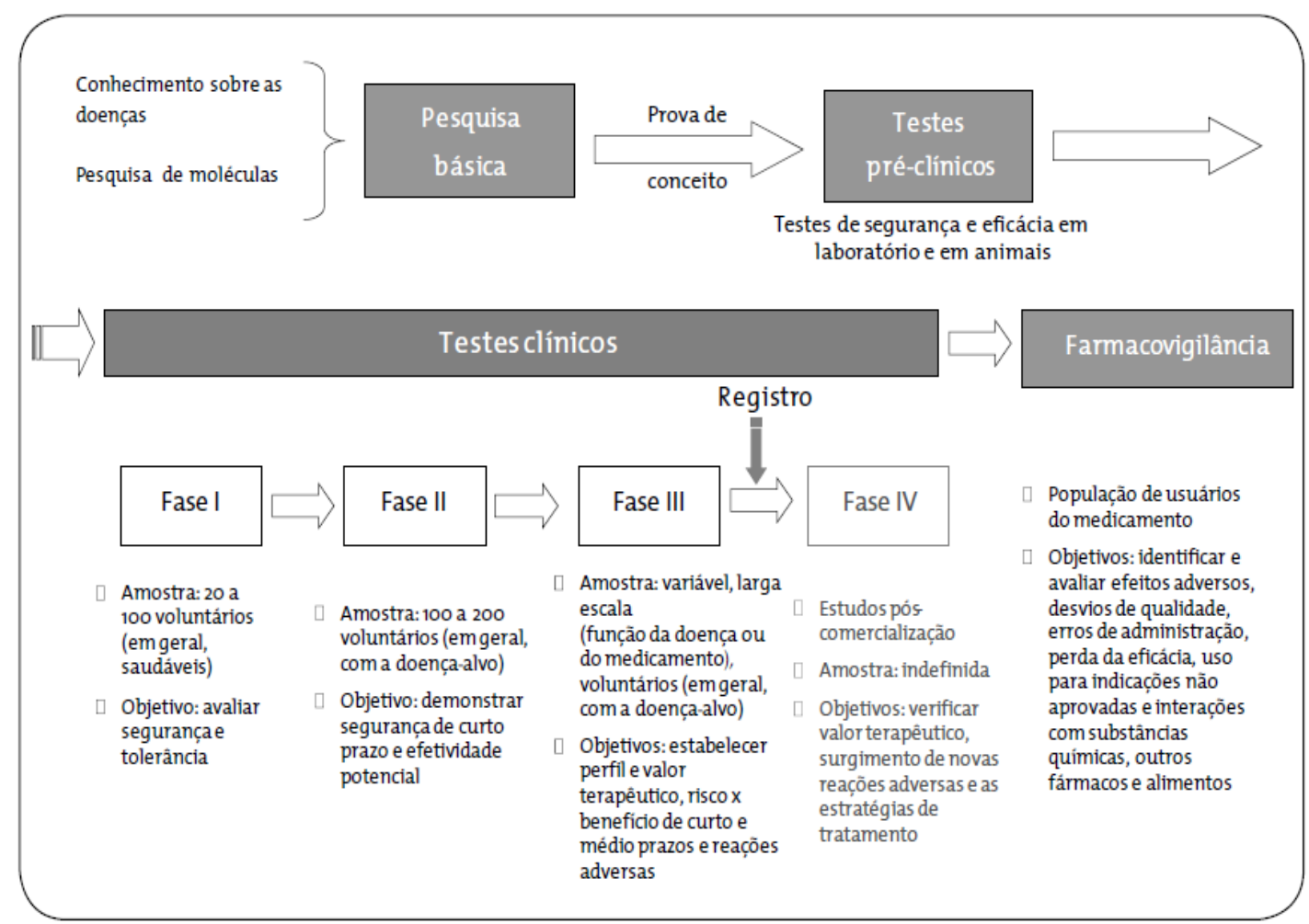

FONTE: Pinho et al. (2012).

\section{Figura 4 - Fases do Processo de Pesquisa e Desenvolvimento}

Apresentam-se as particularidades que cada fase de ensaio clínico necessita cumprir para a esperada obtenção de resultados cientificamente robustos e confiáveis. São dados gerais, uma vez que, na situação de ensaios clínicos de medicamentos para algumas doenças, determinadas particularidades devem ser observadas como, por exemplo, no complexo caso do câncer.

Estima-se que para um novo fármaco/medicamento entrar no mercado são necessários investimentos de aproximadamente U\$ 1 bilhão e pelo menos dez anos de P\&D. Isso acaba por induzir, necessariamente, o estabelecimento de acordos multissetoriais, que envolvam governo, agências de fomento, universidades, hospitais, etc, para se firmar parcerias público-privadas (PPP) (VIANNA et al., 2015). 
Nesse sentido, a Rede Nacional de Pesquisa Clínica, composta por 32 unidades de pesquisas clínicas com expertises médicas e capacidades de operacionalidade distintas, apresenta razoável potencial para dar suporte à execução de ensaios clínicos nas suas diferentes fases e complexidades (Gráfico 3).

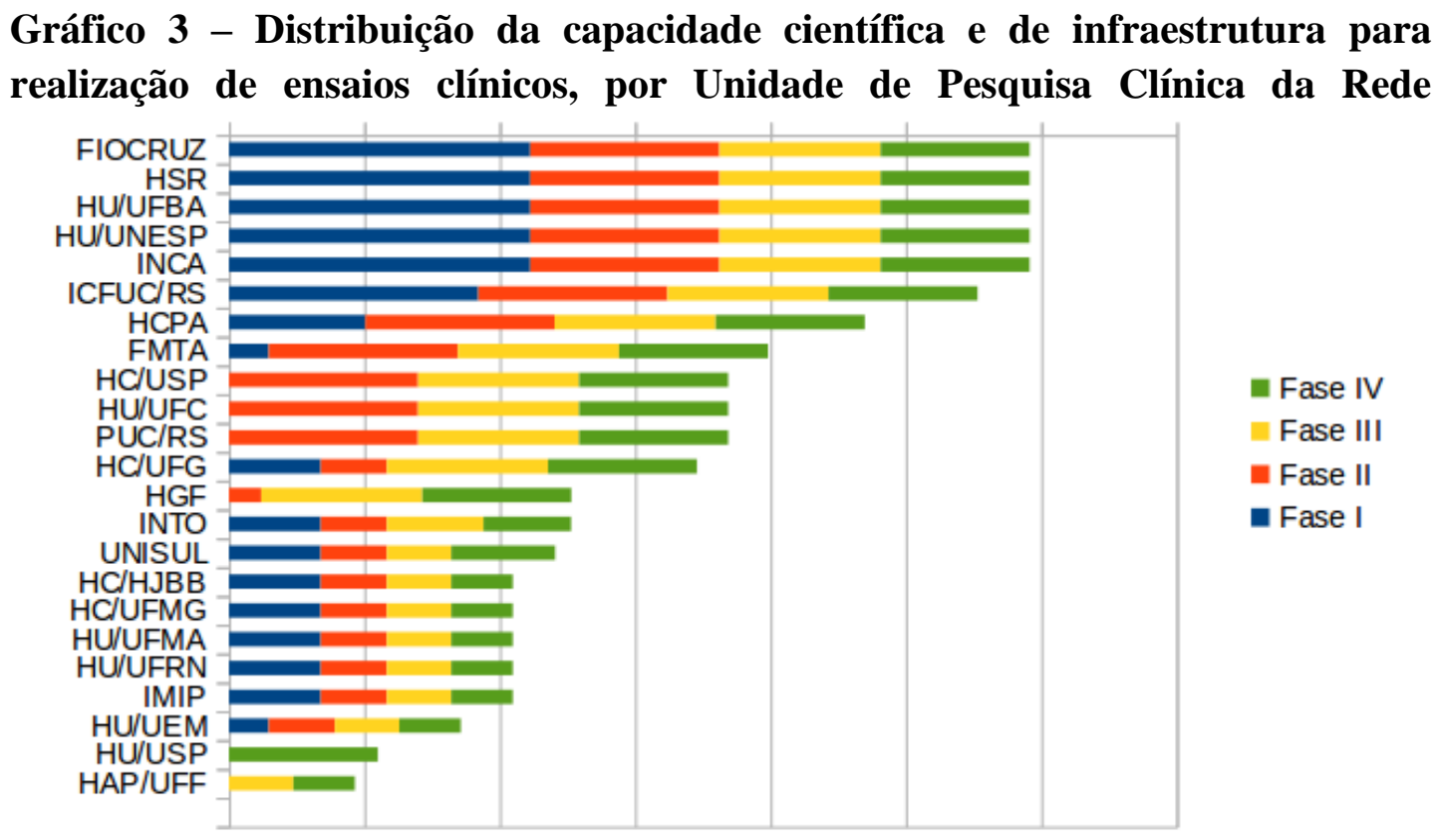

FONTE: Elaboração própria a partir de relatos dos integrantes da Rede.

Legenda: Dentro de cada fase dos ensaios clínicos estão inseridas as capacidades: científica para coordenar ensaios clínicos; científica para ser centro colaborador; e de infraestrutura adequada. Quanto maior a linha maior a capacidade do centro em cada uma das fases.

O (Gráfico 3) retrata a capacidade autorreferida pelos entrevistados, não sendo objeto deste estudo avaliar a capacidade de boas práticas clínicas nas Unidades de Pesquisas Clínicas da RNPC. Dessa forma, então, não se fez necessário que os relatos fossem confirmados in locu. 


\subsection{Considerações finais}

As reflexões apresentadas neste capítulo perpassam importantes marcos teóricos constituídos ao longo dos anos, os quais contribuem para a compreensão e o apontamento de que elementos foram fortalecidos no setor da CT\&I/S e da PD\&I/S e de que maneira é possível aproveitar as janelas de oportunidades que se abrem frente ao direcionamento inerente a cada um deles.

É inegável o esforço do governo federal em disponibilizar instrumentos para fomentar a área produtiva da saúde. Uma questão intrigante para análise, entretanto, refere-se ao inevitável conflito de interesses ${ }^{17}$ entre empresas privadas e a saúde pública, tendo em vista que, como empreendedora, o que a indústria farmacêutica claramente objetiva e prioriza é o lucro.

Por outro lado, não se pode conceber a totalitária noção de que o bem só prevalece em um dos lados. Portanto, é essencial compreender o que representam a ciência e a tecnologia na dinâmica dos atores. Trazer a indústria farmacêutica, especialmente para as parcerias de desenvolvimento de ensaios clínicos, aproveitando a estrutura criada no âmbito da RNPC, pode ser uma estratégia promissora para fortalecer a pesquisa clínica no país, considerando-se os altos custos para realização dessas atividades

Nesse cenário científico, em torno da pesquisa clínica tem-se como "atorchave" o pesquisador-empreendedor que mobiliza os membros da comunidade científica na identificação de expertises comuns para a formação de redes de

\footnotetext{
${ }^{17}$ Segundo o Instituto de Pesquisa Econômica Aplicada (IPEA), conflito de interesse é a situação gerada por um confronto entre interesses públicos e privados que possa comprometer o interesse coletivo ou influenciar, de maneira imprópria, o desempenho da função pública. www.ipea.gov.br/conflitodeinteresses/
} 
colaboração, conseguindo estabelecer parcerias com o governo e o setor privado, criando-se, desse modo, uma "estrutura de gestão compartilhada", além de manter essas relações e assumir que a tomada de decisão é feita a partir de racionalidade limitada, senso de oportunidade e padrões éticos.

Desse contexto, depreende-se que as colaborações, em forma de rede, como reportado por Martins (2013), potencializam a incorporação e o compartilhamento de conhecimentos nos processos de produção. Somado a isso, relacionam-se ainda com cada ator ao firmar parceria e compartir seus recursos, possibilitando a direcionalidade estratégica no sentido de compor a missão, os objetivos e as funções desse tipo de vínculo, os quais se expressam na agenda de prioridades definida pelo SUS.

É inegável que o Complexo Produtivo da Saúde necessita, de modo indeclinável e crescente, da ciência para a sua manutenção. E a pesquisa clínica gera conhecimento científico para resolução dos agravos da saúde pública, a partir de subsídios voltados à geração de novas tecnologias ou incremento de técnicas, processos e tecnologias já existentes, que, por sua vez, serão produzidos, comercializados e empregados nos seus diferentes segmentos, alimentando, assim, todo o processo do CEIS.

Esse movimento proativo culmina com o entendimento de Dal Poz (2006) e o amparo da Teoria Ator-Rede Latour (2012), o qual, ao abordar as fronteiras de uma rede, alerta para que não as limite ao número de atores, mas ao ambiente delimitado pelo fluxo de artefatos que circulam e permitem compartilhar, inclusive, recursos financeiros. Tal ambiente, nada mais é do que o SNI, com seu conjunto de políticas de C\&T, regimes tecnológicos e regulatórios. Essa ideia abrange as redes e seus vínculos. 
Dessa maneira, avaliar tais interrelações, no contexto deste capítulo, é também considerar os progressivos fortalecimento e extensão da interação do sistema de pesquisa e desenvolvimento com o segmento produtivo da saúde, bem como suas capacidades de financiamento e de gestão da estrutura regulatória do Estado. 
CAPÍTULO 2

A PESQUISA CLÍNICA NO BRASIL: possíveis arranjos 


\section{A PESQUISA CLÍNICA NO BRASIL: possíveis arranjos}

\subsection{Introdução}

É correto afirmar que a capacidade de desenvolvimento de fármacos, medicamentos e insumos inovadores para saúde está intimamente ligada às competências necessárias à realização de ensaios clínicos. Por historicamente serem mais empreendedores em conhecimentos e tecnologias, os países desenvolvidos sempre concentraram as demandas de Pesquisa e Desenvolvimento (P\&D).

Recentemente, entretanto, um novo modelo possivelmente já se encontra em curso, efetivamente capaz de inserir os países em desenvolvimento em uma cadeia de alta consistência tecnológica e grande valor agregado por meio da internacionalização de P\&D farmacêutica, contribuindo, assim, para uma estrutura consolidada na indústria (PINHO et al., 2012).

Nos últimos anos a pesquisa clínica alcançou um crescimento expressivo no Brasil. O número de protocolos de ensaios clínicos analisados pela Comissão Nacional de Ética em Pesquisas (Conep) passou de 663, em 2012, para 2.238 em $2015^{18}$

Diversos fatores contribuíram para efetivar essa evolução, a exemplo da internacionalização da pesquisa clínica, cujos parceiros passaram a encontrar essa capacidade científica em ampla ascensão, além de outras questões cruciais para o desenvolvimento de grandes estudos, tais como a heterogeneidade genética da

\footnotetext{
${ }^{18}$ Dados adquiridos da Comissão Nacional de Ética em Pesquisas - Conep, apresentados pelo Dr. Jorge Venâncio em Reunião de Plenária no dia 26/04/2016 em Brasília.
} 
população; facilidade em recrutar, seguir e manter participantes no estudo até a sua conclusão; alta incidência das doenças mais prevalentes nos países desenvolvidos; normas éticas de pesquisa compatíveis com os outros países (DAINESE \& GOLDBAUM, 2012); (PINHO et al., 2012).

A partir dessa perspectiva, este capítulo tem como objetivo apresentar um panorama das características dos grupos de pesquisas que desenvolvem ensaios clínicos no Brasil. Com o propósito de disponibilizar insumos para os gestores frente à tomada de decisão no fomento à $\mathrm{P} \& \mathrm{D}$, pretende-se também identificar possibilidades de estabelecimento de vínculos ou conexões entre os centros e os grupos que se referenciam com capacidade para execução de ensaios clínicos sem, entretanto, se propor a avaliar a qualidade de boas práticas clínicas dos centros nos quais os estudos são executados.

\subsection{Métodos}

Trata-se de um estudo exploratório descritivo, com abordagem quantitativa, realizado a partir de pesquisa documental nacional e internacional, da literatura cinzenta e jornalística, além de bancos de dados nacionais e internacionais.

Foi utilizado o programa scriptLattes para gerar uma rede de coautoria apta a identificar toda a produção acadêmica dos 32 coordenadores das Unidades de Pesquisas Clínicas da RNPC no período de 2010 a 2013, bem como todas as conexões e vínculos realizados por esses pesquisadores por meio de cooperação acadêmica e registrados no Currículo Lattes (MENA-CHALCO \& CESAR Jr., 2009). 
Para a identificação dos grupos de pesquisas em ‘Ensaios Clínicos’ ativos consultou-se o Diretório dos Grupos de Pesquisa da Plataforma Lattes do CNPq (CNPq 2015a). Para isso, recorreu-se ao filtro "Ensaios Clínicos" e, a partir dos dados gerados e importados, procedeu-se à análise do perfil de cada um deles. Quanto aos estudos, com colaboração internacional, foram identificados a partir do banco de registros de pesquisas clínicas ClinicalTrials. gov $^{19}$

Os dados de interesse para esta análise foram recuperados por meio de buscas avançadas. Fez-se o download de todo banco, com o termo "Brazil" no campo "Country 1", selecionando os estudos encontrados e os campos disponíveis (all available fields).

No que concerne aos ensaios clínicos fomentados pelo Decit/MS, foi analisado o banco de dados gerencial do Decit "PesquisaSaude" ${ }^{20}$, classificando-se todos os estudos clínicos e selecionando, entre eles, os ensaios clínicos constantes do banco desde a sua criação.

Todos os dados levantados foram tabulados a partir do software Microsoft Excel®. Esse procedimento fez-se necessário para a construção precisa de cada um dos bancos de dados consultados e também para melhor proceder às análises dos resultados.

\subsection{Resultados e discussão}

A partir da evolução do sistema ético e regulatório da pesquisa clínica brasileiro, da formatação da rede de coautoria e da consulta aos três bancos de dados

\footnotetext{
${ }^{19}$ THE CLINICALTRIALS. Disponível em <https://clinicaltrials.gov/>

20 Base de Dados Gerencial do Decit. 'PesquisaSaude'. Disponível em: <http://200.214.130.94/bdgdecit/index.php?lg=BR.>
} 
(Plataforma Lattes - Diretório dos Grupos de Pesquisas e Currículos Lattes, ClinicalTrials.gov e o PesquisaSaude.), descritos na metodologia, foi possível apresentar os resultados dispostos a seguir.

\subsubsection{O processo regulatório e ético da pesquisa clínica no Brasil: Agência Nacional de Vigilância Sanitária - Anvisa e Comissão Nacional de Ética em Pesquisas - Conep}

O processo de regulamentação de pesquisa clínica no Brasil é realizado por órgãos institucionais, - os Comitês de Ética em Pesquisa (CEP) -, que analisam os aspectos éticos das pesquisas envolvendo seres humanos, sejam das ciências da saúde, das ciências sociais ou humanas, e órgãos governamentais ligados ao Ministério da Saúde, a Agência Nacional de Vigilância Sanitária (Anvisa) e a Comissão Nacional de Ética em Pesquisa (Conep).

A regulação sanitária e ética da pesquisa clínica no Brasil, realizada pela Anvisa, pela Conep e pelo CEP respectivamente, embora tenha iniciado de modo muito brando, apresenta-se atualmente com um visível e expressivo potencial, podendo ser comparável, em nível de igualdade, com os países mais desenvolvidos (NISHIOKA \& SÁ, 2006).

Criada pela Lei no 9.782, de 26 de janeiro de 1999, a Agência Nacional de Vigilância Sanitária (Anvisa) é um órgão regulador com independência administrativa e autonomia financeira, cujo ofício é assegurar controle regulatório à produção e comercialização de produtos e serviços que possam impactar na saúde da população, provendo a vigilância sanitária de todos os produtos para saúde. Exerce, ainda, o papel de fiscal nos portos, aeroportos e fronteiras, além da interlocução junto ao Ministério 
das Relações Exteriores e instituições estrangeiras para deliberação de questões internacionais na área de vigilância sanitária (SILVA, 2013); (CONDESSA, 2016).

No que tange aos ensaios clínicos, a Anvisa é responsável por avaliar os Dossiês de Desenvolvimento Clínico de Medicamento (DDCM), apoiando-se na Resolução de Diretoria Colegiada (RDC) no 9, de 20 de fevereiro de 2015. Essa normativa é aplicável a todos ensaios clínicos com medicamentos para fins de registros (ANVISA, 2015).

Noventa dias é o prazo máximo para que a Anvisa realize as avaliações dos DDCM. Caso a Agência não se manifeste dentro desse período, o estudo poderá ser iniciado, desde que obtenha a devida aprovação pelas instâncias de avaliação ética (CEP/Conep). No caso de ensaios de fase I e II, estudos de produtos biológicos e estudos de desenvolvimento realizado por empresa nacional, o prazo se estende até 180 dias e, nesse caso, o estudo não pode ser iniciado sem a aprovação da Agência (ANVISA, 2015).

O papel da Anvisa diante dos ensaios clínicos vai além do controle no desenvolvimento dos medicamentos. Ao ser disponibilizado no mercado para uso, a vigilância continua por meio da Rede Sentinela, que é uma estratégia de controle PósUso/Pós-Comercialização de Produtos (Vigipós), a qual objetiva prevenir riscos associados ao consumo do novo produto (ANVISA, 2016).

Por sua vez, a Comissão Nacional de Ética em Pesquisas (Conep) é um órgão colegiado vinculado ao Conselho Nacional de Saúde (CNS), de caráter consultivo, deliberativo, normativo, educativo e independente. A Conep é responsável por avaliar os aspectos éticos das pesquisas envolvendo testes em humanos. Tem a 
missão de manter atualizados os instrumentos de proteção dos participantes de pesquisa, além de coordenar os CEP das instituições, (ADAMIL et al., 2014).

De acordo com a Resolução 466/2012, os protocolos de pesquisas clínicas nas áreas temáticas especiais, transcritos no (Quadro 2) devem, necessariamente, ser avaliados e acompanhados pela Conep (BRASIL, 2012).

\section{Quadro 2 - Áreas temáticas sob análise da Comissão Nacional de Ética em Pesquisas (Conep)}

\section{ÀREAS TEMÁTICAS ESPECIAIS}

1.1. envio para o exterior de material genético ou qualquer material biológico humano para obtenção de material genético, salvo nos casos em que houver cooperação com o Governo Brasileiro.

1.2. armazenamento de material biológico ou dados genéticos humanos no exterior e no País, quando de forma conveniada com instituições estrangeiras ou em

1. Genética instituições comerciais.

1.3. alterações da estrutura genética de células humanas para utilização in vivo.

1.4. pesquisas na área da genética da reprodução humana (reprogenética)

1.5. pesquisas em genética do comportamento.

1.6. pesquisas nas quais estejam previstas a dissociação irreversível dos dados dos participantes de pesquisa.

2. 2.1 reprodução assistida.

Reprodução 2.2. manipulação de gametas, pré-embriões, embriões e feto.

Humana 2.3. medicina fetal, quando envolver procedimentos invasivos.

3. Equipamentos e dispositivos terapêuticos, novos ou não registrados no País.

4. Novos procedimentos terapêuticos invasivos.

5. Estudos com populações indígenas.

6. Projetos de pesquisas que envolvam organismos geneticamente modificados (OGM), célulastronco embrionárias e organismos que representem alto risco coletivo, incluindo organismos relacionados a eles, nos âmbitos de: experimentação, construção, cultivo, manipulação, transporte, transferência, importação, exportação, armazenamento, liberação no meio ambiente e descarte.

7. Protocolos de constituição e funcionamento de biobancos para fins de pesquisa.

8. Pesquisas com coordenação e/ou patrocínio originados fora do Brasil, excetuadas aquelas com copatrocínio do Governo Brasileiro.

9. Projetos que, a critério do CEP e devidamente justificados, sejam julgados merecedores de análise pela Conep.

FONTE: Elaboração própria a partir de (BRASIL, 2012). 
Vários aspectos requerem análise por parte das autoridades regulatórias e também pelos pesquisadores e suas equipes ao se iniciar um ensaio clínico. Além das questões éticas que garantem a segurança e a razoabilidade dos testes a serem aplicados nos participantes, destacam-se a relevância do alvo quanto à capacidade de resposta do sistema setorial de inovação em saúde alinhado com as prioridades do Sistema Único de Saúde e a possibilidade de incorporação dos possíveis resultados (GUIMARÃES, 2011); (PALMEIRA et al., 2012).

A partir de outubro de 2011, com a implantação efetiva da Plataforma Brasil - base de registros nacional das pesquisas envolvendo seres humanos -, é possível acompanhar as pesquisas em seus diferentes estágios, desde a sua submissão até a aprovação final. A (Tabela 2) apresenta a evolução de alguns dados que expressam o aumento do número de pesquisas submetidas à Conep para a devida avaliação.

Tabela 2 - Evolução situacional dos protocolos clínicos submetidos à análise da Comissão Nacional de Ética em Pesquisa - Conep, no período de 2012 a 2015

\begin{tabular}{lrrrrr}
\hline Situação & $\mathbf{2 0 1 2}$ & $\mathbf{2 0 1 3}$ & $\mathbf{2 0 1 4}$ & $\mathbf{2 0 1 5}$ \\
\hline Submissão à Plataforma Brasil & 11.258 & 12.587 & 13.354 & 15.226 \\
\cline { 2 - 6 } $\begin{array}{l}\text { Pareceres consubstanciados emitidos pela Conep } \\
\text { Protocolos devolvidos aos CEP }\end{array}$ & 491 & 35 & 17 & 39 \\
Documentos recusados pela Conep & 168 & 65 & 68 & 81 \\
Notificações recusadas pela Conep & 31 & 21 & 81 & 53 \\
Transferidos para outros CEP & 24 & 11 & 0 & 2 \\
\end{tabular}

FONTE: Elaboração própria a partir da Plataforma Brasil. 


\section{Legenda:}

Submissão à Plataforma Brasil - corresponde a todos os projetos submetidos para análise do Sistema CEP/Conep. A maior parte é avaliada pelos CEP institucionais, esses podem ser:

- Protocolos-iniciais $-1^{\circ}$ submissão sem pendências documentais;

- Protocolos-emenda;

- Protocolos-resposta ao parecer Conep pendente;

- Protocolos-resposta ao parecer de indeferimento da Conep;

- Protocolos ressubmetidos das pendências documentais;

- Protocolos Recurso (Conep como última instância recursal).

Pareceres consubstanciados emitidos pela Conep:

- Aprovado;

- Aprovado com recomendação;

- Aprovado ad referendum ${ }^{21}$;

- Pendente;

- Não aprovados.

Protocolos devolvidos ao CEP:

- Quando não são da área especial, conforme resolução 466/12 (BRASIL, 2012);

- Quando o CEP submete erroneamente para análise da Conep.

Documentos recusados pela Conep:

- Protocolos com pendência documental, de acordo com norma operacional 001/1322. Notificações recusadas pela Conep:

- Pendência documental.

Transferidos para outro CEP:

- Quando o CEP é fechado;

- Quando o pesquisador solicitar e a Conep julgar pertinente.

Observa-se que a submissão de documentos na Plataforma Brasil para avaliação dos CEP e Conep aumentou 37,28\% entre o período de 2012 a 2015, enquanto a finalização das análises, cujos processos apresentaram toda a documentação pertinente possibilitando a emissão de pareceres consubstanciados, subiu para $237,5 \%$ no mesmo período, o que nos induz a afirmar que houve um significativo aumento na capacidade operacional da Conep.

${ }^{21}$ Diz-se de todo ato que necessita de aprovação ou ratificação de autoridade.

${ }^{22}$ Dispõe sobre os procedimentos para submissão, avaliação e acompanhamento da pesquisa e de desenvolvimento envolvendo seres humanos no Brasil, nos termos do item 5, do Capítulo XIII, da Resolução n 466/2012 
Ademais, nota-se, a partir de 2013, uma redução importante na devolução de protocolos aos CEP, situação que sugere que a operacionalização dos CEP esteja mais instrumentalizada, tendo em vista que a maioria dos documentos devolvidos era referente a envios equivocados, os quais deveriam ser analisados pelo próprio CEP.

Sabendo-se que somente são avaliados pela Conep os projetos das áreas especiais, não se pode afirmar que o número de ensaios clínicos tenha aumentado, considerando-se apenas esses indicadores. Pode-se inferir, entretanto, que houve um significativo aumento dos projetos nessas áreas, bem como uma maior capacitação dos CEP.

\subsubsection{Os ensaios clínicos na academia}

A concepção, o desenvolvimento e a execução de novas ideias nas universidades constituem as fases mais longas, cientificamente mais trabalhosas -em geral, consideradas pouco importantes para a indústria farmacêutica devido às incertezas inerentes ao próprio desdobramento (CARAMORI, 2013). No entanto, Quental et al. (2001) e Torres-Freire et al. (2014) acreditam que as universidades e instituições de pesquisa são potencialmente capazes de contribuir para os avanços tecnológicos na indústria.

Ao ressaltar a importância da mudança de paradigma na pesquisa acadêmica, no que diz respeito aos avanços adquiridos a partir das parcerias interinstitucionais, Guimarães (2011) destaca três principais aspectos que se tornaram evidentes por meio dos instrumentos de indução à inovação criados pelo governo, 
como os incentivos fomentados principalmente pelos Fundos Setoriais, BNDES, Finep, compreendendo:

(1) aumento da capacidade de indução, no sentido de que à perspectiva de mérito científico sejam agregados componentes de prioridade, definidos por atores de dentro e, principalmente, de fora da comunidade científica; (2) ênfase no componente tecnológico e na busca da inovação, procurando deslocar o tradicional balanço observado na pesquisa realizada no Brasil; e (3) reforço do componente empresarial, contemplando associações de empresas com grupos e instituições de pesquisa e, mais recentemente, estimulando diretamente o desenvolvimento e a inovação nas empresas. (GUIMARÃES, 2011: 5)

Ao promover um ambiente eticamente viável para a realização da pesquisa clínica, a estratégia interministerial de criação da Rede Nacional de Pesquisa Clínica apoiada nas estruturas hospitalares universitárias visou a favorecer, ao mesmo tempo, o fortalecimento do ensino da pós-graduação e a visibilidade das Unidades de Pesquisas Clínicas (UPC) no âmbito institucional, bem como fora delas (BRASIL, 2007a).

Para afirmar que a RNPC promove parcerias e expansão de conhecimento tanto interna quanto externamente às instituições que estão vinculadas, construiu-se um grafo (Figura 5) a partir do programa scriptLattes (MENA-CHALCO \& CESAR Jr., 2009). Os dados foram extraídos automaticamente, após a identificação de todos os 'ID Lattes' dos currículos selecionados. Isso possibilitou, ainda, identificar as conexões estabelecidas com outros atores, dentro e fora das suas instituições, caracterizando, assim, uma rede de coautorias.

$\mathrm{Na}$ (Figura 5) cada nodo representa um pesquisador - os vermelhos e azuis são coordenadores da RNPC do sexo feminino e masculino, respectivamente. Os 
nodos verdes equivalem aos pesquisadores externos à RNPC. Quanto maior o nodo, maior também o número de conexões com outros pesquisadores. Verifica-se uma grande quantidade de nodos e arestas, que são as ligações entre os atores, sendo que estas partem de 1583 conexões estabelecidas no período de referência, ampliando-se a partir dos vínculos com outros coautores.

A figura localizada à esquerda representa a rede total, enquanto a da direita corresponde a um recorte, cuja finalidade é apenas a de ampliar a visualização das conexões. Essa rede se concretizou por meio de diversos tipos de atividades acadêmicas produzidas em parceria com outros pesquisadores ou grupos de pesquisa.

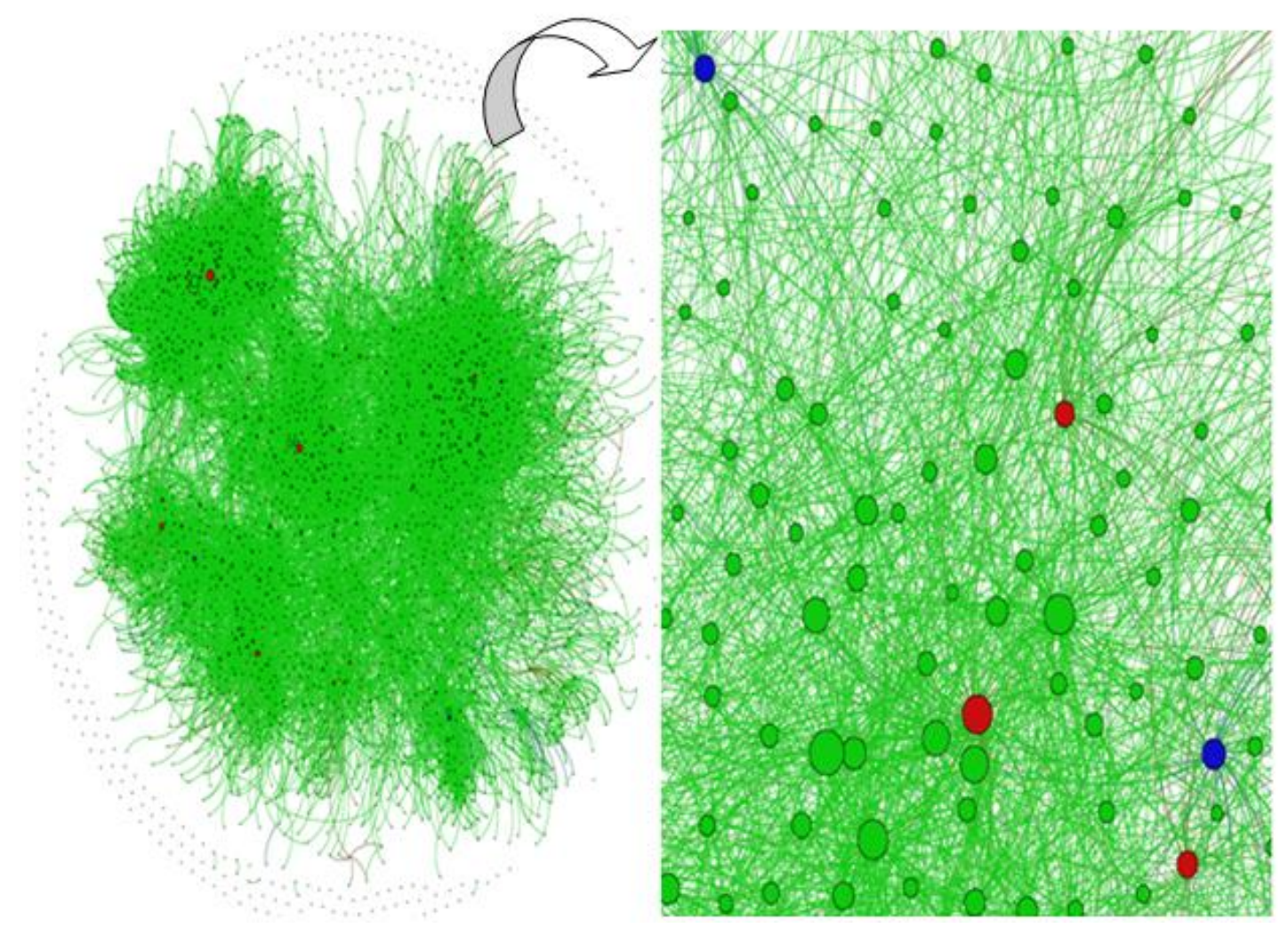

FONTE: Gerado automaticamente por scriptLattes V8.09, a partir de dados do estudo.

Figura 5 - Rede de coautoria formada a partir dos coordenadores das Unidades de Pesquisas Clínicas da Rede Nacional de Pesquisa Clínica em Hospitais de Ensino 
Os produtos que deram origem às conexões da (Figura 5) compreenderam 640 artigos completos publicados em periódicos; 98 capítulos de livros publicados; 13 livros publicados/organizados ou editados; nove trabalhos completos; três resumos expandidos e 408 resumos publicados em anais de congressos; 85 textos em jornais de notícias/revistas; 31 artigos aceitos para publicação; 275 apresentações de trabalho; 21 demais tipos de produção bibliográfica, entre outros (Apêndice 4).

Os coautores considerados no grafo são todos aqueles que o pesquisador o referiu como colaborador no próprio Currículo Lattes. É importante destacar que os dados aqui apresentados correspondem ao somatório da produção constante da plataforma Lattes, referente aos 32 representantes da RNPC, não sendo da responsabilidade dos autores qualquer inconsistência.

Ademais, apesar de se reconhecer o potencial de colaboração entre atores e a formação de arranjos multicêntricos, delineados pela figura, alerta-se para o fato de que os produtos aqui expostos não foram gerados, necessariamente, no contexto da rede, ainda que as informações tenham sido extraídas dos Currículos Lattes dos coordenadores das UPC integrantes da RNPC.

\subsubsection{Ensaios Clínicos e Grupos de Pesquisas}

O Diretório dos Grupos de Pesquisa da Plataforma Lattes do CNPq $(\mathrm{CNPq}$, 2015b) sistematiza dados sobre os grupos de pesquisa brasileiros, compreendendo, entre esses, pesquisadores, estudantes, técnicos, linhas de pesquisa ativas, produção científica, tecnológica e artística. 
Por se tratar de uma base que evidencia os cursos de pós-graduação do país e a maior visibilidade dos pesquisadores e seus grupos, acaba por representar, com bastante razoabilidade, a comunidade científica nacional (RAPINI, 2007).

As informações dessa sessão foram obtidas por meio da análise da base corrente do Diretório dos Grupos de Pesquisas do CNPq. A partir do filtro "ensaios clínicos", foram identificados 125 grupos cadastrados, entretanto, dois deles não foram incluídos por não se tratar de estudos envolvendo seres humanos, mas de grupos da medicina veterinária. Acrescentaram-se duas colunas à planilha gerada pela Plataforma Lattes, uma delas indicando as regiões nas quais cada grupo está sediado e outra com a especialidade predominante no grupo (Apêndice 5). Ratificou-se, por meio da análise em cada grupo, a existência da linha de pesquisa voltada para "ensaios clínicos", confirmando-se o total de 123 grupos.

Dos grupos selecionados, $51 \%$ se localizam na região Sudeste do país, corroborando com o que ocorre em outras áreas da ciência e tecnologia, historicamente perpetuada; $24 \%$ deles situados no Nordeste; $21 \%$ no Sul, e apenas $4 \%$ nas regiões Centro-Oeste e no Norte.

Os grupos identificados provêm de 51 instituições de ensino e pesquisa. Por ordem decrescente, as dez primeiras que aparecem com maior frequência são: Fiocruz (14), Universidade de São Paulo (11), Universidade Estadual Paulista Júlio de Mesquita Filho (6), Universidade Federal de Santa Catarina (6), Universidade Federal de São Paulo (6), Hospital das Clínicas de Porto Alegre (5), Universidade Federal do Ceará (5), Universidade Federal da Paraíba (5), Universidade Federal do Rio Grande do Sul (5), Universidade Federal da Bahia (4), Universidade Federal de Pernambuco (4). 
Quanto às especialidades dos grupos selecionados, registraram-se 23 áreas distintas como exposto no (Tabela 3). Medicina aparece com maior frequência, seguida de Odontologia e Farmácia. Os grupos de Medicina estão em sua maioria $52 \%$ - sediados no Sudeste, sendo que $64 \%$ dos grupos dessa região se concentram em três instituições, a saber, Fiocruz, Unifesp e USP.

Apesar do esforço governamental em destinar recursos por meio de instrumentos de gestão, como, por exemplo, os fundos setoriais geridos pela Finep, as regiões Norte e Centro-Oeste ainda não aportaram a capacidade científica necessária para alavancar a competitividade frente às demais (TORRES-FREIRE et al., 2014).

Nessa direção, Cavalcante (2011) sustenta que o fluxo de recursos para C\&T e a capacidade científica estão interrelacionados, ou seja, quanto maior a base científica maior será a capacidade de captação de recursos. Essa percepção possibilita presumir que as regiões com menor adensamento técnico/científico contam com mecanismos de transmissão mais precários entre a ciência e a tecnologia, inibindo, desse modo, a atuação das empresas que implementam inovações. Nesse caso específico dos ensaios clínicos, é praticamente impossível a manutenção ativa de grupos de pesquisa, sem a capacidade científica de alto nível (DAINESE \& GOLDBAUM, 2012).

A conformação apresentada na (Tabela 3) permite conceber com clareza as instituições que apresentam possibilidade de arranjos para compartilhamento de colaborações. 
Tabela 3 - Distribuição das especialidades dos grupos de pesquisas de ensaios clínicos por instituição, registrados na Plataforma Lattes

\begin{tabular}{|c|c|c|}
\hline ESPECIALIDADE & INSTITUIÇÃO & QTD \\
\hline \multirow{3}{*}{ Bioquímica } & - Instituto Butantan & 1 \\
\hline & •Universidade de Ribeirão Preto & 1 \\
\hline & •Universidade de São Paulo & 1 \\
\hline $\begin{array}{l}\text { Ciência da } \\
\text { Computação }\end{array}$ & • Universidade de São Paulo & 1 \\
\hline $\begin{array}{l}\text { Ciência e } \\
\text { Tecnologia de } \\
\text { Alimentos }\end{array}$ & •Universidade de São Paulo & 1 \\
\hline Direito & -Universidade Federal da Bahia & 1 \\
\hline \multirow{2}{*}{ Enfermagem } & -Universidade Federal da Paraíba & 1 \\
\hline & -Universidade Federal de Alagoas & 1 \\
\hline \multirow{2}{*}{$\begin{array}{l}\text { Engenharia } \\
\text { Biomédica }\end{array}$} & - Universidade Camilo Castelo Branco & 1 \\
\hline & •FK Biotecnologia & 1 \\
\hline \multirow{7}{*}{ Farmácia } & -Universidade Bandeirante de São Paulo & 1 \\
\hline & -Universidade Estadual de Londrina & 1 \\
\hline & -Universidade Federal da Paraíba & 2 \\
\hline & •Universidade Federal de Goiás & 1 \\
\hline & - Universidade Federal de Pernambuco & 1 \\
\hline & -Universidade Federal do Ceará & 1 \\
\hline & - Universidade Metodista de Piracicaba & 1 \\
\hline \multirow{6}{*}{ Farmacologia } & $\begin{array}{l}\text { - Instituto de Ensino e Pesquisa da Santa Casa de Belo } \\
\text { Horizonte }\end{array}$ & 1 \\
\hline & •Universidade Federal de Pernambuco & 1 \\
\hline & - Universidade Federal de Santa Catarina & 1 \\
\hline & -Universidade Federal do Espírito Santo & 1 \\
\hline & - Universidade Federal do Rio Grande do Norte & 1 \\
\hline & -Universidade José do Rosário Vellano & 1 \\
\hline Filosofia - Bioética & -Universidade Estadual de Londrina & 1 \\
\hline \multirow[b]{2}{*}{ Fisiologia } & - Universidade Federal do Ceará & 1 \\
\hline & $\begin{array}{l}\text { - Universidade Regional do Noroeste do Estado do Rio } \\
\text { Grande do Sul }\end{array}$ & 1 \\
\hline \multirow{4}{*}{$\begin{array}{l}\text { Fisioterapia e } \\
\text { Terapia } \\
\text { Ocupacional }\end{array}$} & -Universidade Cidade de São Paulo & 2 \\
\hline & •Universidade Federal de São Paulo & 1 \\
\hline & -Universidade Federal de Sergipe & 1 \\
\hline & -Universidade Federal de Uberlândia & 1 \\
\hline Fonoaudiologia & -Universidade de São Paulo & 1 \\
\hline \multirow{2}{*}{ Genética } & -Universidade Federal de Mato Grosso do Sul & 1 \\
\hline & -Universidade Federal do Rio Grande do Sul & 2 \\
\hline \multirow{3}{*}{ Imunologia } & $\bullet$ Fiocruz & 2 \\
\hline & - Universidade Federal de Santa Catarina & 1 \\
\hline & -Universidade Federal Fluminense & 1 \\
\hline $\mathbf{M}$ & $\bullet$ Fiocruz & 6 \\
\hline
\end{tabular}


- Fundação de Medicina Tropical Doutor Heitor Vieira Dourado

- Fundação Hospitalar do Estado de Minas Gerais 1

- Hospital de Clínicas de Porto Alegre 4

-Instituto de Cardiologia do Rio Grande do Sul 1

-Instituto Evandro Chagas

- Pontifícia Universidade Católica do Paraná

- Pontifícia Universidade Católica do Rio Grande do Sul

- Universidade de Brasília

- Universidade de Caxias do Sul

- Universidade de São Paulo

- Universidade do Estado do Rio de Janeiro

- Universidade do Sagrado Coração

- Universidade Estadual de Campinas

- Universidade Estadual Paulista Júlio de Mesquita Filho

- Universidade Federal da Bahia

- Universidade Federal da Paraíba

- Universidade Federal de Alagoas

- Universidade Federal de Juiz de Fora

- Universidade Federal de Minas Gerais

- Universidade Federal de Pernambuco

- Universidade Federal de Santa Catarina

- Universidade Federal de São Paulo

- Universidade Federal do Ceará

- Universidade Federal do Ceará

- Universidade Federal do Rio de Janeiro

- Universidade Federal do Rio Grande do Norte

- Universidade Federal do Rio Grande do Sul

\begin{tabular}{lll}
\hline Microbiologia & $\bullet$ Instituto Adolfo Lutz & 1 \\
\hline Morfologia & $\bullet$ Universidade Federal de Santa Catarina & 1 \\
\hline \multirow{2}{*}{ Nutrição } & $\bullet$ Universidade Federal da Bahia & 1 \\
& $\bullet$ Escola Superior de Ciências da Saúde & 1 \\
\hline & $\bullet$ Universidade de Pernambuco & 1 \\
& $\bullet$ Universidade de São Paulo & 2 \\
& $\bullet$ Universidade Estadual Paulista Júlio de Mesquita Filho & 3 \\
& $\bullet$ Universidade Federal da Bahia & 1 \\
& $\bullet$ Universidade Federal da Paraíba & 2 \\
Odontologia & $\bullet$ Universidade Federal de Pelotas & 1 \\
& $\bullet$ Universidade Federal de Santa Catarina & 1 \\
& $\bullet$ Universidade Federal de Sergipe & 1 \\
& $\bullet$ Universidade Federal de Uberlândia & 1 \\
& $\bullet$ Universidade Federal do Rio Grande do Norte & 1 \\
& $\bullet$ Universidade Federal Fluminense & 1 \\
\hline Parasitologia & $\bullet$ Fiocruz
\end{tabular}




\begin{tabular}{lll} 
& $\bullet$ Universidade Federal de Minas Gerais & 1 \\
\hline Probabilidade e & $\bullet$ Universidade Estadual Paulista Júlio de Mesquita Filho & 1 \\
Estatística & $\bullet$ Universidade Federal Rural do Rio de Janeiro & 1 \\
\hline \multirow{2}{*}{ Qú́mica } & $\bullet$ Universidade Federal de Pernambuco & 1 \\
& $\bullet$ Universidade Federal do Recôncavo da Bahia & 1 \\
\hline \multirow{3}{*}{ Saúde Coletiva } & $\bullet$ Fiocruz & 4 \\
& $\bullet$ Hospital de Clínicas de Porto Alegre & 1 \\
& $\bullet$ Instituto Federal do Ceará & 1 \\
& $\bullet$ Universidade de São Paulo & 1 \\
\hline
\end{tabular}

FONTE: elaboração própria a partir do Diretório dos Grupos de Pesquisas do CNPq.

Legenda: a primeira coluna à esquerda representa as especialidades dos grupos de pesquisa, na segunda coluna estão agregadas as instituições por especialidade e na última coluna, apresenta-se a quantidade de grupos por instituição na especialidade da linha em que está inserida.

No desenvolvimento dos ensaios clínicos em particular, as parcerias institucionais são fundamentais, tendo em vista a inegável importância de participantes de pesquisas provenientes de todas as regiões do país, orientadas no sentido de representar a miscigenação da população brasileira, bem como de centros de pesquisas com profissionais altamente qualificados. Essas conexões podem transformar-se em uma relevante estratégia, devendo, então, ser fortemente priorizada e estimulada, já que favorece as duas iniciativas, seja a de capacitar e fortalecer os grupos de menor competitividade seja a de facilitar a inclusão de participantes nos estudos (TORRESFREIRE et al., 2014).

\subsubsection{Registro de ensaios clínicos brasileiros no banco de dados ClinicalTrials.gov}

O banco de dados de registro primário de ensaios clínicos ClinicalTrials.gov reúne registros de ensaios clínicos de todo mundo desde 1997. Essa iniciativa é fruto da Lei de Modernização do Food and Drug Administration (FDA), 
que visou a estabelecer informações mundiais dos ensaios clínicos independentemente do tipo de financiamento, público ou privado. Por meio de uma criação conjunta do National Institutes of Health (NIH) com FDA, o site foi disponibilizado ao público em fevereiro de 2000. Atualmente, é mantido pela National Library of Medicine (NLM) do NIH (DEBORAH et al., 2011); (THE CLINICALTRIALS, 2016).

A partir da análise dos dados extraídos, constatou-se que, na data de referência (29/03/2016), constavam do banco ClinicalTrials.gov 201.577 ensaios clínicos provenientes de 193 países dos cinco continentes. Entretanto, a maior proporção desses estudos, 150.941 (74,8\%) inclui os Estados Unidos e da Europa.

Os dados de interesse para esta análise foram recuperados por meio de busca avançada. Fez-se o download do banco com o termo "Brazil" no campo “Country 1", selecionando todos os estudos encontrados e os campos disponíveis (all available fields), exportando-os, então, para a planilha 4.888 estudos resultantes da investigação. Apesar desse número, não é possível afirmar que são de financiamento totalmente brasileiro, uma vez que essa informação não está disponível no banco.

Com o propósito de observar como se comportam os países BRICS e os da América do Sul nesse cenário, também foram extraídos dados do "Mundo", “Brasil”, "Rússia, "Índia”, "China” e "África do Sul” utilizando-se para cada palavrachave o filtro "Country 1 ".

A partir da busca relacionada aos países BRICS, somaram 20.541 estudos selecionados, o que representa apenas $9 \%$ do total do banco de dados, enquanto a população desse conjunto de países equivale a 43,2\% do montante global (UNESCO, 2015); (BRASIL, 2015). A disposição do número de ensaios clínicos para cada país dos BRICS está assim disposta: Brasil (4.888, 24\%), Rússia (3.299, 16\%), Índia 
(2.814, 14\%), China (7.379, 36\%), e África do Sul (2.161, 10\%), apresentados na (Figura 6).

Em referência aos registros de estudos na América do Sul, procedeu-se ao mesmo tipo de análise, possibilitando resgatar 10.261 estudos, o equivalente a 5\% do total de registros do banco, enquanto a população desse grupo de países corresponde a 5,6\% do total mundial (IBGE, 2016). O Brasil, com relação a esse grupo de países, é detentor do maior número de estudos (4.888, 48\%), seguido da Argentina (2.035, 20\%), Chile (1.137, 11\%), Colômbia (916, 9\%), Peru (907, 8\%), Venezuela (155, 2\%), Equador (105, 1\%). Já os demais países - Uruguai (54), Bolívia (36), Paraguai (24), Suriname (03), e Guiana (01) - somam juntos somente 1\% (Figura 6).

Os dados obtidos corroboram para delinear a posição que o Brasil tem alcançado frente aos países BRICS e a seus vizinhos integrantes da América do Sul, legitimando Caramori (2013), e Torres-Freire, et al. (2014) ao visualizarem o crescimento da pesquisa clínica em todo mundo, especialmente nos países em desenvolvimento.

Entende-se que o número de estudos desenvolvidos nesses países, frente à representação e diversidade das suas populações no cenário mundial, fortalece a possibilidade de parcerias para execução de pesquisas clínicas, principalmente de colaborações com grandes potenciais na área.

O desafio maior seria fazer com que as prioridades do SUS, a capacidade científica instalada e o potencial de expansão do país sejam atendidos, e não apenas demarcados pelos executivos dos laboratórios farmacêuticos. Os números brasileiros sinalizam que já existe no país uma considerável massa científica para responder a essa demanda. 


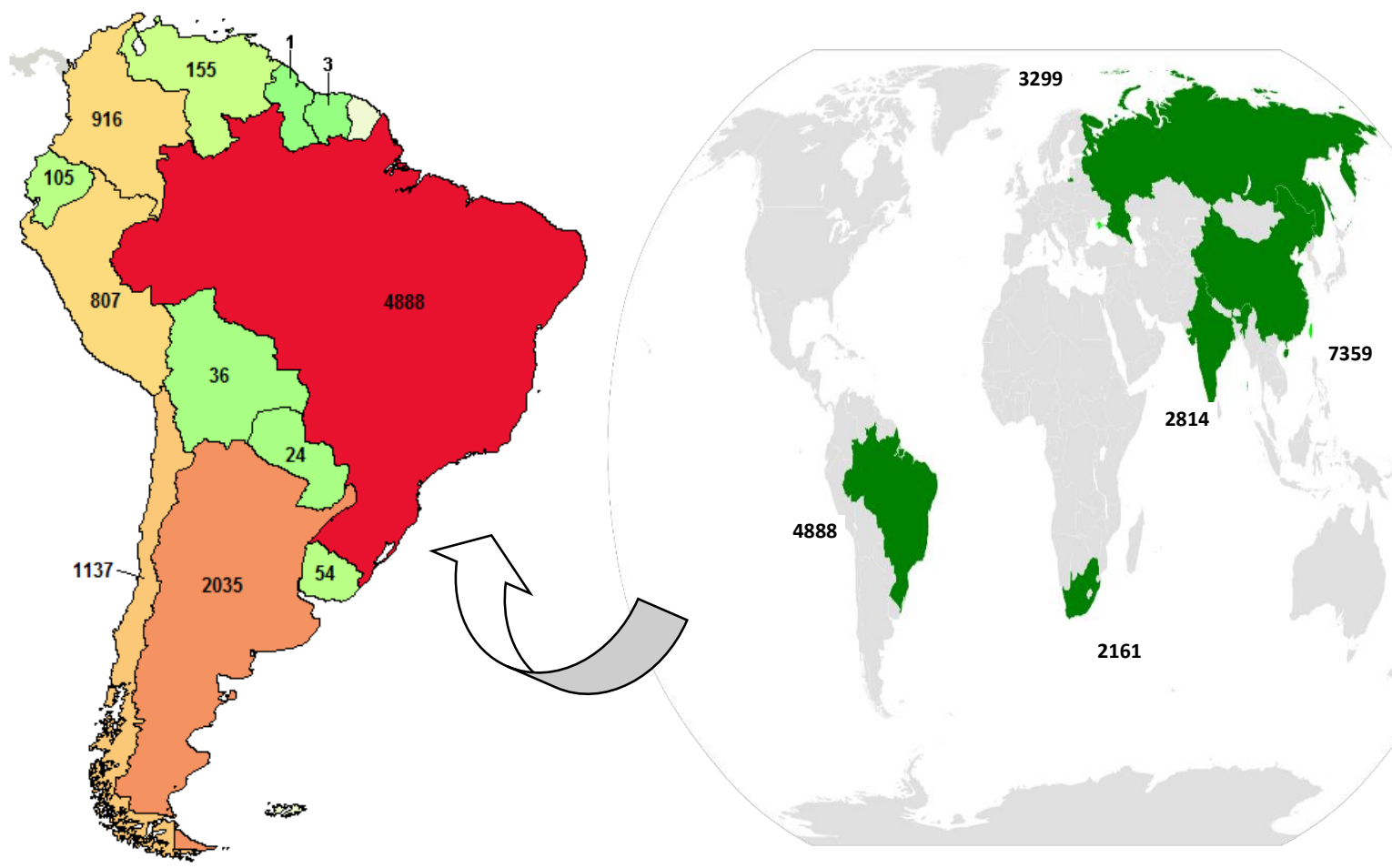

Fonte: Gerado automaticamente de ClinicalTrials.gov, e imagem da Internet - domínio público $^{23}$ - , com adaptações próprias.

Figura 6 - Distribuição do número de ensaios clínicos, por países da América do Sul e por países BRICS, registrados no ClinicalTrials.gov

\section{Legenda}

A figura do lado esquerdo representa a América do Sul com a delimitação de seus países e o número de ensaios clínicos registrados no ClinicalTrials.gov.

A figura do lado esquerdo, representa o mapa-múndi, destacando na cor verde os países BRICS.

A segunda parte da análise dos dados brasileiros registrados no ClinicalTrials.gov, constou da identificação dos ensaios clínicos (fases I,II,III e IV), excluindo-se da amostra total os estudos clínicos observacionais. Procedeu-se à apreciação dos dados importados para a planilha com todos os estudos brasileiros resgatados $(n=4.888)$, aplicando-se os filtros "intervenção" com o status do estudo "recrutando" $(\mathrm{n}=1.003)$ e "ativo não recrutando" $(\mathrm{n}=502)$, totalizando 1.505.

\footnotetext{
${ }^{23}$ Disponível em: https://commons.wikimedia.org/wiki/File:BRICS.svg
} 
Acredita-se que esses filtros possibilitam a seleção de estudos mais recentes, uma vez que grande parte deles não apresenta os dados atualizados na plataforma, permanecendo a dúvida se ainda estão em curso, se foram concluídos, ou se abandonados. Observa-se a pertinência desse cuidado por existirem estudos que acompanham a evolução da doença ou efeito da droga testada sob a sobrevida global dos pacientes, e que podem comprometer muitos anos até se alcançar a conclusão (MAROTTI, 2007).

O (Gráfico 4) apresenta como estão distribuídos os estudos frente ao número de pacientes. Apesar de se constatar que a maioria deles é de pequeno porte, não necessariamente desenvolvidos em um único centro. Quando se trata, por exemplo, de estudos que envolvem doenças raras ou pacientes com perfis de difícil seleção, mesmo que sejam pequenos, necessitam de centros colaboradores para completar a representatividade da amostra (VIEIRA \& HOSSNE, 2015).

\section{Gráfico 4 - Distribuição de ensaios clínicos com participação do Brasil, por tamanho amostral, registrados no ClinicalTrials}

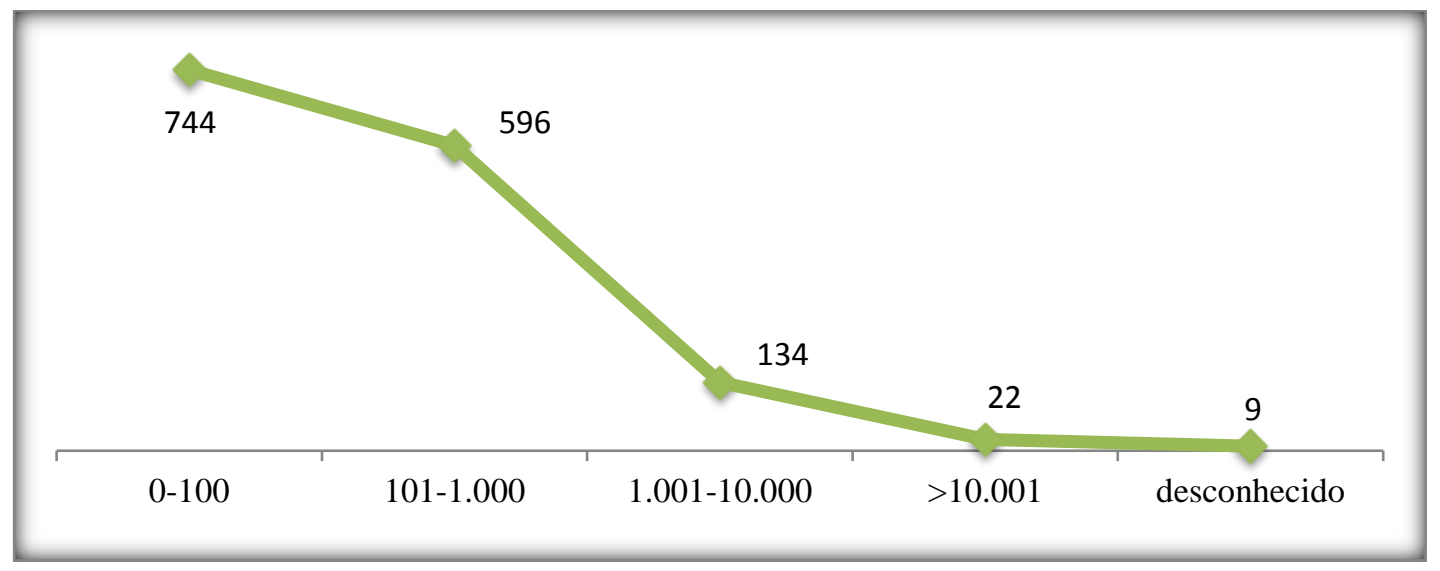

Fonte: Elaboração própria a partir de dados coletados do ClinicalTrials.gov.

Os nove estudos apresentados como 'desconhecidos' foram individualmente checados, entretanto não foram registradas na plataforma as informações associadas ao número de participantes em cada investigação. 
Com relação à evolução do número de estudos por ano, ilustrado no (Gráfico 5), considerou-se a data constante no campo 'start date', a qual corresponde a seu início. Verifica-se uma evolução bastante significativa ao longo dos anos desde 2001. No entanto, no ano de 2015 , houve um declínio de $16 \%$ em relação ao ano anterior. Para 2016, considerando-se a data de referência (29/03/2016) na qual os dados foram recuperados, já estavam registrados, à época, 26 estudos. Três deles foram apontados como desconhecidos por não registrarem a data de início no campo adequado.

\section{Gráfico 5 - Distribuição dos estudos ao longo dos anos com participação do Brasil, registrados no ClinicalTrials}

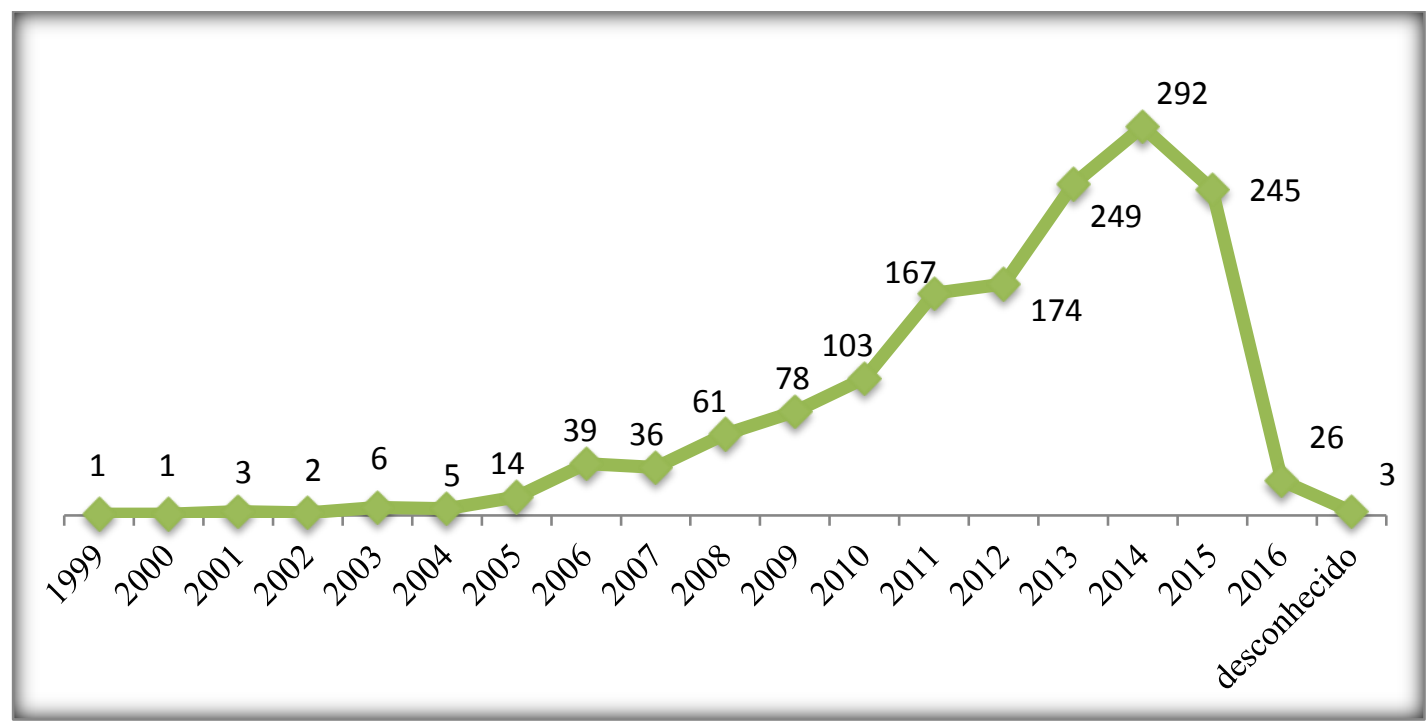

Fonte: Elaboração própria a partir de dado coletados do ClinicalTrials.gov.

Quanto ao financiador dos estudos com participação brasileira, demonstrado no (Gráfico 6), definiu-se três categorias, para essa análise, considerando-se a impossibilidade de identificação dos valores investidos por cada parceiro financeiro. Assumiu-se, então, que os termos que aparecem como primeiro financiador constituem a fonte principal de investimento, incluindo, entretanto, 
cofinanciadores, que podem corresponder à seguinte configuração ${ }^{24}:(1)$ Indústria: Industry, Industry/NIH, Industry/Other e Industry/U.S. Fed; (2) Outros: Other, Other/Industry, Other/NIH, Other/NIH/Industry, Other/NIH/U.S. Fed e Other/U.S. Fed/NIH; (3) Governo americano: NIH e U.S. Fed.

Gráfico 6 - Distribuição de estudos com participação do Brasil por tipo de financiamento considerando-se a fonte principal, registrados no ClinicalTrials

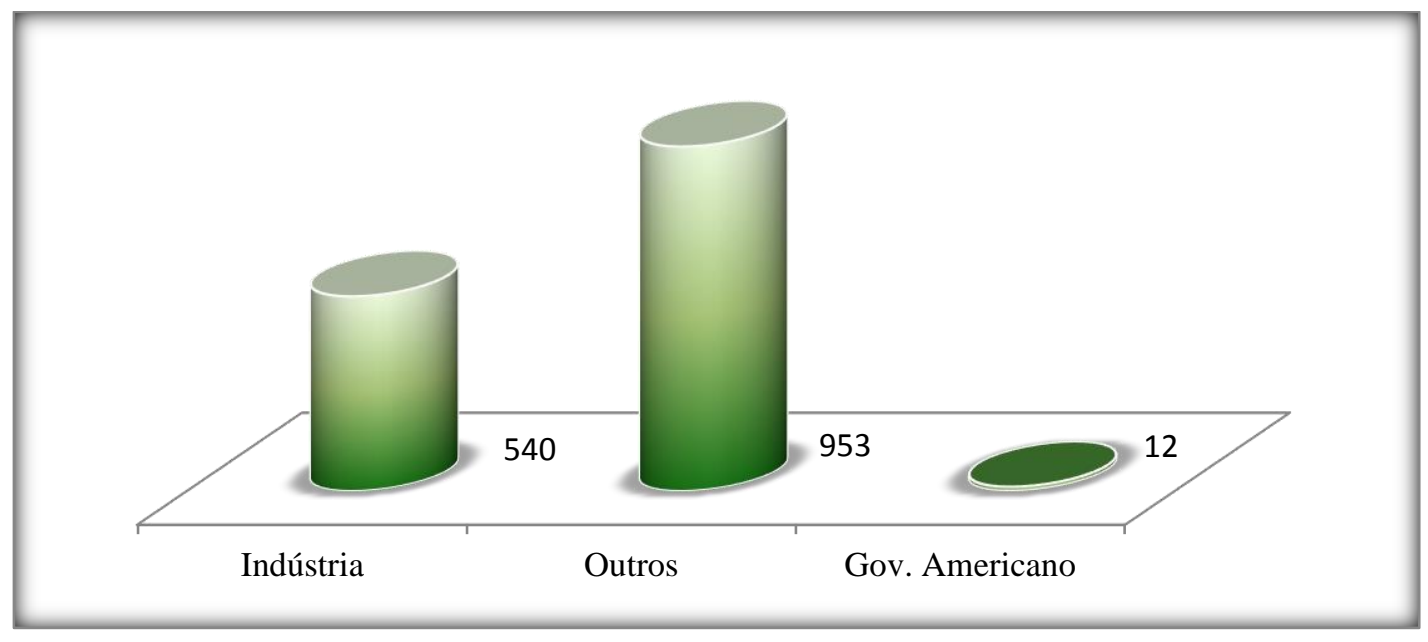

Fonte: Elaboração própria a partir de dado coletados do ClinicalTrials.gov .

No (Gráfico 6) é possível conferir que o maior número de estudos obteve recursos de 'outros' como fonte principal de financiamento - estes correspondem aos investimentos patrocinados por indivíduos (pessoas físicas ou jurídicas), universidades (públicas ou privadas) e organizações sociais.

\footnotetext{
${ }^{24}$ NIH: National Institutes of Health; U.S. Fed.: Agências Federais Americanas: Ex., a Food and Drug Administration (FDA), Centros de Controle e Prevenção de Doenças (CDC), Departamento de Assuntos de Veteranos dos EUA; Indústria: Empresas farmacêuticas e de dispositivos médicos; Todos os outros: indivíduos, universidades, organizações.
} 
Chama-se atenção para a diversidade de coparticipação no financiamento dos ensaios clínicos, e esse fato se deve aos altos custos desses estudos, sendo praticamente obrigatório o estabelecimento dessas parcerias para executar todas as fases necessárias. O governo norte-americano, apesar de aparecer como fonte principal em um número menor de estudos, consta em muitos outros associados a categorias ‘indústria' e 'outros' como cofinanciador.

Entre os 12 estudos financiados pelo governo americano, 11 deles são pelo NIH. Todos são realizados com medicamentos, somente um com biológico. Quanto ao alvo desses estudos, 10 são para testes em HIV e um em câncer de fígado. O único financiado pela U.S. Fed é em odontologia.

Com relação à distribuição de estudos por fase, identificados na análise (Gráfico 7), do total de 1.505 com participação brasileira, um número bastante expressivo de registros não identificou no campo adequado a fase do estudo - estes representaram 32,75\% (493), sendo então rotulados como desconhecidos.

Entre os ensaios clínicos que aparecem com maior frequência, destacamse os de fase III (519). Dentre esses, 406 estudos têm financiamento principal da indústria, sendo 92,36\% (375) exclusivamente industry, 6,89\% (28) industry/other e 0,73\% (3) industry/U.S. Fed.

Esses dados corroboram com o já preconizado pela literatura brasileira (GUIMARÃES et al, 2011); (CARAMORI, 2013) de que os ensaios clínicos brasileiros são planejados no exterior, e não refletem as necessidades da saúde pública nacional. 
Gráfico 7 - Distribuição de estudos por tipo de fase clínica, registrados no ClinicalTrials

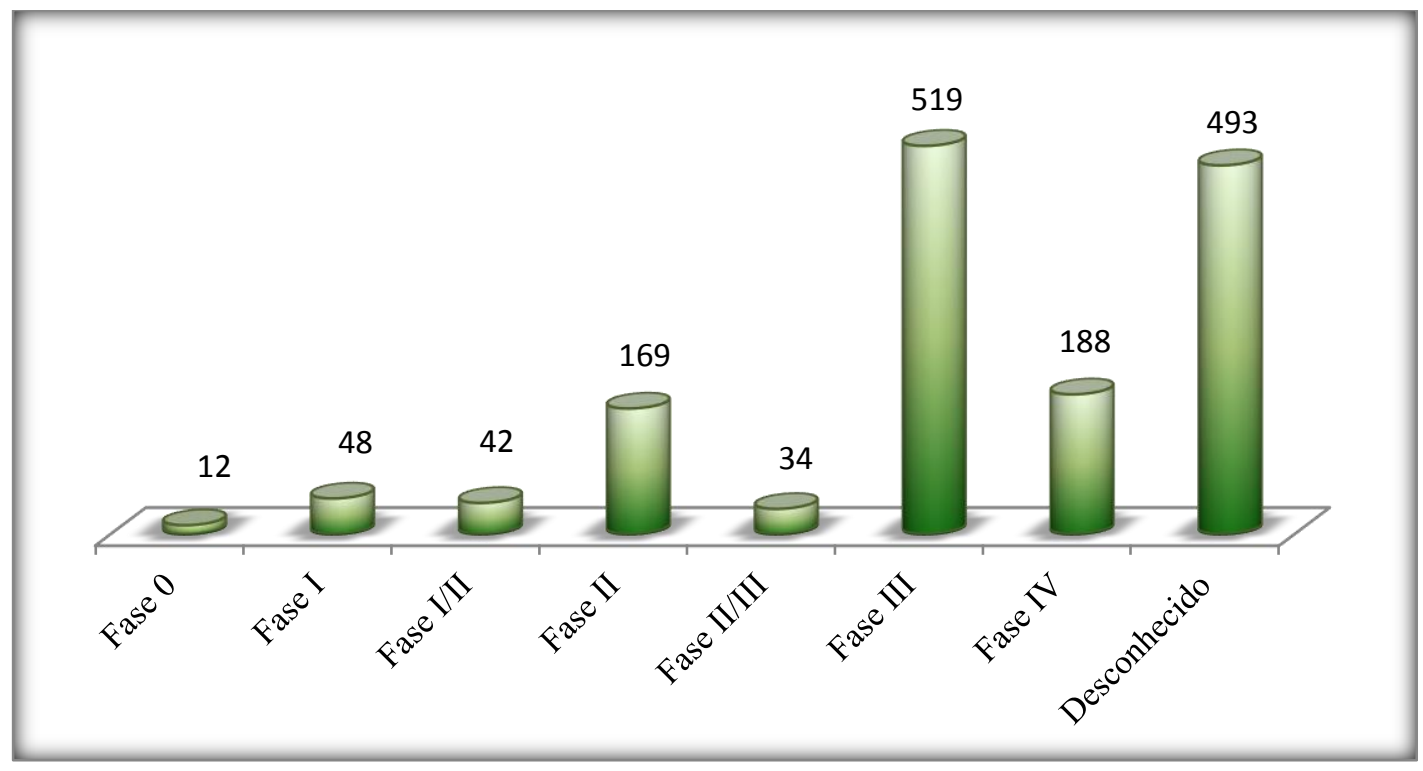

Fonte: Elaboração própria a partir de dado coletados do ClinicalTrials.gov

Apesar da fase 3 se apresentar em maior número (Gráfico 7), não se pode afirmar, com segurança, as inferências abordadas, tendo em vista o alto número de ensaios com fases desconhecidas, 493 estudos.

\subsubsection{Ensaios clínicos na base gerencial de dados do Departamento de Ciência e} Tecnologia do (Decit) do Ministério da Saúde 'PesquisaSaude'.

O Departamento de Ciência e Tecnologia (Decit) disponibiliza acesso livre a uma ferramenta eletrônica que unifica dados de 5.479 pesquisas, na data de referência 20/04/2016 - informações fomentadas em parceria com o Ministério de Ciência Tecnologia e Inovação (MCTI) por meio do CT-Saúde, CT- Biotec e CT-Infra e de suas agências CNPq e Finep. As parcerias financeiras nacionais se estendem também 
às Fundações de Amparo à Pesquisa (FAP) dos Estados; Coordenação de Aperfeiçoamento de Pessoal de Nível Superior (Capes) do Ministério da Educação (MEC); Organização das Nações Unidas para o Desenvolvimento da Educação, Ciência e Cultura (Unesco); Organização Panamericana de Saúde (OPAS); Banco Nacional de Desenvolvimento Econômico e Social (BNDES); Secretarias de Saúde dos Estados; Fundação Nacional do Índio (Funasa); Áreas Técnicas do MS; Fundo Nacional de Saúde (FNS), entre outros. Além dessas, algumas cooperações internacionais foram firmadas com a Fundação Bill e Melinda Gattes.

Denominada 'PesquisaSaude', essa ferramenta possibilita a divulgação dos projetos fomentados pelo Decit e as áreas temáticas prioritárias do Ministério da Saúde, conferindo a esperada transparência aos modelos de fomento praticados pelo Departamento e, ao mesmo tempo, colaborando efetivamente para produzir indicadores para os pesquisadores e gestores da área de saúde.

Tais pesquisas estão classificadas como: (1) ciências sociais; (2) desenvolvimento tecnológico; (3) em fase de classificação; (4) epidemiológica; (5) infraestrutura; (6) não informada; (7) outras ações de C\&T; (8) Pesquisa Biomédica (stricto sensu); (9) pesquisa clínica; (10) pesquisa clínica - fase I; (10) pesquisa clínica - fase II; (10) pesquisa clínica - fase III; (10) pesquisa clínica - fase IV; (10) pesquisa clínica epidemiológica/observacional; (11) pesquisa em saúde coletiva; (12) pesquisa pré-clínica; e (13) sistemas de saúde, planejamento e gestão de políticas, programas e serviços de saúde.

O sistema disponibiliza várias estratégias de busca, conforme apresentado na (Figura 7), a ser planejada pelo usuário de modo fácil e funcional. 


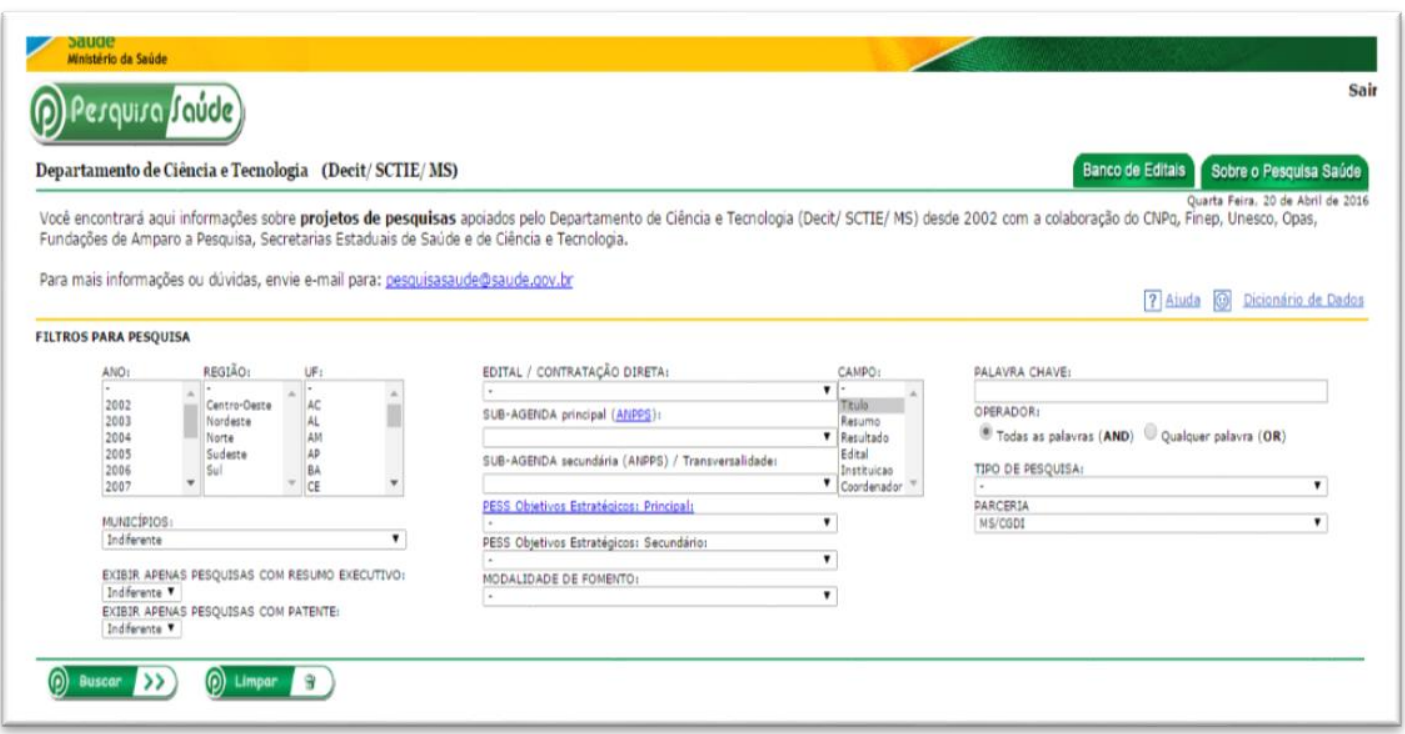

Fonte: PesquisaSaude 25

\section{Figura 7 - Layout da base de dados gerencial do Decit - 'PesquisaSaude'}

Por meio dessa plataforma, faz-se possível extrair diversos indicadores na forma de gráficos e tabelas, agregando-se ainda a possibilidade de exportação dos resultados.

Ao se analisar o banco de dados gerencial do Decit, verificou-se o volume total de 5.479 pesquisas registradas na data de referência (20/04/2016). Entre essas, estão inseridas as Pesquisas Clínicas que neste caso, especificamente correspondem aos ensaios clínicos (fases I, II, III e IV), integrando a amostra selecionada para análise e contando com 253 estudos fomentados ao logo dos doze anos registrados no banco, conforme demonstrado no (Gráfico 8).

\footnotetext{
${ }^{25}$ Disponível em: <http://200.214.130.94/bdgdecit/index.php?lg=BR.>
} 


\section{Gráfico 8 - Distribuição do número de ensaios clínicos fomentados pelo Ministério da Saúde e parceiros, no período de 2002 a 2014 registrados no 'PesquisaSaude'}

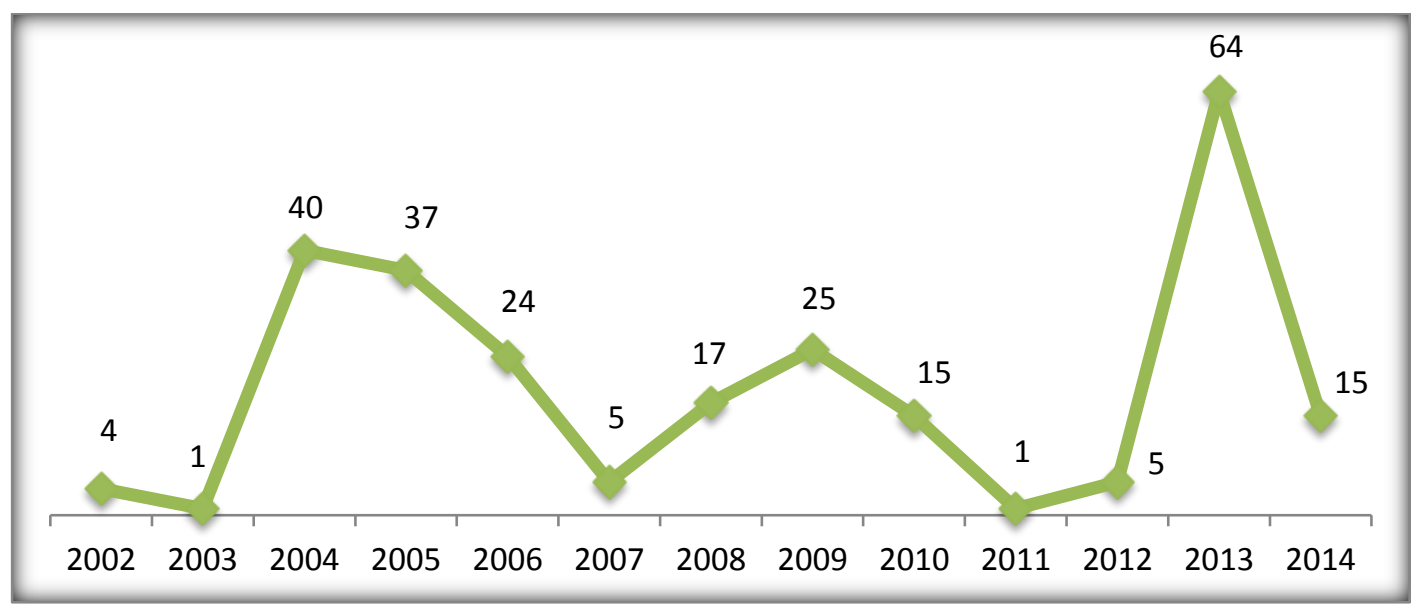

FONTE: Elaboração própria a partir do banco de dados gerencial do Decit: 'PesquisaSaude'.

Nos anos em que houve chamadas públicas nos estados por meio do Programa de Pesquisas para o SUS (PPSUS), atesta-se que houve um incremento no número de projetos apoiados. Em 2013, período em que aparece o maior número de ensaios clínicos implementados, além dos editais PPSUS, realizaram-se também duas chamadas públicas do fomento nacional direcionadas exclusivamente para pesquisas clínicas.

Para contratação do conjunto de 253 ensaios clínicos, foram investidos R \$ 81,4 milhões, conforme a (Tabela 4), sendo que $87 \%$ desse valor foram pagos por meio de chamadas públicas do fomento nacional, enquanto apenas $2 \%$ na forma de contratações diretas. Outro dado importante a ser observado é o valor total investido por modalidade de fomento frente ao número de projetos, o que demonstra que os projetos contratados por meio do fomento descentralizados parecem ser de menor porte, ou seja, menor tamanho amostral e de incrementos, uma vez que foram 
contratados 115 estudos (45\%), aplicando-se nesse montante apenas $11 \%$ do valor total do recurso investido nessa área.

Tabela 4 - Distribuição do número de projetos fomentados pelo Ministério da Saúde e parceiros, por modalidade de fomento no período de 2002 a 2014

\begin{tabular}{|c|c|c|c|c|}
\hline & $\begin{array}{c}\mathrm{N}^{\circ} \text { de } \\
\text { projetos }\end{array}$ & $\begin{array}{l}\% \mathrm{~N}^{\circ} \mathrm{de} \\
\text { projetos }\end{array}$ & $\begin{array}{c}\text { R\$ Investidos } \\
\text { (milhão) }\end{array}$ & $\begin{array}{c}\% \mathbf{R} \$ \\
\text { Investidos }\end{array}$ \\
\hline Fomento Nacional & 133 & $53 \%$ & 71,2 & $87 \%$ \\
\hline $\begin{array}{l}\text { Fomento Descentralizado } \\
\text { PPSUS }\end{array}$ & 115 & $45 \%$ & 8,8 & $11 \%$ \\
\hline Contratação Direta & 5 & $2 \%$ & 1,4 & $2 \%$ \\
\hline TOTAL & 253 & $100 \%$ & 81,4 & $100 \%$ \\
\hline
\end{tabular}

FONTE: Elaboração própria a partir do banco de dados gerencial do Decit: 'PesquisaSaude'

A (Tabela 4) demonstra, com clareza e objetividade, que a modalidade de fomento de contratação direta não é uma atividade corriqueira no Decit, induzindo, então, ao pensamento de que existe vontade política em se disponibilizar recursos de forma igualitária à comunidade científica como um todo, dado que tanto o fomento descentralizado - PPSU quanto o fomento nacional são executados por meio de chamadas públicas de editais temáticos, cuja avaliação é feita a partir da análise entre os pares concorrentes. Essa ação vem ao encontro dos princípios do SUS, que tem como alicerces a universalidade, a integralidade e a equidade. 
Os ensaios clínicos fomentados por contratação direta estão relacionados às doenças negligenciadas ${ }^{26}$. Dois desses ensaios clínicos são sobre HIV/Aids, dois acerca de hanseníase e outro, tuberculose.

No que diz respeito aos ensaios clínicos registrados no 'PesquisaSaude', observa-se a mesma configuração regional dos demais bancos de dados nacionais analisados nesse capítulo. A região Sudeste lidera, mais uma vez, o ranking no desenvolvimento de estudos, nas proporções apresentadas no (Gráfico 9).

\section{Gráfico 9 - Distribuição do número de ensaios clínicos fomentados pelo Ministério da Saúde e parceiros, segundo região do país, no período de 2002 a 2014, registrados no 'PesquisaSaude'}

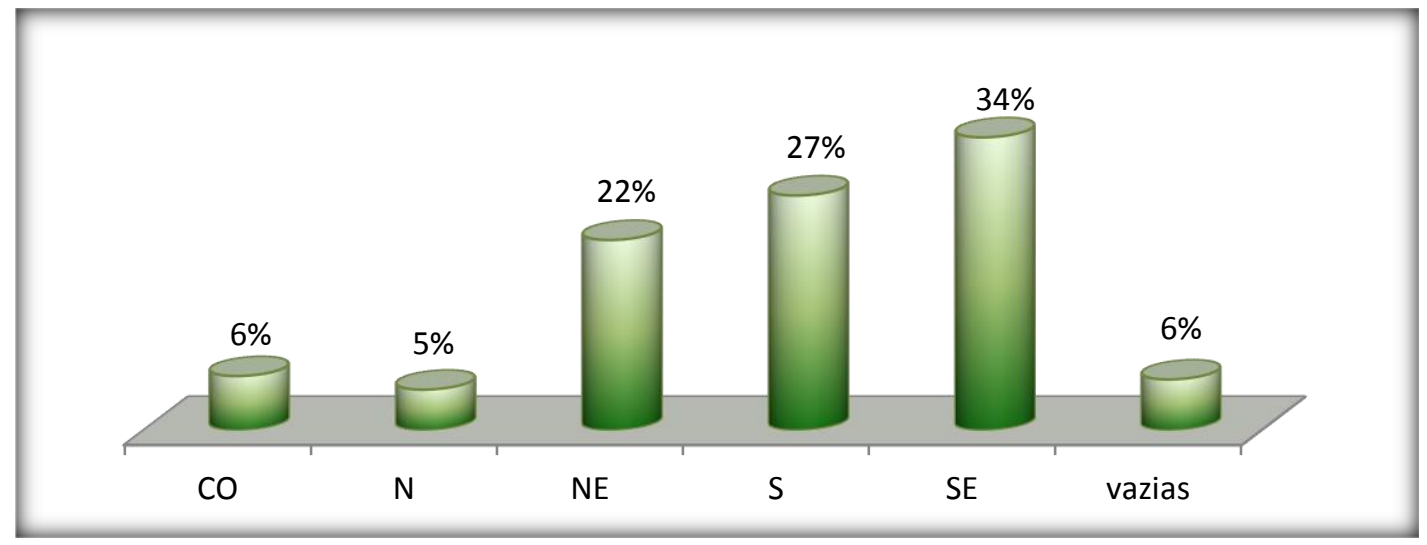

FONTE: Elaboração própria a partir do banco de dados gerencial do Decit: 'PesquisaSaude'.

O banco 'PesquisaSaude' apresenta algumas limitações, como a falta de preenchimento de alguns campos, com dados que acabam por dificultar a leitura fidedigna dos indicadores. Nesse aspecto, os dados apresentados sobre a distribuição regional do número de projetos poderiam se mostrar comprometidos por apresentar

\footnotetext{
${ }^{26}$ Doenças negligenciadas, segundo a Organização Mundial de Saúde, são aquelas causadas por agentes infecciosos ou parasitas, consideradas endêmicas em populações de baixa renda. Essas enfermidades propiciam indicadores inadmissíveis e investimentos reduzidos em pesquisa, produção de medicamentos e em seu controle.
} 
$6 \%$ de células vazias, uma vez que, caso esses campos correspondessem à região Nordeste, por exemplo, esta, ultrapassaria o Sul do país, ou se as vazias fossem preenchidas com projetos do Norte, estaria à frente do Centro-Oeste. Entretanto, se analisarmos o que vem-se configurando a partir dos dados adquiridos nos demais bancos de dados, infere-se que essas células, sem informações, não têm representatividade, como demonstrado no (Gráfico 9).

Entre os dados, assumem destaque as instituições com o maior número de projetos, selecionando-se as dez mais que seguiram o seguinte ranking: $\left(1^{\circ}\right)$ Universidade de São Paulo - 21 estudos; $\left(2^{\circ}\right)$ Universidade Federal do Rio Grande do Sul - 19 estudos; $\left(3^{\circ}\right)$ Universidade Federal do Rio de Janeiro - 12 estudos; $\left(4^{\circ}\right)$ Fundação Oswaldo Cruz - 9 estudos; (5º Universidade Federal de Pernambuco - 9 estudos $\left(6^{\circ}\right)$ Universidade Federal de Minas Gerais -8 estudos; $\left(7^{\circ}\right)$ Universidade Estadual de Londrina - 7 estudos; $\left(8^{\circ}\right)$ Universidade Federal da Bahia - 7 estudos; $\left(9^{\circ}\right)$ Universidade de Brasília - 6 estudos; $\left(10^{\circ}\right)$ Pontifícia Universidade Católica do Rio Grande do Sul - 5 estudos.

No entanto, caso a análise partisse do critério de maior volume de recursos recebidos por instituição, certamente o ranking não seria igual ao apresentado, justamente por se tratar de projetos com porte e status diferentes. A vantagem em ranquear pelo número de projeto é que, a partir desse dado, conclui-se que são vários os grupos da instituição executando pesquisas na mesma área, ao passo que se o ranqueamento se desse por recursos recebidos, configurar-se-ia a capacidade de captação de recursos da instituição. Como o foco do estudo é a capacidade científica optou-se, então, por essa abordagem. 


\subsection{Considerações finais}

Nesse estudo foi verificada uma razoável capacidade instalada nas instituições de pesquisa e hospitais de ensino brasileiro, aptos tanto para realizar P\&D como para incrementar a cadeia produtiva de produtos para saúde humana. Entretanto, avulta a ausência de envolvimento mais efetivo de empresas nacionais, comprometendo, assim, o segmento da cadeia produtiva nacional. Os resultados corroboram com o preconizado por Torres-Freire et al. (2014) quando avaliam que existe no Brasil baixa inovação das farmacêuticas nacionais no setor de biotecnologia, pelo fato de o país ainda ser formado por empresas muito jovens e pouco capitalizadas.

Sem dúvida, trata-se ainda de um momento de transição, no qual, porém, várias janelas de oportunidades se abrem, constituindo, assim, uma providencial ocasião para vincular as diferentes competências em ações conjuntas e intensificar o seguimento de Pesquisa e Desenvolvimento em Saúde (P\&D/S) por meio da aplicação de novos investimentos aportados por distintos atores.

Verifica-se, ainda, efetividade nas ações de fomento do governo por meio de suas agências e do aporte de recursos às instituições de ensino e pesquisa, embora se note a menor frequência das ações que correspondem à indução de parcerias das indústrias farmacêuticas com as universidades, a depreender da análise dos dados adquiridos.

Nesse sentido, Caramori (2013) afirma que no Brasil, atualmente, a indústria está em ascensão, sendo desejável que essa ação prossiga evoluindo. Acrescenta-se, ainda, que é missão da comunidade científica disponibilizar pesquisas para a promoção desse processo. 
A assimilação da identidade científica envolvida com o desenvolvimento de ensaios clínicos, apresentada neste capítulo, configura fator primordial para o reconhecimento dos padrões da capacidade nacional, assumindo condição estratégica para nutrir as agências financiadoras de modo a orientar a continuidade ou reorientação de futuras induções à $\mathrm{P} \& \mathrm{D}$ para redes estabelecidas, bem como com novas parcerias.

Some-se a essas variáveis o fato de que apreender o atual panorama se apresenta como fundamental e estratégico para o gestor de redes de pesquisas nessa área, considerando-se a evidente e contínua necessidade de rearranjos institucionais e expertises para a conformação de redes voltadas à esperada e imprescindível execução de estudos. 
CAPÍTULO 3

ESTRUTURA DE PESQUISA EM REDE: O Caso da Rede

Nacional de Pesquisa Clínica em Hospitais de Ensino - RNPC 


\section{ESTRUTURA DE PESQUISA EM REDE: o Caso da Rede Nacional de Pesquisa Clínica em Hospitais de Ensino - RNPC.}

\subsection{Introdução}

Entre os setores produtivos de Pesquisa e Desenvolvimento (P\&D), o desenvolvimento das fases clínicas de um medicamento, devidamente precedidas das pesquisas básicas e pré-clínicas, constitui um dos mais longos, onerosos e elaborados processos, motivando, desse modo, os arranjos colaborativos com a indústria farmacêutica como a forma mais viável para execução desses estudos (PINHO et al., 2012); (GUIMARÃES, 2013).

De acordo com o Banco Nacional de Desenvolvimento (BNDES), o lançamento de um único produto novo pode comprometer até mais de dez anos de pesquisas, demandando investimentos superiores a US\$ 1 bilhão. De cada conjunto de cem mil novos compostos estudados, estima-se que apenas 250 dispõem de requisitos suficientes para prosseguir nos testes pré-clínicos (estudos em animais). Destes, meramente cinco iniciam as fases de ensaios clínicos em humanos por apresentarem segurança, chegando ao mercado, por fim tão somente um novo e determinado medicamento (PINHO et al., 2012).

Historicamente, diversos e variados protocolos de pesquisa clínica vinham sendo desenvolvidos pela indústria farmacêutica internacional no Brasil, por meio da compra de serviços, porém sem o efetivo comprometimento com as demandas da saúde pública do País. A participação da comunidade científica brasileira, nesse 
processo, limitava-se à coleta de dados segundo os protocolos de pesquisas préestabelecidos (CARAMORI, 2013); (DAINESE \& GOLDBAUM, 2012).

Em geral, a análise e a posse dos dados adquiridos nos estudos, pertenciam aos parceiros estrangeiros e das Contract Research Organization (CRO). Justamente por conta desse privilégio exclusivo, não está longe da verdade a afirmação de que a pesquisa clínica configura a única modalidade de pesquisa realizada no Brasil, em que a maior parte das decisões é tomada no exterior, não sendo relevante, portanto, para os grupos de pesquisas, instituições e pacientes envolvidos, nem para o país enquanto promotor de Saúde e de Ciência, Tecnologia e Inovação (PINHO et al., 2012); (CARAMORI, 2013); (DAINESE \& GOLDBAUM, 2012).

Com a publicação da Resolução do Conselho Nacional de Saúde (CNS) 196 de 1996, posteriormente revogada pela Resolução 466 de 2012 a qual regulamenta as diretrizes e normas éticas de pesquisas envolvendo seres humanos, as atividades em pesquisa clínica foram significativamente facilitadas e ampliadas. (BRASIL, 1996); (BRASIL, 2012). O reconhecimento da capacitação brasileira no contexto da pesquisa clínica internacional tem favorecido as parcerias multicêntricas e proporcionado a profissionalização na área (DAINESE \& GOLDBAUM, 2012).

Atualmente, há 1.670 pesquisadores doutores e 123 grupos de pesquisas registrados no Diretório de Grupos de Pesquisas do Conselho Nacional de Desenvolvimento Científico e Tecnológico que atuam na área relacionada com ensaios clínicos $(\mathrm{CNPq}, 2015 \mathrm{a} ; 2015 \mathrm{~b})$. As parcerias entre a indústria farmacêutica, a academia e o governo, no atual cenário, podem ser benéficas para todas as partes envolvidas, desde que respeitados os limites éticos e os créditos das colaborações (DAINESE \& GOLDBAUM, 2012); (ZAGO, 2004). 
Na tentativa de fortalecer estruturas e grupos de pesquisa clínica no Brasil, vislumbrava-se, em longo prazo, maior atenção às demandas do Sistema Único de Saúde (SUS), com a redução da dependência estrangeira e em resposta à Constituição Federal, a qual estabelece em seu artigo 200, inciso V entre as competências do Sistema Único de Saúde (SUS), 'incrementar, em sua área de atuação, o desenvolvimento científico e tecnológico e a inovação' (BRASIL, 1988); (PAULA et al., 2012).

Nesse sentido, no ano de 2005 e por iniciativa conjunta dos Ministérios da Saúde (MS) e da Ciência Tecnologia e Inovação (MCTI), e com o apoio deliberativo de representantes de diversas instituições ligadas ao Ensino, Pesquisa e Gestão de Ciência, Tecnologia e Inovação (CT\&I), o governo federal estruturou 18 Unidades de Pesquisas Clínicas (UPC) em hospitais de ensino, visando a estabelecer uma rede brasileira de ensaios clínicos, então denominada Rede Nacional de Pesquisa Clínica em Hospitais de Ensino (RNPC) (BRASIL, 2007a; 2007b; 2010a; 2010b).

Respondendo a apelos de diversas instituições, declaradas com capacidade para execução de pesquisas clínicas, no ano de 2009 foram incluídos mais 12 UPC à Rede que passou a ser estruturada com 32 unidades dispostas em 14 estados das cinco regiões (BRASIL, 2009). A RNPC conta, desde a sua formação, com um Comitê Gestor, composto pelo MS, MCTI, Financiadora de Estudos e Projetos (Finep) e o CNPq, além de um Centro Coordenador que corresponde a uma das UPC e tem como função operar como articulador entre o Comitê Gestor e todas as unidades. O Centro Coordenador dispõe do suporte de quatro grupos de trabalho: capacitação, regulação, institucionalização e novas moléculas (BRASIL, 2010a). 
A RNPC possui uma estrutura de gestão montada e estabelecida por meio de Portaria Ministerial (BRASIL, 2010a). A literatura, entretanto, enfatiza que a gestão de redes equivale a uma nova abordagem, em contínua mutação, tendo em vista o surgimento de modelos e arranjos colaborativos, caracterizados, em geral, tanto pela ênfase na cooperação entre atores como na produção de inovação (NODARI et al., 2015); (VALE, et al., 2006).

Atualmente, estudos e análises sobre as características das estruturas de redes de pesquisa clínica que possam subsidiar a sua gestão foram tratados na literatura brasileira somente a partir da abordagem da gestão de redes sociais (RODAN \& GALUNIC, 2004). Há, porém, modelos bem-sucedidos, a exemplo do caso da The European Clinical Research Infrastructures Network (ECRIN), iniciativa que corresponde a um consórcio de redes de vários países europeus, incluindo a França, Alemanha, Itália, Roma, Espanha, Reino, Irlanda, Suécia, Dinamarca, Finlândia, Suíça, Áustria, Bélgica, Hungria e Polônia (DEMOTES-MAINARD \& KUBIAK, 2011); (KUBIAK et al., 2009).

Com o propósito de questionar e, consequentemente, buscar respostas a respeito da capacidade operacional dessa rede aos pesquisadores e gestores da saúde e da ciência e tecnologia no contexto do Brasil, o presente trabalho elenca quais são as características da estrutura da RNPC que dificultam ou promovem esforços de pesquisas clínicas bem-sucedidas. A importância desta pesquisa recai justamente na possibilidade de análise descritiva das alternativas de conexões relacionais e janelas de oportunidades passíveis de fomentar, expandir e fortalecer a pesquisa clínica junto aos grupos brasileiros. 


\subsection{Métodos}

Trata-se de um estudo exploratório descritivo, com abordagem quantitativa, do tipo estudo de caso. Realizou-se pesquisa documental em artigos publicados sobre gestão de rede, abordando (RODAN \& GALUNIC, 2004); (VARDA \& RETRUM, 2012); (LONG et al., 2013); (CORLEY et al., 2006); (YOUTIE et al., 2006); (FLEURY, 2011), e modelos de gestão de redes de pesquisas clínicas apresentados por (DEMOTES-MAINARD \& KUBIAK, 2011); (KUBIAK et al., 2009).

Avaliando-se ainda todos os documentos referentes à RNPC que integram o acervo do Departamento de Ciência e Tecnologia (Decit) do Ministério da Saúde (MS). Este estudo conta com resultados de questionários, encaminhados por e-mail, aos 32 coordenadores de UPC da RNPC, estruturados em 22 questões relacionadas à forma de colaboração/interação entre as unidades, capital social interno e externo à rede, capacidade técnica e científica e desenvolvimento institucional. Os 24 integrantes que aceitaram participar do estudo assinaram os Termos de Consentimento Livre e Esclarecido (TCLE), devolvendo-os escaneados junto aos questionários respondidos. Os dados foram analisados de modo a assegurar o sigilo dos participantes.

\subsubsection{Tabulação e caracterização dos dados}

Os dados foram tabulados a partir do software Microsoft Excel®. Esse procedimento fez-se necessário para a construção precisa e fidedigna da estrutura de colaboração entre as UPC, representada por meio de uma matriz quadrada em que as linhas e colunas representam as UPC e cujas células sugerem a presença ou a ausência 
de colaboração. Células com valor zero indicam ausência de relação, e com valor igual a 1, demonstram relação entre elas (Apêndice 6)

\subsubsection{Métodos de análise dos dados}

Essa investigação se valeu do método de análise de redes sociais por buscar a compreensão dos aspectos relacionais e estatísticos causais dos fenômenos identificados, semelhantes ao descrito por Rossoni, et al., (2008). Para essa finalidade, foram incluídas, assim, informações associadas ao relacionamento entre as unidades e os seus integrantes.

Procedeu-se à identificação e representação da rede de colaborações foi identificada sob a forma de um grafo a partir de um software desenvolvido especialmente para este projeto. Cada nodo representa uma UPC ou área médica. Determinada aresta ou ligação ilustra as relações entre dois nodos. A rede considerada neste trabalho é não direcionada, isto é, não há diferença na direção do relacionamento entre dois nodos.

A estrutura criada na forma de redes de colaboração permite a utilização de um arcabouço matemático robusto relacionado com a análise de redes sociais. Desse modo, é possível estudar as redes considerando-se as métricas topológicas como providenciais no sentido de aportar conhecimento e informações de caminhos e entidades mais importantes, e que seria difícil obter a partir da tabulação dos dados. As métricas que consideramos são: Centralidade de grau; Centralidade de intermediação; Centralidade de proximidade; e Coeficiente de agrupamento.

A visualização da rede foi realizada por meio do software Gephi, utilizando-se o algoritmo de desenho (layout) Force Atlas 2. Esse algoritmo permite a 
visualização e o agrupamento de nodos com maior relacionamento. Dessa forma, nodos com menor relacionamento passam a se posicionar a uma maior distância na visualização.

\subsection{Resultados e discussão}

Dos 32 coordenadores de UPC integrantes da Rede convidados a participar do estudo, apenas oito se negaram. Desse modo, algumas informações não correspondem ao universo total da Rede, sendo essa uma das limitações assumidas do presente estudo, embora reconheçamos ser confiável e representativa a investigação.

Também não pertence ao propósito deste trabalho o que se associa à capacidade física e operacional das UPC, no que se refere às Boas Práticas Clínicas preconizadas pela Agência Nacional de Vigilância Sanitária (Anvisa), uma vez que não foram checadas 'in locu'.

Discutem-se nesse estudo os relatos adquiridos a partir dos questionários recebidos e os dados coletados de documentos disponibilizados pelo Decit, amparados pelo suporte da literatura (RODAN \& GALUNIC, 2004); (VARDA \& RETRUM, 2012); (LONG et al., 2013); (CORLEY et al., 2006); (YOUTIE et al., 2006); (FLEURY, 2011).

O (Quadro 3) representa as Unidades que compõem a Rede Nacional de Pesquisa Clínica e as suas localizações. 


\section{Quadro 3 - Distribuição das Unidades de Pesquisa Clínicas integrantes da Rede Nacional de Pesquisa Clínica ampliada, segundo instituição, cidade e região a que pertencem}

\begin{tabular}{|c|c|c|c|}
\hline Hospital & Instituição & Cidade & $\begin{array}{l}\mathbf{U} \\
\mathbf{F}\end{array}$ \\
\hline Hospital das Clínicas da Universidade Federal de Goiás (HC-UFG) & UFG & Goiânia. & $\begin{array}{l}\mathrm{C} \\
\mathrm{O}\end{array}$ \\
\hline Hospital Universitário de Brasília (HUB - UnB) & UnB & Brasília & $\begin{array}{l}\mathrm{C} \\
\mathrm{O}\end{array}$ \\
\hline Fundação de Medicina Tropical do Amazonas (FMTA) & FMTA & Manaus & $\mathrm{N}$ \\
\hline Hospital Universitário João de Barros Barreto (HU-HJBB) & UFPA & Belém & $\mathrm{N}$ \\
\hline Hospital Geral de Fortaleza (HGF) & UEC & Fortaleza & $\begin{array}{l}\mathrm{N} \\
\mathrm{E}\end{array}$ \\
\hline Hospital Messejana (HM-UFC) & UFC & Fortaleza & $\begin{array}{l}\mathrm{N} \\
\mathrm{E}\end{array}$ \\
\hline Hospital São Rafael - Monte Tabor (HSR) & HSR & Salvador & $\begin{array}{l}\mathrm{N} \\
\mathrm{E}\end{array}$ \\
\hline $\begin{array}{l}\text { Hospital Universitário da Universidade Federal do Maranhão (HU- } \\
\text { UFMA) }\end{array}$ & UFMA & São Luis & $\begin{array}{l}\mathrm{N} \\
\mathrm{E}\end{array}$ \\
\hline Hospital Universitário Onofre Lopes (HU-UFRN) & UFRN & Natal & $\begin{array}{l}\mathrm{N} \\
\mathrm{E}\end{array}$ \\
\hline Hospital Geral da Universidade de Pernambuco (HG-UPE) & UPE & Recife & $\begin{array}{l}\mathrm{N} \\
\mathrm{E}\end{array}$ \\
\hline Hospital Universitário Professor Edgard Santos (HU-UFBA) & UFBA & Salvador & $\begin{array}{l}\mathrm{N} \\
\mathrm{E}\end{array}$ \\
\hline Hospital Universitário Walter Cantídio (HU-UFC & UFC & Fortaleza & $\begin{array}{l}\mathrm{N} \\
\mathrm{E}\end{array}$ \\
\hline Instituto Materno Infantil Professor Fernando Figueira (IMIP) & IMIP & Recife & $\begin{array}{l}\mathrm{N} \\
\mathrm{E}\end{array}$ \\
\hline Hospital de Clínicas de Porto Alegre (HCPA) & UFRGS & Porto Alegre & $\mathrm{S}$ \\
\hline Hospital Nossa Senhora da Conceição (HU-UNISUL) & UNISUL & Florianópolis & $\mathrm{S}$ \\
\hline Hospital São Lucas (PUC/RS) & PUC/RGS & Porto Alegre & $\mathrm{S}$ \\
\hline Hospital Universitário Regional de Maringá (HU-UEM) & UEM & Maringá & $\mathrm{S}$ \\
\hline Instituto de Cardiologia do Rio Grande do Sul (IC-FUC/RS) & FUC & Porto Alegre & $\mathrm{S}$ \\
\hline Fundação Oswaldo Cruz (FIOCRUZ) & FIOCRUZ & Rio de Janeiro & SE \\
\hline $\begin{array}{l}\text { Hospital das Clínicas da Faculdade de Medicina de Botucatu (HC- } \\
\text { UNESP) }\end{array}$ & UNESP & Botucatu & SE \\
\hline $\begin{array}{l}\text { Hospital das Clínicas da Faculdade de Medicina de Ribeirão Preto (HC- } \\
\text { USP/RP) }\end{array}$ & USP/RP & Ribeirão Preto & SE \\
\hline $\begin{array}{l}\text { Hospital das Clínicas da Universidade Estadual de Campinas (HC- } \\
\text { UNICAMP) }\end{array}$ & UNICAMP & Campinas & SE \\
\hline $\begin{array}{l}\text { Hospital das Clínicas da Universidade Federal de Minas Gerais (HC- } \\
\text { UFMG }\end{array}$ & UFMG & B. Horizonte & SE \\
\hline Hospital de Clínicas da Faculdade de Medicina da USP (HC-USP) & USP & São Paulo & SE \\
\hline Hospital São Paulo (HU-UNIFESP) & UNIFESP & São Paulo & SE \\
\hline Hospital Universitário Antônio Pedro (HUAP-UFF) & UFF & Niterói & SE \\
\hline Hospital Universitário Clementino Fraga Filho (HU-UFRJ) & UFRJ & Rio de Janeiro & SE \\
\hline Hospital Universitário da Universidade de São Paulo (HU-USP) & USP & São Paulo & SE \\
\hline Instituto de Medicina Integral Professor Fernandes Figueira (FIOCRUZ) & FIOCRUZ & Rio de Janeiro & SE \\
\hline Instituto Nacional de Câncer (INCA) & INCA & Rio de Janeiro & SE \\
\hline Instituto Nacional de Cardiologia Laranjeiras (INC) & UFRJ & Rio de Janeiro & SE \\
\hline Instituto Nacional de Traumato-Ortopedia (INTO) & INTO & Rio de Janeiro & SE \\
\hline
\end{tabular}

FONTE: Elaboração própria com adaptações de BRASIL (2010a; 2010b) 
Diferentemente das demais UPC, que se localizam em ambientes de enfermarias de hospitais universitários, a unidade da Fundação Oswaldo Cruz, funciona como um Academic Research Organization (ARO), ou seja, um escritório gerencial que acompanha os 370 estudos que estão sendo executados por aproximadamente 60 grupos de pesquisas dispersos nas seguintes unidades: Instituto Leônides e Maria Deane/AM, Centro de Pesquisas René Rachou (CPqRR)/MG, Centro de Pesquisas Ageu Magalhães (CPqAM)/PE, Instituto Gonçalo Moniz (IGM)/BA, Instituto Carlos Chagas (ICC)/PR, Instituto de Tecnologia em Fármacos (Farmanguinhos)/RJ, Instituto de Tecnologia em Imunobiológicos (Biomanguinhos)/RJ, Instituto Nacional de Infectologia Evandro Chagas (INI)/RJ, Instituto Nacional de Saúde da Mulher, da Criança e do Adolescente Fernandes Figueira (IFF), Instituto Oswaldo Cruz (IOC)/RJ. Conta ainda com sedes que também realizam pesquisas nos estados do Ceará, Mato Grosso do Sul, Piauí e Rondônia. Particularmente a Fiocruz opera uma rede interna denominada Rede Fiocruz de Pesquisa Clínica, sendo essa integrante da RNPC e, ao mesmo tempo, independente.

Na (Figura 8) está disposta a representação na forma de Rede de colaboração entre as UPC. A colaboração foi estabelecida tendo como base o conjunto das informações constantes nos questionários respondidos. A abordagem suscitada corresponde a colaborações voltadas para a realização de estudos e de intercâmbio técnico e/ou de formação. 


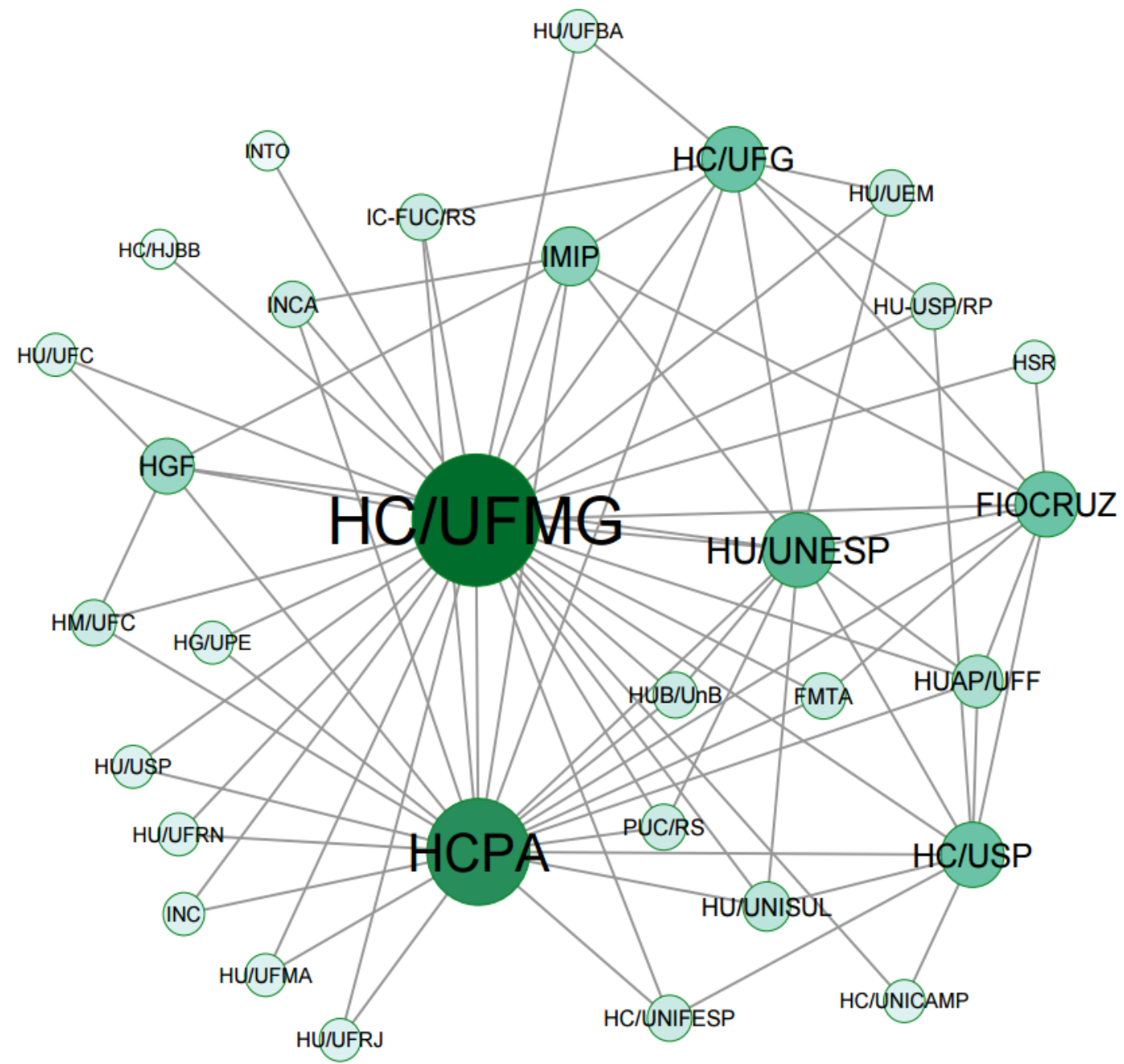

FONTE: Elaboração própria a partir dos questionários aplicados.

Figura 8 - Sociograma das Unidades de Pesquisa Clínica da Rede Nacional de Pesquisa Clínica em Hospitais de Ensino

O destaque para a UPC da Universidade Federal de Minas Gerais (UFMG) ocorreu, especialmente, em função de essa unidade ter sido o centro coordenador da Rede no período de 2010 a 2014, desenvolvendo a capacitação científica a todas unidades integrantes. Já a unidade HCPA, o primeiro centro coordenador da Rede, identificada como a segunda UPC mais colaborativa na RNPC, não fomentou intensa 
capacitação científica, como a do HC/UFMG, mas firmou, entretanto, parceria para a realização de estudos multicêntricos em pelo menos 70,4\% das unidades da Rede.

Esse tipo de representação permite observar e identificar quais as UPC que se destacam como centrais (aquelas que têm maior centralidade de grau), assim como as que são periféricas (aquelas com menor centralidade de grau). O tamanho e a cor dos nodos estão relacionados com a centralidade de grau (número de arestas).

\subsubsection{Recursos humanos na Rede}

O processo estratégico para o fortalecimento do Complexo Industrial e Econômico da Saúde (CEIS) abordado por Viana et al. (2011) e Costa et al. (2013) materializado, a partir da instalação das UPC em hospitais de ensino, as quais favoreceram a capacitação de recursos humanos da área médica quanto aos aspectos éticos e regulatórios da pesquisa clínica, indubitavelmente, acaba por promover a discussão de pesquisas com foco no SUS (PINHO et al., 2012); (CARAMORI, 2012). A partir de 2010, foram fomentados, no âmbito da Rede, cursos de pesquisa clínica nas modalidades básica, avançada e de pós-graduação (especialização), além de treinamentos diversos.

Excluindo-se os pesquisadores da Fiocruz, pelos motivos já mencionados neste capítulo, a Rede conta, atualmente, com aproximadamente 327 profissionais colaboradores, dos quais $75 \%$ possuem formação específica em gestão e execução de pesquisa clínica e $72 \%$ têm formação em nível de mestrado e doutorado - todos atuando na área. Cem por cento dos centros dispõem de profissionais médicos, enfermeiros e farmacêuticos. Algumas unidades têm em seus quadros, adicionalmente, 
biólogos, nutricionistas, fisioterapeutas, dentistas, epidemiologistas, estatísticos, administradores, e educadores físicos.

\subsubsection{Especialidades e conexões}

É importante destacar que não havia registro algum nos documentos analisados, publicados ou internos, disponibilizados pelo Decit, no que diz respeito à capacidade de articulação entre as unidades da Rede, seja pela capacidade de execução de estudos por fases dos ensaios clínicos, especialidades seja por qualquer outro tipo de colaboração.

Foram identificadas nos questionários 81 especialidades médicas, declaradas pelos representantes das UPC em suas instituições, conforme apresentadas no (Quadro 4) a seguir, para as quais fomos fiéis aos relatos por parte dos respondentes. As especialidades com mais centros disponíveis são, respectivamente: Cardiologia, Reumatologia, Oncologia, Neurologia e Ginecologia.

As especialidades médicas apresentadas no (Quadro 4) foram compiladas e transformadas em áreas médicas visando à construção de uma rede de relacionamento (veja Figura 9). A partir dela, é possível identificar a capacidade de interação entre as unidades, demonstrando as possibilidades de estabelecimento de parcerias para a execução de atividades, projetos ou estudos. Nesse sentido, a Rede configura uma grande janela de oportunidades, conforme defendido por Viana et al. (2011), ao se referir, nesse contexto, ao papel central do Ministério da Saúde enquanto membro gestor da RNPC. 


\section{Quadro 4 - Especialidades médicas disponíveis nas Unidades de Pesquisas Clínicas, segundo reportado pelos seus integrantes}

\begin{tabular}{|c|c|c|c|}
\hline$\checkmark$ Obesidade mórbida & $\begin{array}{l}\checkmark \text { Doenças do olho e } \\
\text { anexos }\end{array}$ & $\checkmark$ Hipercolesterolemia & $\checkmark$ Tuberculose \\
\hline$\checkmark$ Anestesiologia & $\checkmark$ Obstetrícia & $\checkmark \mathrm{HIV}$ & $\checkmark$ Oftalmologia \\
\hline$\checkmark$ Câncer digestivo & $\checkmark$ Hepatites & $\checkmark$ Infecção cirúrgica & $\checkmark$ Endocrinologia \\
\hline$\checkmark$ Pneumologia & $\checkmark$ Doenças infecciosas & $\checkmark$ Infectologia & $\checkmark$ Enxaqueca \\
\hline$\checkmark$ Proctologia & $\checkmark$ Parkinson & $\checkmark$ Dengue & $\checkmark$ Urologia \\
\hline$\sqrt{ }$ Cirurgia geral & $\checkmark$ Reumatologia & $\checkmark$ Dermatologia & $\checkmark$ Pediatria \\
\hline$\checkmark$ Tireoidopatias & $\checkmark$ Oncologia & $\checkmark$ LER & $\sqrt{ }$ Cardiologia \\
\hline$\checkmark$ Cirurgia cardíovascular & $\checkmark$ Ortopedia & $\checkmark$ Lúpus & $\checkmark$ Cérebro-vascular \\
\hline$\checkmark$ Terapia intensiva & $\checkmark$ Epilepsia & $\checkmark$ Anestesiologia & $\checkmark$ Psoríase \\
\hline$\checkmark$ Clínica médica & $\checkmark$ Odontologia & $\checkmark$ Medicina Tropical & $\checkmark$ Retinopatia \\
\hline$\checkmark$ Demências & $\checkmark$ Esclerose múltipla & $\checkmark$ Traumatologia & $\checkmark$ Doenças renais \\
\hline$\checkmark$ Neoplasmas & $\checkmark$ Fibrilação arterial & $\checkmark$ Nefrologia & $\checkmark$ Cirurgias \\
\hline$\checkmark$ Insuficiência renal & $\sqrt{ }$ Gastroenterologia & $\checkmark$ Insuficiência cardíaca & $\checkmark$ Cirurgia cardíaca \\
\hline$\checkmark$ Diabetes & $\checkmark$ Ginecologia & $\checkmark$ Neurologia & $\checkmark$ Vacinas \\
\hline$\checkmark$ Hepatologia & $\checkmark$ Doenças & $\checkmark$ Nutrição & $\checkmark$ Transplante renal \\
\hline$\checkmark$ Doença de chagas & neuroinfecciosas & $\checkmark$ Malária & $\checkmark$ Hematologia \\
\hline $\begin{array}{l}\checkmark \text { Afecções originadas no } \\
\text { período perinatal }\end{array}$ & $\begin{array}{l}\checkmark \text { Doenças do aparelho } \\
\text { respiratório }\end{array}$ & $\begin{array}{l}\checkmark \text { Doenças do aparelho } \\
\text { geniturinário }\end{array}$ & $\begin{array}{l}\checkmark \text { Esclerose lateral } \\
\text { amiotrófica }\end{array}$ \\
\hline $\begin{array}{l}\checkmark \text { Micobactéria não } \\
\text { tuberculosa }\end{array}$ & $\begin{array}{l}\checkmark \text { Síndrome coronariana } \\
\text { aguda }\end{array}$ & $\begin{array}{l}\checkmark \text { Transtornos mentais e } \\
\text { comportamentais }\end{array}$ & $\begin{array}{l}\checkmark \text { Doenças do aparelho } \\
\text { digestivo }\end{array}$ \\
\hline $\begin{array}{l}\checkmark \text { Doenças do aparelho } \\
\text { circulatório }\end{array}$ & $\begin{array}{l}\checkmark \text { Doenças do sistema } \\
\text { nervoso }\end{array}$ & $\begin{array}{l}\checkmark \text { Doenças infecciosas e } \\
\text { parasitárias }\end{array}$ & $\begin{array}{l}\checkmark \text { Doenças } \\
\text { cardiovaculares }\end{array}$ \\
\hline$\checkmark$ Doenças endócrinas, nut & cionais e metabólicas & \multicolumn{2}{|c|}{$\begin{array}{l}\checkmark \text { Doenças do sistema osteomuscular e do tecido } \\
\text { conjuntivo }\end{array}$} \\
\hline $\begin{array}{l}\checkmark \text { Malformações congênita } \\
\text { cromossômicas }\end{array}$ & deformidades e anomalias & \multicolumn{2}{|c|}{$\begin{array}{l}\checkmark \text { Sintomas, sinais e achados anormais de exames } \\
\text { clínicos e de laboratório não classificados em } \\
\text { outra parte }\end{array}$} \\
\hline \multicolumn{2}{|c|}{$\begin{array}{l}\checkmark \text { Doenças do sangue e dos órgãos hematopoéticos e } \\
\text { alguns transtornos imunitários }\end{array}$} & \multicolumn{2}{|c|}{$\begin{array}{l}\checkmark \text { Lesões, envenenamentos e algumas outras } \\
\text { consequências de causas externas }\end{array}$} \\
\hline
\end{tabular}

FONTE: Elaboração própria a partir dos dados adquiridos dos questionários. 


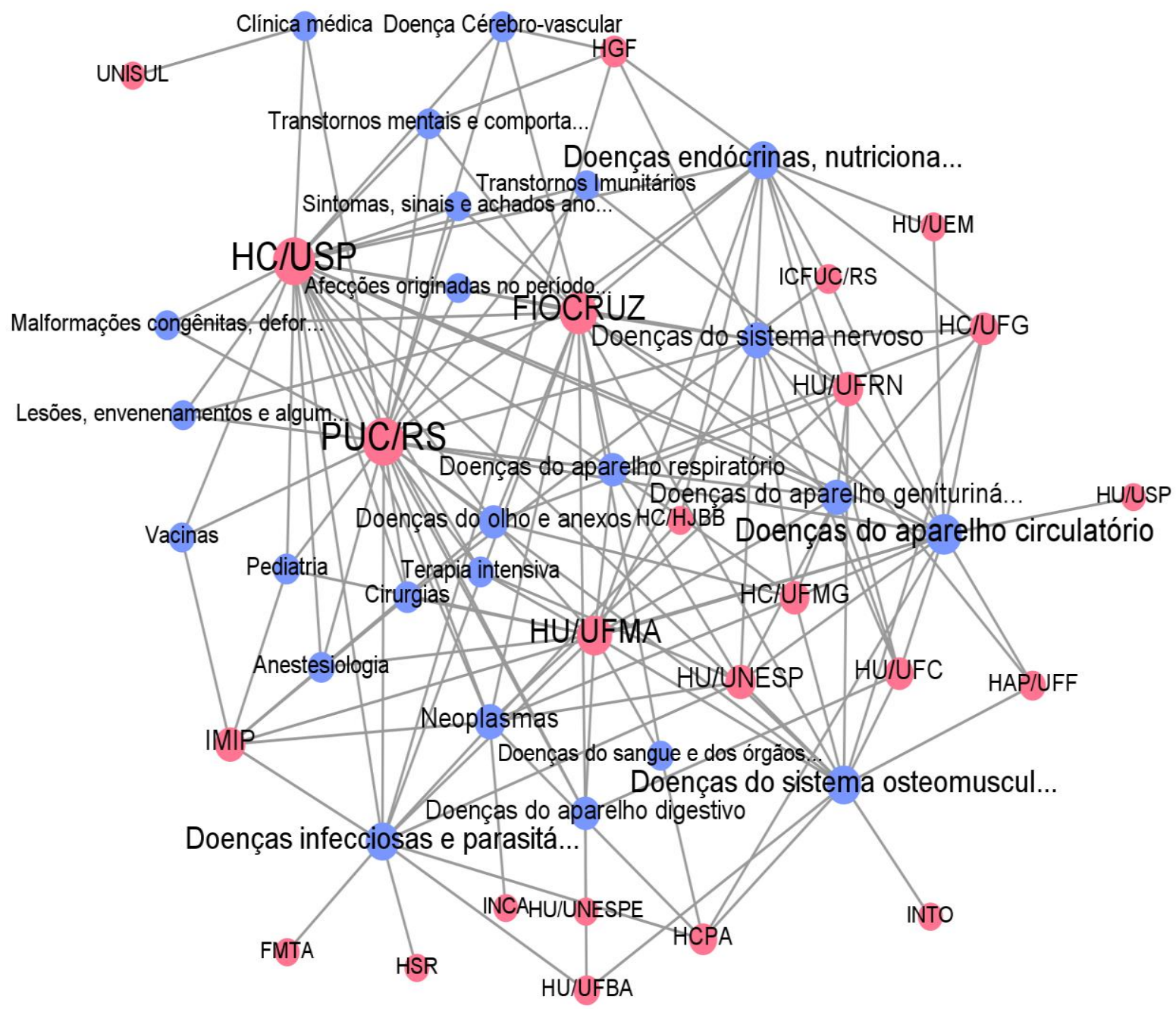

FONTE: Elaboração própria a partir dos questionários.

Figura 9 - Sociograma das áreas médicas disponíveis nas Unidades de Pesquisa Clínica da Rede Nacional de Pesquisa Clínica, segundo relatos dos seus integrantes

Legenda: Enquanto cada nodo vermelho representa uma UPC, o nodo azul ilustra uma área médica, a qual abriga várias especialidades. A ligação entre eles significa que tais UPC possuem capacidade técnica-científica para desenvolver estudos na área. Os nodos foram dimensionados de acordo com a centralidade de grau, ou seja, o número de conexões possíveis entre as UPC e as áreas médicas.

Ainda sobre a janela de oportunidades, Guimarães (2011) afirma que a competitividade internacional na geração de inovação, tem-se voltado à compreensão 
de como se desenvolvem e se articulam os atores nesse processo, objetivando justamente qualificar tais intervenções para se valer dos processos estratégicos em favor do fortalecimento do CEIS.

\subsubsection{O fomento à pesquisa para a Rede}

Após a formação da Rede com investimentos na ordem de 35 milhões de reais para estruturação das UPC, foram lançadas cinco chamadas públicas para fomentar a execução de estudos na RNPC nos anos de 2007, 2008, 2010 e duas em 2013, visando a fortalecer a Rede e formalizar parcerias entre as UPC. O Decit/MS em parceria com os Fundos Setoriais de Saúde (CT-Saúde) do MCTI aportaram R\$68 milhões de reais para o conjunto de chamadas públicas.

Desse volume de recursos, entretanto, foram empenhados apenas $\mathrm{R} \$ 54,3$ milhões de reais para contratação de 55 projetos de pesquisas, tendo em vista vários fatores, incluído principalmente, dificuldades com os trâmites documentais dos contemplados junto às suas fundações institucionais. $77 \%$ dos projetos contratados eram provenientes de instituições componentes da Rede, entretanto, a maior parte delas não tinha colaboração com as UPC.

A distribuição de recursos e projetos de pesquisa se concentrou, sobretudo, nos estados do Rio Grande do Sul (29\% dos recursos e $16 \%$ dos projetos), São Paulo ( $28 \%$ dos recursos e $29 \%$ dos projetos), Rio de Janeiro (22\% dos recursos e $15 \%$ dos projetos). Chama atenção a região Norte, posicionar-se a frente da região Centro-Oeste em captação de recursos e projetos de grande porte, ao que se considerou a expertise 
desenvolvida na Fundação de Medicina Tropical do Amazonas voltada ao tratamento das doenças negligenciadas, especialmente a malária.

A partir das informações constantes na (Tabela 5), é possível reafirmar a concentração historicamente marcada pela maior densidade de capacidade técnica, científica e de infraestrutura das regiões sudeste e sul do país.

Tabela 5 - Distribuição de recursos por número de projetos e percentual, segundo as regiões brasileiras - Editais 2007, 2008, 2010 e 2013

\begin{tabular}{ccccc}
\hline Região & N. Projetos & \% projetos & R\$ recebidos & $\%$ de recursos \\
\hline CO & 4 & $7 \%$ & 1.16 milhões & $2 \%$ \\
N & 2 & $4 \%$ & 1.25 milhões & $3 \%$ \\
NE & 9 & $16 \%$ & 5.41 milhões & $10 \%$ \\
S & 14 & $26 \%$ & 18.62 milhões & $34 \%$ \\
SE & 26 & $47 \%$ & 27.84 milhões & $51 \%$ \\
\hline
\end{tabular}

FONTE: Elaboração própria a partir de documentos internos do DECIT.

Quanto às instituições que receberam maior volume de recursos, foram respectivamente: Hospital das Clínicas de Porto Alegre - (HCPA), Universidade Estadual Paulista - (Unesp), Universidade de São Paulo - (USP), Pontifícia Universidade Católica do Rio Grande do Sul - (PUC/RS) e o Instituto do Câncer (INCA).

Várias questões corroboraram para que o esforço em fomentar parcerias no âmbito da Rede, por meio de editais e chamadas públicas, não fossem atingidos: 1) os editais não exigiam que os projetos fossem multicêntricos nem construídos em parcerias com as UPC membros da Rede; 2) os critérios de elegibilidade dos editais 
não explicitavam que a Rede estava restrita às UPC, possibilitando que outras unidades das instituições fossem beneficiadas; 3) os editais não eram exclusivos para ensaios clínicos e 4) os editais não vetavam a submissão de estudos observacionais.

\subsubsection{Estratégia de gestão}

A RNPC possui mecanismo de gestão verticalizado, que se utiliza de um comitê gestor, um centro coordenador e quatro grupos de trabalho. Possui estratégia de comunicação, que consiste em encontros mensais por meio de um espaço virtual situado no Centro de Apoio de Educação à Distância (CAED) da UFMG, com o suporte técnico da Rede Universitária de Telemedicina (Rede-RUTE), a qual tem como objetivo o incentivo de trabalhos multicêntricos.

As reuniões constituem vias de mão dupla por constituírem um espaço de compartilhamento de informações do Comitê Gestor para as UPC e vice-versa. No entanto, segundo o nosso entendimento, a adesão das UPC às reuniões é mínima. Ao longo de um ano, a reunião com maior número de unidades participantes contou com 12 representantes.

Faz-se importante destacar que a diversidade de instituições que compõem uma rede exige uma gestão horizontalizada com fluxo de conhecimento sem hierarquias e que aposte no gerenciamento colaborativo, no qual os indivíduos sejam capazes de exercer sua criatividade e colocar em prática novas ideias (MARTINS et al., 2012). Sem dúvida, esse é o grande desafio da gestão de inovação. 


\subsubsection{Desenvolvimento institucional}

Segundo relatos dos questionários, a Rede vem imprimindo capital social aos seus integrantes no âmbito institucional (45\%) e um pouco menos (40\%) fora dela. Atualmente, estão sendo desenvolvidos 722 projetos nas instituições integrantes da Rede com a participação das UPC. Apenas $15 \%$ delas, porém, confirmaram que os projetos de pesquisa clínica da instituição estão obrigatoriamente sob o monitoramento da UPC. Por outro lado, quatro unidades revelaram não se relacionar com os projetos realizados na instituição, e outras três UPC não detinham a informação, sugerindo, assim, falta de entrosamento no âmbito institucional.

Não há registro fidedigno em todas as UPC sobre o número de pósgraduandos que já utilizaram as instalações para execução de seus projetos acadêmicos. Entretanto, foram identificados 1.017 alunos em nível de mestrado e doutorado, seja para capacitação em técnicas da pesquisa clínica seja para a utilização de equipamentos das unidades, desde o período que a UPC integrou à Rede (2005 ou 2009) até dezembro de 2015.

De acordo com Guimarães (2011), o papel da política de pós-graduação no setor de saúde humana, nos próximos anos, deveria ser o de reforçar o sistema setorial de inovação em saúde, enfrentando o desafio de articular de maneira sólida a pós-graduação com as prioridades do SUS (prioridades de pesquisa e de serviço). Segundo Maia et al. (2004), na medida em que se entenda rede, em seu conceito ampliado, é necessário desenvolver novos conceitos para gerenciamento das redes organizacionais. Nesse caso, reforçar o papel da RNPC no contexto institucional é absolutamente estratégico e extremamente importante. 


\subsection{Considerações finais}

A partir dessa análise, é possível inferir que as estruturas que promovem resultados bem-sucedidos no âmbito da Rede estão relacionadas à capacitação de profissionais, ao fomento à pesquisa com foco no SUS em ambiente acadêmico de pósgraduação e ao intercâmbio técnico científico entre as instituições. Os resultados sinalizam que tanto as expertises quanto as forças institucionais podem contribuir para a eficácia das colaborações, devendo ser explorada e fortemente incentivada entre os integrantes da Rede.

Com relação às estruturas que dificultam resultados bem-sucedidos, consideramos que estas padecem de falhas de gestão. Foi verificada a ausência de acompanhamento e avaliação das UPC, bem como da posse de conhecimentos sobre as estruturas e capacidades técnicas operacionais de cada UPC, por parte do comitê gestor.

O relacionamento entre as unidades também mostrou fragilidades e pouca interação. Foi identificada a necessidade de se introduzir na rotina da Rede uma abordagem em que se contemple o monitoramento do desempenho atual e, simultaneamente, focalize a atuação futura, buscando, desse modo, potencializar energias, lideranças e expertises dos integrantes, em prol da Rede.

Como principal dificuldade para que a Rede se mantenha aquecida, identificamos a ausência de geração de demandas pelo Comitê Gestor, as quais reflitam as prioridades da saúde pública brasileira, e que possam ser aproveitadas e convertidas em questões de pesquisas clínicas, viabilizando a criação de um portfólio voltado às competências da Rede. Esse foi um dos principais entraves encontrado na 
estrutura da RNPC, em comparação às redes bem-sucedidas, a exemplo das redes componentes da The European Clinical Research Infrastructures Network (ECRIN) (KUBIAK et al., 2009).

Destaca-se ainda a necessidade da criação de uma home page da RNPC, que seja funcional e interativa aos participantes e, ao mesmo tempo, confira visibilidade e mostre a capacidade da Rede para o resto do mundo, como forma de reunir, assim, esforços para fortalecer a Rede enquanto instituição.

Acredita-se que este estudo possa constituir um significativo insumo para a elaboração de um plano estratégico de reposicionamento das instituições integrantes da Rede, no sentido de ampliar e validar ainda mais as suas conexões, a fim de expandir as colaborações além das fronteiras, legitimando, assim, mesmo que em longo prazo, a pesquisa clínica com foco no SUS em território brasileiro. 
CAPÍTULO 4

GESTÃO E PERCEPÇÃO DE PESQUISA EM REDE: uma visão sobre a Rede Nacional de Pesquisa Clínica em Hospitais de Ensino 


\section{GESTÃO E PERCEPÇÃO DE PESQUISA EM REDE: uma visão a partir da Rede Nacional de Pesquisa Clínica em Hospitais de Ensino}

\subsection{Introdução}

Uma das primeiras formas de colaboração entre autores, identificada na literatura, são os chamados “colégios invisíveis" (DE SOLA et al., 1966). Entretanto, a existência de parcerias e de colaborações científicas são fenômenos tão antigos quanto à ciência (VELHO, 2001). Informalmente instituídas, essas colaborações geralmente ocorriam em encontros científicos, nos quais se compartilhavam conhecimentos e experiências e, posteriormente, eram formalizadas a partir de publicações científicas e de colaborações técnicas e acadêmicas.

Em termos retrospectivos, o primeiro artigo científico escrito em coautoria que se tem registro foi publicado em 1678 (BEAVER \& ROSEN, 1978). Já as colaborações internacionais datam do século XIX. Atualmente, parte considerável do empenho na produção de inovação vem sendo concretizado por meio de colaborações multicêntricas.

Como reflexo de políticas específicas, a tendência em se firmar cooperações multicêntricas é crescente e acelerada (ACERO \& KLEIN, 2013). Gestores de projetos e tomadores de decisão estão, cada vez mais, apoiando as colaborações multicêntricas, o que acaba por envolver equipes multidisciplinares, de diferentes instituições e com capacidade para responder a perguntas de pesquisas mais complexas, a exemplo dos EUA, que, pautados por sua política de ciência e tecnologia, evoluiu nas últimas três décadas, saltando do apoio descentralizado a pequenos 
projetos de pesquisa para a concessão centralizada a grupos de pesquisas multidisciplinares - fase essa conhecida como a "era das colaborações interinstitucionais" (MELO \& AGOSTINHO, 2007); (CORLEY et al., 2006). Por outro lado, os pesquisadores tendem a estabelecer colaborações principalmente para alcançar maior visibilidade, prestígio, bem como habilidades complementares e acesso a novos recursos (ACERO \& KLEIN, 2013).

O termo "rede", o qual compreende arranjos multicêntricos, foi exaustivamente debatido em diversas áreas durante a década de 1990. Nessa mesma época já havia documentos e experiências nacionais e internacionais relevantes sobre a conformação de redes (ALBUQUERQUE, 2013).

As tecnologias de comunicação convertidas em redes, de acordo com Castells (1999), têm inspiração não apenas nas teorias econômicas de mercado, mas também na teoria dos espaços e fluxos, e são bastante utilizadas em estudos sobre o relacionamento social. A respeito desses modelos, Moraes (2004) entende que uma rede de atores se concretiza a partir da produção de conexões em uma dada atividade, e não pela mobilização dos atores para efetivamente formar a rede visando à execução de um produto ou ação, sugerindo uma forma inversa, frente aos modelos utilizados pela maioria das redes de pesquisas no Brasil, a exemplo da RNPC.

Nesse sentido, Marques (1999) ao se referir à avaliação dos mecanismos relacionais nesses arranjos, considera que a força dos resultados das análises está na construção de estudos precisos em termos descritivos, sem impor uma estrutura à realidade e aos atores. $\mathrm{O}$ autor considera serem possíveis três principais tipos de análise: a respeito do efeito das posições dos atores; sobre os fenômenos situacionais existentes e em relação aos efeitos de diferentes modelos de estrutura diante dos 
distintos tipos de fenômenos (MARQUES, 2007a). Essa abordagem confere uma nova interpretação às relações, caso sejam levados em conta a posição e o papel dos atores dentro da organização.

Para Mendes (2007), na definição de redes de atenção à saúde, as organizações, que compartilham missão e objetivos, trabalham de forma colaborativa e interdependente, relacionando-se horizontalmente e agregando valor para a população. O autor afirma também haver, na literatura internacional, evidências de que essas redes podem melhorar a qualidade da oferta clínica, a satisfação dos usuários e ainda colaborar na redução dos gastos envolvidos no processo. No Brasil, o tema é relativamente incipiente, entretanto, estudos de casos indicam que tais arranjos tendem a agregar contribuições significativamente positivas nos níveis de saúde da população beneficiada, apresentando ainda custos suportáveis pelo Sistema Único de Saúde (SUS) (MENDES, 2010).

A literatura em administração pública define rede como um campo organizacional cujo propósito está relacionado ao desenvolvimento de um produto ou ação (FLEURY, 2011). A autora acrescenta que os estudos sobre rede, ao aproximarem seus vínculos com outras correntes teóricas, além de construírem fundamentos mais consistentes, contribuem também para a formulação de estratégias multidisciplinares subsidiando o gestor na tomada de decisão em diversas dimensões.

Muitas variáveis definem a eficácia das colaborações, nesse sentido o modelo de gestão aplicado a uma rede define o grau de ações bem-sucedidas. Goldsmith \& Eggers (2006) trazem para o debate a necessidade de conciliar a governança hierárquica do tipo top down, que é um modelo verticalizado e autoritário, com as redes que atualmente vêm estruturando-se, cujos modelos adotados são do tipo 
horizontalizados, fundamentados em uma teia de parcerias para realizar atividades em comum. Marques (2007b) avalia que as estruturas dessas redes costumam ser duradouras. Apesar das contínuas transformações advindas do estabelecimento ou a rescisão de vínculos, essa situação se explica pelo fato de o componente em transformação, em geral, ser relativamente menor quando comparado à totalidade dos vínculos estabelecidos entre os atores.

Com relação à estrutura comunicacional no âmbito de uma rede, Johnson (2011) afirma que a estrutura deve incorporar elementos informais e formais. A estrutura informal opera como facilitadores da interação, constituindo ainda a melhor forma de se preservar a coesão entre os atores. Já a estrutura formal, deve envolver tecnologias de informação que facilitem o acesso, aumentem as possibilidades de controle e de comunicação externa, além de minimizar os limites hierárquicos no campo da gestão.

Embora existam estudos que abordem questões intrínsecas à colaboração de atores que estabelecem vínculos a partir de pesquisas, configurando-se redes de pesquisadores, tais análises não aprofundam tanto o quanto pretendemos neste presente caso, por se tratarem de cooperações que se valem, exclusivamente, de espaço virtual na sua estrutura funcional. Ainda assim, os resultados sugerem que redes de coautorias tendam a ser colaborações estratégicas para o fortalecimento de redes de pesquisas e de produção do conhecimento. Mullins et al. (1977) e Mena-Chalco et al. (2014), por exemplo, testaram várias hipóteses sobre redes de pesquisadores e estratificaram as colaborações entre os cientistas por meio da combinação de análise de coautoria, a partir de fontes de dados qualitativos, indicando a frequência e a 
densidade dos contatos. Eles concluíram que autores de trabalhos altamente cocitados formavam grupos sociais distintos.

Acedo et al. (2006) e Haddad et al. (2015) também empreenderam estudos nesse campo, segundo outra abordagem, mas com metodologia semelhante, e acrescentaram que as coautorias extrapolam as colaborações científicas e que essa expansão surge como um mecanismo relevante tanto para o salto qualitativo da produção científica quanto para a difusão do conhecimento, inclusive em regiões mais remotas. Ademais, contribui, indiretamente, para o fortalecimento de grupos emergentes e o surgimento de novos grupos em diferentes áreas do conhecimento.

A carência de base teórica em relação à gestão desses novos arranjos/modelos de colaborações que têm surgido é uma das dificuldades de se avaliar o fluxo interno (organizacional e da pesquisa) durante a execução de pesquisas em rede. Nesse sentido, objetivamos, com o estudo desenvolvido neste capítulo, apresentar uma contribuição teórica, explicando-a sob a luz de um estudo de caso, cujo objeto é a Rede Nacional de Pesquisa Clínica em Hospitais de Ensino (RNPC) ${ }^{27}$, composta por trinta e duas unidades de pesquisas, além de apresentar um modelo que se adeque à atual realidade.

As hipóteses consideradas, e que governam este estudo, são as seguintes: a RNPC funciona com algumas fragilidades em relação aos atuais modelos de gestão disponíveis na literatura; o grau de institucionalização que as Unidades de Pesquisas Clínicas (UPC), componentes da rede, possuem reflete na sustentabilidade da RNPC; e os integrantes da rede ainda não enxergam a si e a seus pares como atores-chave na

27 Ver detalhes sobre essa ação no Relatório de Gestão do Decit, 2005, pág. 69 a 77. Disponível em http://bvsms.saude.gov.br/bvs/publicacoes/relatorio_gestao_decit_2005.pdf 
promoção de estudos no âmbito da rede, no que diz respeito às possibilidades de conexões entre suas áreas de conhecimentos ou de suas expertises.

\subsection{Métodos}

Trata-se de um estudo de caso exploratório e analítico, de abordagem quantitativa (YIN, 2005). Sujeitos: em amostra intencional foram selecionados os pesquisadores que coordenam as UPC da RNPC e distribuídos por meio de correio eletrônico 32 questionários estruturados autopreenchíveis com 21 blocos de perguntas, disponível no Apêndice 2, voltadas para o desenho institucional, nível e tipo de institucionalização (organizacional e científica).

Houve retorno de 24 questionários. De forma complementar, realizaramse oito entrevistas (Apêndice 3) abertas e em profundidade. As entrevistas foram previamente agendadas e realizadas de forma presencial no local de trabalho do entrevistado ou via Skype. Outras fontes de evidência incluíram pesquisa documental no Decit - abrangendo documentos internos não publicados -, literatura técnica nacional e internacional, além da literatura cinzenta e jornalística.

Análise: os dados foram transcritos e lidos exaustivamente, seguido da análise técnica e da análise de conteúdo/enunciado (BAXTER \& JACK, 2008); (MINAYO, 2010); (BARDIN, 2011). A coleta de dados foi interrompida, ao se observar sinais de saturação teórica (FONTANELLA et. al., 2008).

Validade e confiabilidade: foi realizado estudo-piloto para aprimorar a clareza e a concisão do questionário e do roteiro de entrevistas.

Além do uso de diferentes técnicas, aceita-se que a diversidade de fontes, a diversidade de versões ou as diferenças de espaço e tempo se conformam em 
elementos de triangulação de pesquisa (MINAYO, 2010). No estudo aprovado pelo CEP da Faculdade de Medicina da USP, a todo entrevistado foi explicado o objetivo da pesquisa, assegurado o sigilo e solicitada a assinatura de TCLE.

\subsection{Resultados e discussão}

\subsubsection{O valor heurístico do estudo de caso da RNPC e do arranjo multicêntrico}

Entre as razões para o estudo da RNPC destacam-se: tratar-se de uma das estratégias do Plano Brasil Maior ${ }^{28}$, constituindo um marco importante no reconhecimento institucional de caráter estratégico do complexo da saúde para o desenvolvimento nacional; ser uma iniciativa interministerial instituída há mais de dez anos (FINEP, 2005); possuir ambiente propício para execução de pesquisas clínicas, pois são centros dotados de infraestruturas adequadas, inseridos em hospitais de ensino e, por isso, com maior capacidade de atuar como elo de difusão de conhecimento, além das facilidades em se agregar outras expertises diferentes das áreas médicas, tais como bioinformatas, farmacêuticos, biólogos, nutricionistas fisioterapeutas, educadores físicos, engenheiros, entre outros; permitir estabelecer parcerias com outras entidades, públicas ou privadas, para financiamento e execução de estudos e, principalmente, ser gerenciada pelo Departamento de Ciência e Tecnologia (Decit) do Ministério da Saúde, responsável por identificar e fomentar as prioridades de pesquisas diante dos agravos de saúde pública do país. (BRASIL, 2007a; 2007b).

\footnotetext{
${ }^{28}$ Lançado em 08 fev 2011, com slogan "Inovar para competir. Competir para crescer", compôs um dos pilares da Política Industrial, Tecnológica e de Comércio Exterior (PITCE) - (2011-2014). (BRASIL, 2011c).
} 
As expectativas dos idealizadores da rede, no âmbito das perspectivas futuras de médio e longo prazo, quando da sua criação, são hoje ricamente respaldadas por Viana \& Elias (2007), Gadelha et al. (2015b), e Metten et al. (2015) que se referem ao fortalecimento do Complexo Econômico e de Inovação em Saúde (CEIS) como prioridade do Plano Brasil Maior.

Aplicado às possibilidades existentes na Rede, constitui-se em um espaço politicamente democrático, com capacidade de estabelecer parcerias entre instituições de excelência e instituições com menos vocação favorecendo, assim, o desenvolvimento de novos talentos, técnico e científico, além de possibilitar a execução de estudos multicêntricos, com potencial para ampliação da pesquisa clínica no país, tanto no aspecto dos que as executam quanto para aqueles que delas podem se beneficiar.

\subsubsection{Análise do caso no ambiente organizacional}

A RNPC contou, desde o seu início, com um Centro Coordenador composto por uma das Unidades de Pesquisa Clínica (UPC) integrante da RNPC, e um Comitê Gestor formado por um membro do Decit que o coordena, além de representantes da Financiadora de Estudos e Projetos (Finep) e do Conselho Nacional de Desenvolvimento Científico e Tecnológico (CNPq) (BRASIL, 2010a; 2010b).

A partir da ampliação, em 2009, a rede passou de 19 para 32 UPC. Com o propósito que os centros operassem em colaboração interinstitucional, no sentido de envolver cada vez mais as UPC entre elas, foram criados quatro grupos de trabalho com as suas devidas competências: a) GT-capacitação, de aprimoramento, em pesquisa clínica, de recursos humanos ligados aos centros; b) GT-regulação, de 
fomento ao debate e auxílio nas questões éticas e de regulamentação da pesquisa clínica, especialmente ao sistema CEP/Conep e à Anvisa; c) GT-institucionalização, de fortalecimento das UPC no âmbito do hospital, avalizando a sua sustentabilidade; d) e GT-novas moléculas, de identificação de estudos com potencial de inovação no setor saúde, BRASIL (2010a; 2010b). (Veja Figura 10)

Além da constituição dos grupos de trabalho, criou-se também, nessa mesma época, uma coordenação específica para gerenciar os projetos de pesquisas clínicas no próprio Decit. Apesar de não constar do organograma oficial da Secretaria de Ciência e Tecnologia (SCTIE) do MS, a Coordenação Geral de Pesquisa Clínica funciona com o apoio de técnicos especializados na área, para acompanhar, avaliar e dar suporte aos projetos de pesquisas clínicas, fomentados pelo Decit, bem como dirigir o comitê gestor da RNPC e ainda promover a cooperação técnica científica da rede interna e externamente.

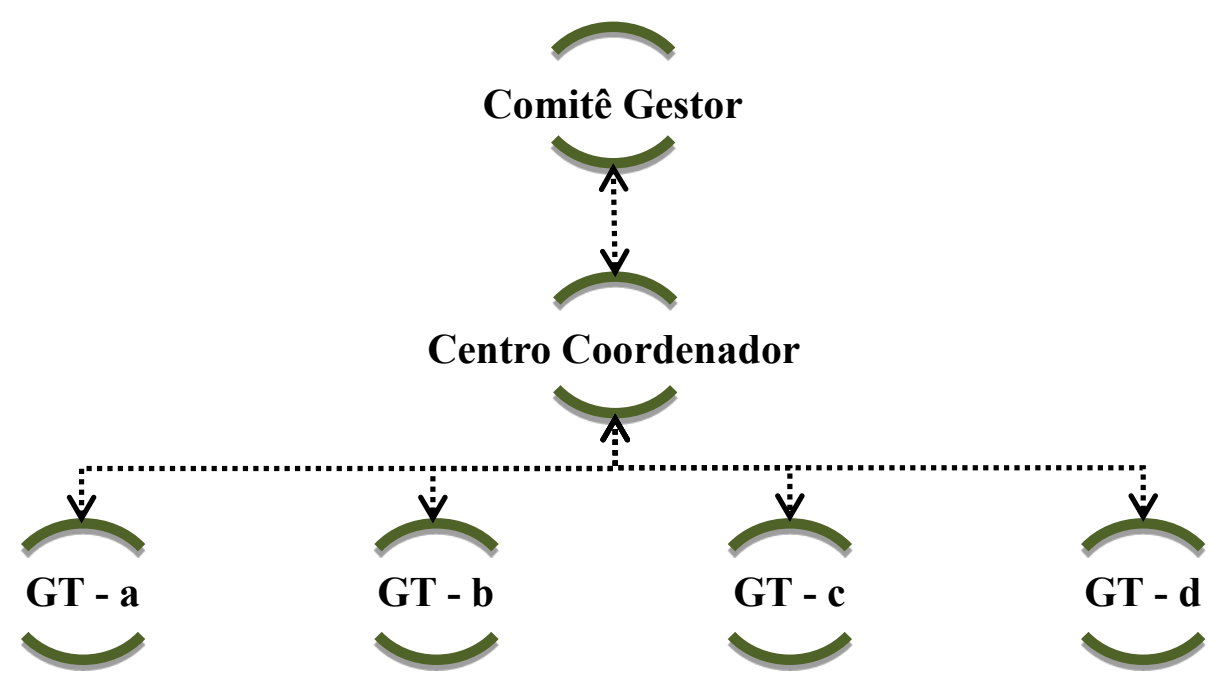

FONTE: Elaboração própria a partir de (BRASIL, 2007b; 2010a; 2010b).

Figura 10 - Organograma da atual estrutura de gestão da Rede Nacional de Pesquisa Clínica em Hospitais de Ensino 
Essa estrutura gerencial, de acordo com os documentos analisados, segue a configuração apresentada na (Figura 10), demonstrada. Segundo relatos, entretanto, a despeito de formalizada, essa estrutura não funcionou efetivamente no que diz respeito à interação dos grupos de trabalho e geração de produtos ou qualquer outro resultado.

Quando entrevistado, um dos diretores de uma Contract Research Organization $(C R O)$ - também denominadas Organizações Representativas de Pesquisa Clínica, entidade que entre outras atribuições - responsável pela gestão de ensaios clínicos e de farmacovigilância, patrocinados em sua maioria pela indústria farmacêutica, ponderou sobre a estrutura e o funcionamento da RNPC:

[...] o que eu vejo... que eu entrei em contato foi com um grupo de centros individuais...trabalhando individualmente sobre o nome de uma rede....mas eu nunca vi a rede funcionando como uma rede...é como se a gente tivesse os pontos...os nós da rede estabelecidos sem os cabos que conectam um ponto ao outro[...]

O relato de Lima et al. (2004) traz uma importante contribuição sobre esse comentário, ao afirmar que, em estruturas de Pesquisa e Desenvolvimento (P\&D), o conhecimento acerca das relações estabelecidas a partir da gestão praticada é tão importante quanto os resultados das pesquisas - também fruto da interação dos grupos envolvidos. A isso, o autor denominou de "manejo de interação social", algo a ser desenvolvido independentemente da forma de organização do trabalho de pesquisa, merecendo ser fortemente incentivados. 


\subsubsection{Comunicação interna}

Na rede, a estrutura comunicacional deve ser constituída por elementos que, segundo Johnson (2011), estejam associados à difusão da comunicação (formal e/ou informal) por meio de elementos facilitadores. Para o sucesso da implementação desse processo, faz-se necessário identificar os líderes de opinião, os indivíduos com múltiplas relações internas e externas, além dos que dispõem de maior centralidade ante os seus pares, compreendendo aqueles com maior número de conexões na rede. Johnson (2011) acrescenta ainda que quanto mais diversificada a comunicação maior a adesão dos seus entes, e mais positivos os efeitos sob as ações propostas.

Apesar de a RNPC usufruir de uma plataforma com recursos audiovisuais, sediada na Universidade Federal de Minas Gerais (UFMG), a qual possibilita reuniões virtuais com os representantes das UPC, tal ferramenta não vem funcionando como o esperado ambiente de discussão e adesão de todos integrantes.

A respeito do fluxo de comunicação no âmbito da Rede entre os grupos, as agências de fomento e a coordenação da Rede, um médico e pesquisador da região Sudeste acrescentou:

"Bom...existe uma ferramenta de contato com o resto do pessoal da rede...eu diria assim...que ainda nesse aspecto o que funciona, ou o que tem funcionado, tem sido muito mais contatos individuais entre pesquisadores... que a gente se encontra nas reuniões da rede... ou que a gente já conhece... e acaba estabelecendo essa relação de uma maneira é...mais produtiva [...] se você me perguntar hoje o que o pessoal do Maranhão está fazendo? Eu não sei. O que é que o pessoal do Paraná está fazendo? Eu não sei e certamente eles não sabem o que é que eu estou fazendo e assim por diante". 


\subsubsection{O ambiente da pesquisa}

A análise das entrevistas possibilitou a identificação da capacidade científica das UPC para ensaios clínicos e observacionais nas diversas fases e áreas médicas. Os integrantes da rede revelaram não dispor de informações sobre as expertises de seus pares. Esse conhecimento também não existia nos documentos analisados nem junto ao comitê gestor, devendo constituir, porém, um fator necessário e urgente a ser explorado, por se tratar do principal ponto a ser observado quando se planejam as parcerias e colaborações.

As estratégias utilizadas pela gestão da rede para fomentar o desenvolvimento científico compreendem o financiamento a pesquisas por meio de chamadas públicas e a capacitação profissional dos seus integrantes. Mas nem sempre a visão sobre essas estratégias é vista como equitativa, como revela um médico, coordenador de uma das UPC de um dos centros da região Nordeste, que se associou à RNPC em 2009, mas não obteve recursos para estruturação do seu centro, cuja avaliação demarca sua queixa:

[...] as linhas de financiamento exigem que os pesquisadores tenham trabalhos publicados... principalmente o CNPq... então a gente não consegue pegar financiamento porque não tem trabalho publicado...a gente não consegue publicar porque não faz pesquisa, porque não tem financiamento...então há alguma coisa errada aí...[...]

Na realidade, a ampliação da rede em 2009 havia lidado com a questão no documento "critérios obrigatórios para inclusão à rede", que, além de critérios de infraestrutura e recursos humanos, exigia declaração de experiência do pesquisador no 
desenvolvimento de ensaios clínicos, comprovado por meio de publicações (BRASIL, 2014). Em que pese uma ideia geral observada nas entrevistas, o modelo de fomento adotado configura-se como "lento", "burocrático" e "trabalhoso". Ainda sobre a atuação da gestão referente ao formato de fomento adotado, vale destacar a avaliação sobre o futuro da RNPC de um pesquisador-médico, coordenador de uma das UPC da região Sudeste integrante da rede desde 2005 e com forte atuação junto à gestão:

[...] há necessidade de uma explicitação das demandas do Ministério. Eu penso assim, que a rede deveria funcionar melhor no futuro na forma de demandas apresentadas diretamente pelo Ministério Por exemplo, estudos encomendados à rede, discutidos com áreas específicas da rede, talvez sem necessidade de um edital especificamente.

\subsubsection{Fluxo organizacional da pesquisa multicêntrica e proposta de modelo.}

Os ensaios clínicos valem-se, necessariamente, de colaborações multicêntricas, e os protocolos clínicos impostos aos estudos devem ser rigorosamente seguidos. Divergências entre metodologias de uma mesma área podem apresentar obstáculos significativos nos resultados das pesquisas, os quais têm de oferecer regras claras e objetivas para a execução das atividades compartilhadas (CORLEY et al., 2006).

O modelo esquemático proposto para gestão do fluxo organizacional da RNPC, apresentado na (Figura 11), favorece a adesão da parceria, já estabelecida entre academia e governo, com um terceiro elemento: a parceria privada seguindo o modelo da "Triplice Helix" que se propõe a agregar a "academia", como indutora na promoção de parcerias, com a "empresa", produtora de bens e serviços, e com o "governo", regulador e fomentador (ETZKOWITZ \& LEYDESDORFF, 2000) e 
(LEYDESDORFF \& ETZKOWITZ, 1996). Trata-se de uma dinâmica que promove as políticas de ciência, tecnologia e inovação e amplia a interação entre os atores das diferentes hélices. Além disso, pode favorecer a consolidação das instâncias gestoras do SUS ao integrar e consolidar centros de pesquisas em saúde, instituições de ensino superior e empresas nacionais, com ênfase na pesquisa para produção de insumos e equipamentos para saúde (VIANA et al. 2012); (VIANA \& SILVA, 2012).

O fluxo do modelo, aqui proposto, tem início a partir da adesão de uma UPC à rede, com a concordância institucional a qual é vinculada abrigando, necessariamente, infraestrutura suficiente para a execução de ensaios clínicos nas diversas fases e especialidades além de profissionais capacitados, em cumprimento aos critérios de inclusão pré-estabelecidos.

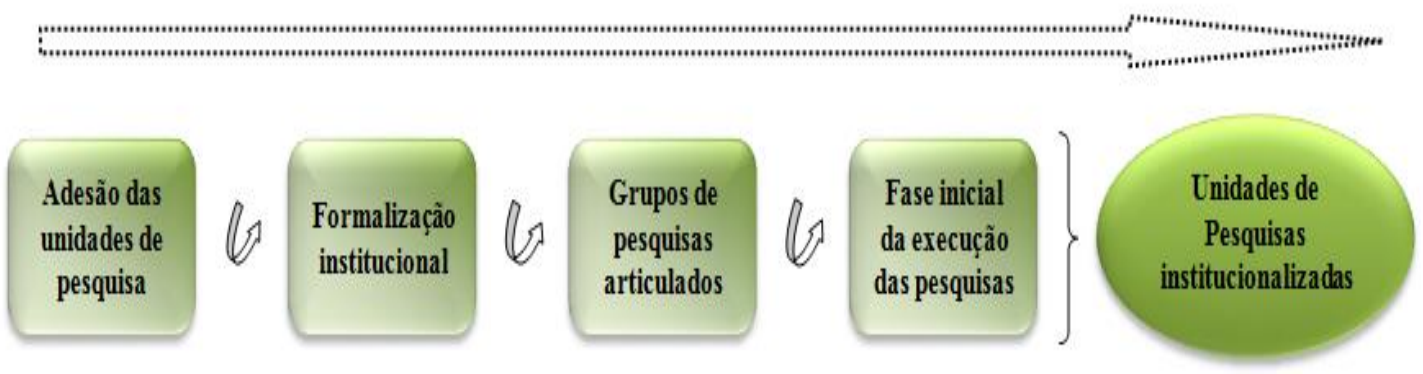

FONTE: Elaboração própria.

Figura 11 - Modelo de fluxo das etapas para institucionalização organizacional de estudos em rede

O processo de adesão das instituições deverá ser firmado por meio de contrato entre as partes (Diretor de pesquisa da instituição ou similar e Comitê Gestor da Rede). Será elegível todo e qualquer grupo de pesquisa da instituição integrante que se mostrar interessado em participar da execução de estudos propostos pela RNPC 
posteriormente, desde que disponha de capacidade técnica e científica. Os grupos de pesquisas deverão discutir aspectos técnicos e científicos sobre o fluxo de comunicação e da execução dos estudos - ao final, caso concordem, estabelecerão a parceria. O início da execução da pesquisa demandada será possível apenas quando essa estrutura estiver adequadamente articulada entre as UPC identificadas para o estudo.

Nesse sentido, considera-se que a proposta de modelo apresentada (Figura 11), além de possibilitar a agregação opcional do terceiro parceiro (empresa), coincide e reforça o modelo II de Gibbons, et al. (2011) apresentado em seu livro The new production of knowledge, o qual se pauta nos arranjos firmados "temporariamente" entre grupos de pesquisas multidisciplinares, devendo o tempo da colaboração ser limitado à solução ou à redefinição da hipótese do estudo proposto.

Em outras palavras, as UPC integram efetivamente a estrutura física da rede. Entretanto, as colaborações entre as unidades serão estabelecidas somente durante a vigência de um projeto de pesquisa, desfazendo-se quando este é finalizado por qualquer razão.

Na gestão desse modelo, apoiamo-nos nas proposições apresentadas por Lima et al. (2004), as quais apontam como necessária, na gestão da inovação tecnológica, a forma de organização do trabalho da pesquisa, devendo esta, constituirse a partir de todo arcabouço de suporte organizacional, disponibilização de insumos necessários e, ainda, estratégias de ação e controle organizacional. 


\subsection{Considerações finais}

Ao explorar o fluxo do modelo de gestão aplicado à RNPC e buscar suporte na literatura atual sobre vários outros modelos, este capítulo atesta e endossa a necessidade de diferentes abordagens no âmbito da gestão de redes de pesquisas, justamente por envolver vários autores, com incentivos e culturas institucionais distintas.

A partir desta investigação, foi possível identificar que as principais vulnerabilidades da RNPC referindo-se à necessidade de implementação de um nível relativamente elevado de incremento no domínio do gerenciamento estrutural, podem conciliar o atual modelo utilizado com a governança hierárquica do tipo top down, adaptando-o aos modelos que atualmente emergem, voltados à gestão compartilhada horizontalmente e baseados em uma teia de colaborações e vínculos que fortalece a relação dos atores e dos grupos, bem como a realização de atividades em comum. A tendência é que esses novos modelos contemplem, além dos processos estruturais e burocráticos, as influências internas e externas à rede.

Some-se a isso, a necessidade de exploração da parceria no campo institucional para suporte às UPC como forma de depositar status aos seus integrantes e fomentar um espaço de referência dentro da instituição, o qual possa agregar o maior número de grupos colaborativos, aumentando, assim, a sustentabilidade da rede. Tal estratégia implica, necessariamente, o envolvimento de uma liderança à frente da UPC.

Por fim, construir um portfólio que contemple integralmente a capacidade de resposta (técnica e cientificamente) da rede, mas que esteja voltado às necessidades do SUS, visando ao fortalecimento da pesquisa clínica no país e, consequentemente, 
ao CEIS, constituindo também uma estratégia para que os integrantes da rede enxerguem a si e aos seus pares como atores-chave nesse processo.

A partir do percurso analítico, evidenciou-se que o modelo de fluxo proposto pode permitir a avaliação continuada do desempenho da rede enquanto organização, e consequentemente as devidas readequações em tempo hábil, quando se fizerem necessárias. Outro ganho inegavelmente significativo, é a disseminação eficaz do conhecimento nas instituições a que pertencem, desse modo extrapolando, de forma esperada e efetiva, o além-fronteiras da rede. 
CONCLUSÕES 


\section{CONCLUSÕES}

De modo a concluir, a tese identificou que a partir da implementação da Política Nacional de Ciência, Tecnologia e Inovação em Saúde (PNCTIS) e da Agenda Nacional de Prioridades de Pesquisa em Saúde (ANPPS), em 2004, o Ministério da Saúde (MS) tem-se tornado um dos principais protagonistas no fomento à Pesquisa \& Desenvolvimento (P\&D) em saúde do país, fomentando a academia por meio de editais temáticos nacionais, chamadas públicas estaduais promovidas pelo Programa Pesquisa para o SUS (PPSUS), bem como contratações diretas de pesquisa de excelência em áreas estratégicas.

O Departamento de Ciência e Tecnologia (Decit), por sua vez, tem atuado como agente conector entre os Ministérios de Ciência, Tecnologia e Inovação (MCTI) e da Educação (MEC) no sentido de fortalecer as ações de fomento pautadas pelo Ministério da Saúde. Exemplo disso, são os termos de cooperação firmados entre essas instituições com o MS, com o propósito de efetivação de ações estratégicas com o aporte de recursos financeiros e de disponibilização das estruturas gerenciais das agências de fomento: Conselho Nacional de Desenvolvimento Científico e Tecnológico (CNPq), Financiadora de Estudos e Projetos (Finep) e Coordenação de Aperfeiçoamento de Pessoal de Nível Superior (Capes) respectivamente, para contratação de projetos e implementação de bolsas de pesquisas.

Nos últimos cinco anos, intensificou-se, no Decit, a estruturação de estudos em rede, contemplando os principais problemas de saúde pública no país, tais 
como câncer, acidente vascular cerebral, doenças cardiovasculares, doenças negligenciadas e pesquisas clínicas perpassando por todas elas.

Esse empreendimento também incorporou a cooperação interministerial, fortalecendo, assim, a institucionalidade da ação, além de concorrer para o debate que engloba a produção de C\&T para geração de insumos estratégicos de enfrentamento aos agravos à saúde, oportunizando-se, desse modo, uma interface entre inovação e produção com assistência. Sendo assim, o Estado vale-se da sua função intermediadora para formular e aplicar ações que geram desenvolvimento para o aparato social.

Frente a esse contexto, este estudo possibilitou ponderar que a PNCTIS se apresenta em uma nova etapa, podendo utilizar-se da pesquisa clínica como agente catalisador, diante da necessidade de intensificar as atividades de fomento à inovação, na perspectiva de reduzir a vulnerabilidade tecnológica do SUS. Some-se a isso a necessidade de promover efetivamente as parcerias universidade - empresa, propiciando, dessa forma, a aproximação das indústrias brasileiras para produção em setores considerados estratégicos para a saúde, o que acaba por fortalecer, consequentemente, o Complexo Econômico e Industrial da Saúde (CEIS).

$\mathrm{O}$ argumento desenvolvido nesta tese, responde às questões de base inicialmente apresentadas, fundamentadas em instrumentos de políticas, literatura técnico-científica e bases de dados nacionais e internacionais de registros de C\&T. Foi alcançado, portanto, o objetivo principal que motivou a realização desta pesquisa, a qual consistiu em identificar modelos de gestão de redes que possam incrementar o fluxo operacional de arranjos institucionais de pesquisas, produzir conhecimento e recomendações para o fortalecimento da gestão de CT\&I/S. 
Depreende-se, portanto, que o cenário atual da pesquisa clínica, dispõe de janelas de oportunidade que permitem às economias emergentes, como o Brasil, reposicionarem-se na geração e produção do conhecimento frente ao cenário internacional. Também, deve-se considerar que atualmente a regulação sanitária e ética da pesquisa clínica no Brasil apresenta visível e expressivo potencial, podendo ser comparável, em nível de igualdade, com os países desenvolvidos, levando a novas possibilidades de internacionalização da pesquisa.

Mesmo com números modestos, comparados à produção da indústria farmacêutica, a estrutura de execução de pesquisas clínicas na academia tem-se tornado um espaço de geração e multiplicação de conhecimentos e de vantagem competitiva, no que tange à infraestrutura de $\mathrm{C} \& \mathrm{~T}$, sendo estas potencialmente capazes de subsidiar a cadeia produtiva de produtos para saúde humana. Entretanto, a lacuna da parceria com empresas nacionais necessita ser preenchida.

Com o suporte da literatura foi possível identificar pontos relevantes para o incremento da gestão de redes, tendo como referência o caso da RNPC. O entendimento é de que os antigos modelos de governança hierárquica do tipo top down passam a ser menos efetivos quando comparados aos que apresentam gestão compartilhada horizontalmente, cujos atores, por possuírem incentivos e culturas institucionais distintas, posicionam-se de forma a contribuir na conformação do fluxo de atividades na rede, sendo mais fácil de lidar com os diferentes níveis de incrementos institucionais. Além disso, abre espaço para o surgimento de novos talentos, ideias e lideranças, uma vez que a estrutura funcional da rede estará sempre voltada à solução ou à redefinição da hipótese dos estudos propostos. 
Ademais, ao se incorporar o conceito de Ator-Rede, é possível compreender a rede em seu aspecto mais amplo, considerando todo arcabouço de suporte organizacional, disponibilização de insumos necessários e, ainda, estratégias de ação e controle organizacional, e não apenas os indivíduos humanos. A tendência é a de que esses novos modelos contemplem, além dos processos estruturais e burocráticos, as influências internas e externas à rede.

A importância de envolver a instituição que a UPC está integrada é uma das principais estratégias no sentido de fortalecer o grupo e aportar capital social aos seus integrantes e ainda adicionar capital às ações de fomento realizadas.

Este estudo constatou também a importância de aperfeiçoar o processo de monitoramento e avaliação do impacto da pesquisa, para que os indicadores gerados se mostrem úteis para a melhoria da relação entre a produção científica, a produção tecnológica e a efetividade do modelo de gestão.

Por outro lado, existem limitações no processo de gestão que escapam aos modelos aplicados às estruturas das redes, já que correspondem a diferentes ordens e ações que não são contempladas pela intervenção de políticas, como, por exemplo, os vícios institucionais aos quais as UPC são subordinadas.

Por fim, além das sugestões dispostas ao longo dos capítulos sobre possíveis intervenções para incrementar a pesquisa clínica e a gestão de redes de pesquisas, a tese apontou ainda para a necessidade da realização de novos estudos que abordem as questões acerca das estruturas físicas dos centros que executam ensaios clínicos, especialmente no que diz respeito às boas práticas clínicas e à identificação aprofundada sobre ensaios clínicos realizados por meio da cooperação universidade - 
empresa, explorando, principalmente, os agentes facilitadores e entraves burocráticos desses arranjos.

Outra possibilidade de investigação está relacionada à origem e composição dos recursos investidos na realização dos estudos e também à natureza das relações estabelecidas entre os diversos atores, visando tanto ao entendimento dessas relações quanto à possibilidade de replicação dos modelos nas regiões com menor aparato técnico-científico.

Este estudo buscou evidenciar as relações entre as capacidades de gestão de redes de pesquisas e de desenvolvimento de pesquisas clínicas no país como insumo imprescindível para a inovação. O percurso investigativo traçado nesta tese impeliu ao entendimento de que essas pesquisas constituem esperados e importantes subsídios para a formulação de políticas de C\&T cada vez mais procedentes e eficientes, as quais vêm aportando, aos gestores públicos, novas e variadas possibilidades de fomento à inovação - necessária instância de desenvolvimento estratégico para a nação. 


\section{APÊNDICES}


APÊNDICE 1 - Termo de consentimento Livre e Esclarecido - TCLE

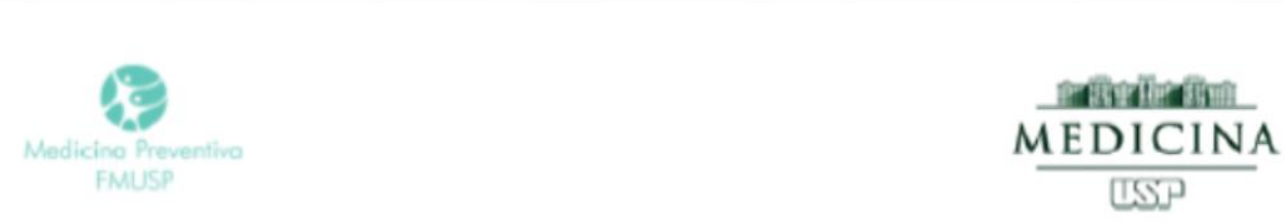

TERMO DE CONSENTIMENTO LIVRE E ESCLARECIDO (TCLE)

A Gestão de Redes de Pesquisa Cientifica, Tecnológica e de Inovação em Saúde no Brasil.

1) Dados de identificação do sujeito da pesquisa

Nome: Sexo: M $\square \mathrm{F} \square$

Documento de Identidade: Data Nascimento:

Endereço:

Cidade: Estado: CEP:

Telefone: (............)

Prezado participante,

"Você está sendo convidado(a) para participar da pesquisa "A Gestão de Redes de Pesquisa Cientifica, Tecnológica e de Inovação em Saúde no Brasil”, desenvolvida como doutoramento de Marge Tenório, no Departamento de Medicina Preventiva na Universidade de São Paulo, sob orientação do Professor Dr. Moisés Goldbaum e Co-orientação do Professor Dr. Guitherme Arantes Méllo. O estudo tem como objetivo central avaliar a gestão de redes de ciência, tecnologia e inovação em saúde no Brasil, buscando identificar condicionantes de processos e indicadores de monitoramento e avaliação, visando potencializar o fomento e a consolidação destas redes no pais.

Sua participação é voluntária e autônoma, cabendo somente a você decidir se quer ou não participar. Esta consistirá em responder a um roteiro de entrevista, que preferencialmente será gravada caso autorize. O tempo de duração da entrevista é de aproximadamente uma hora, e ela será transcrita e armazenada em arquivos digitais, arquivados por pelo menos 5 anos, conforme Resolução 466/2012 e orientações do CEP/FMUSP. Este Termo serve também para garantir total confidencialidade e a privacidade das informações prestadas, fora do circulo da pesquisadora e orientadores.

A qualquer momento, durante ou após a entrevista, você poderá solicitar informações sobre sua participação ou sobre a pesquisa através dos contatos presentes neste Termo. De igual modo, a qualquer momento pode decidir retirar seu consentimento de participação, sem que isto acarrete qualquer tipo de penalidade ou constrangimento. 


\section{Cont. Apêndice 1.}
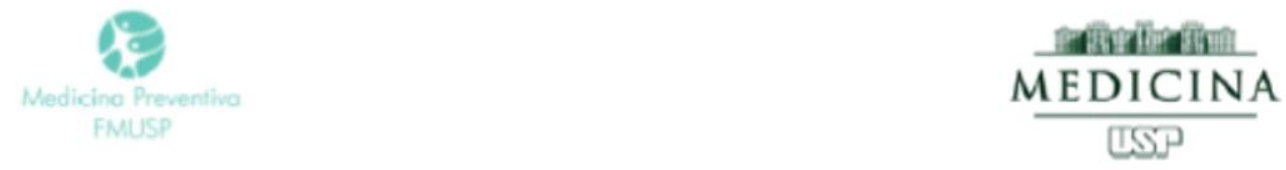

Seu beneficio em colaborar com esta pesquisa é indireto, na forma de contribuição para o entendimento da dinâmica das redes colaborativas em CTIS, e possivel identificação de condicionantes e ferramentas de análises de estruturação e efetividade do fomento de redes de pesquisas.

Como toda pesquisa, esta oferece o risco do (a) entrevistado (a) sentir-se constrangido (a) com alguma pergunta ou emocionalmente sensibilizado com o direcionamento da entrevista. A entrevistadora estará atenta e, ante a possiveis sinais, oferecerá conforto, explicações e mesmo a opção de interrupção da entrevista.

Não há despesas pessoais para o participante em qualquer fase do estudo. Também não há compensação financeira relacionada à sua participação. Se existir qualquer despesa adicional, ela será absorvida pelo orçamento da pesquisa.

Os resultados deste estudo serão publicados na forma de tese de doutorado, e poderão ser também divulgados em palestras, congressos, reuniões cientificas, relatórios individuais, artigos cientificos.

Declaro que entendi os objetivos e condições de minha participação na pesquisa e concordo em participar.

Concordo que a entrevista seja gravada

Não concordo que a entrevista seja gravada

$\overline{\text { Assinatura do entrevistado (sujeito da pesquisa) }}$

Local de data

Marge Tenório (pesquisadora responsável)

Local e data

Contatos: Endereço: Depto. de Medicina Preventiva, Faculdade de Medicina da USP. Rua Dr. Amaldo 455, sala 2162. São Paulo-SP. CEP: 01246-903. http://www. fm usp.br/preventiva Tel/Fax: (11) 3061.7091 - E-mail: marge Qusp.br, marge.tenorio@gmail.com

Telefone pessoal: (61) 8118.0919

Em caso de dúvida quanto à condução ética do estudo, por favor, entre em contato com o CoMitrê de ética eM pesqtisa da Factidade de Medicina da Untversidade de São Patlo:

Endereço: Av. Dr. Amaldo, 455 - Instituto Oscar Freire $-1^{\circ}$ andar- tel: (11)3061-8004, FAX (11)3061-8004-E-mail: cep. fmusp@ hcnet.usp.br

*Este Termo é redigido em duas vias, sendo uma para o participante e outra para o pesquisador.

*Todas as páginas deverão ser rubricadas pelo pesquisador e pelo sujeito de pesquisa.

Fonte: Elaboração própria. 
APENDICE 2 - Questionário aplicado aos pesquisadores e gestores

\title{
QUESTIONÁRIO ESTRUTURADO PARA OS PESQUISADORES DA REDE NACIONAL DE PESQUISA CLINICA EM HOSPITAL DE ENSINO - RNPC
}

\author{
INSTITUIÇÃo:
}

NOME DO CENTRO DE PESQUISA C CÍNICA (CPC):

COORDENADOR:

ANO QUE INTEGROU A RNPC:

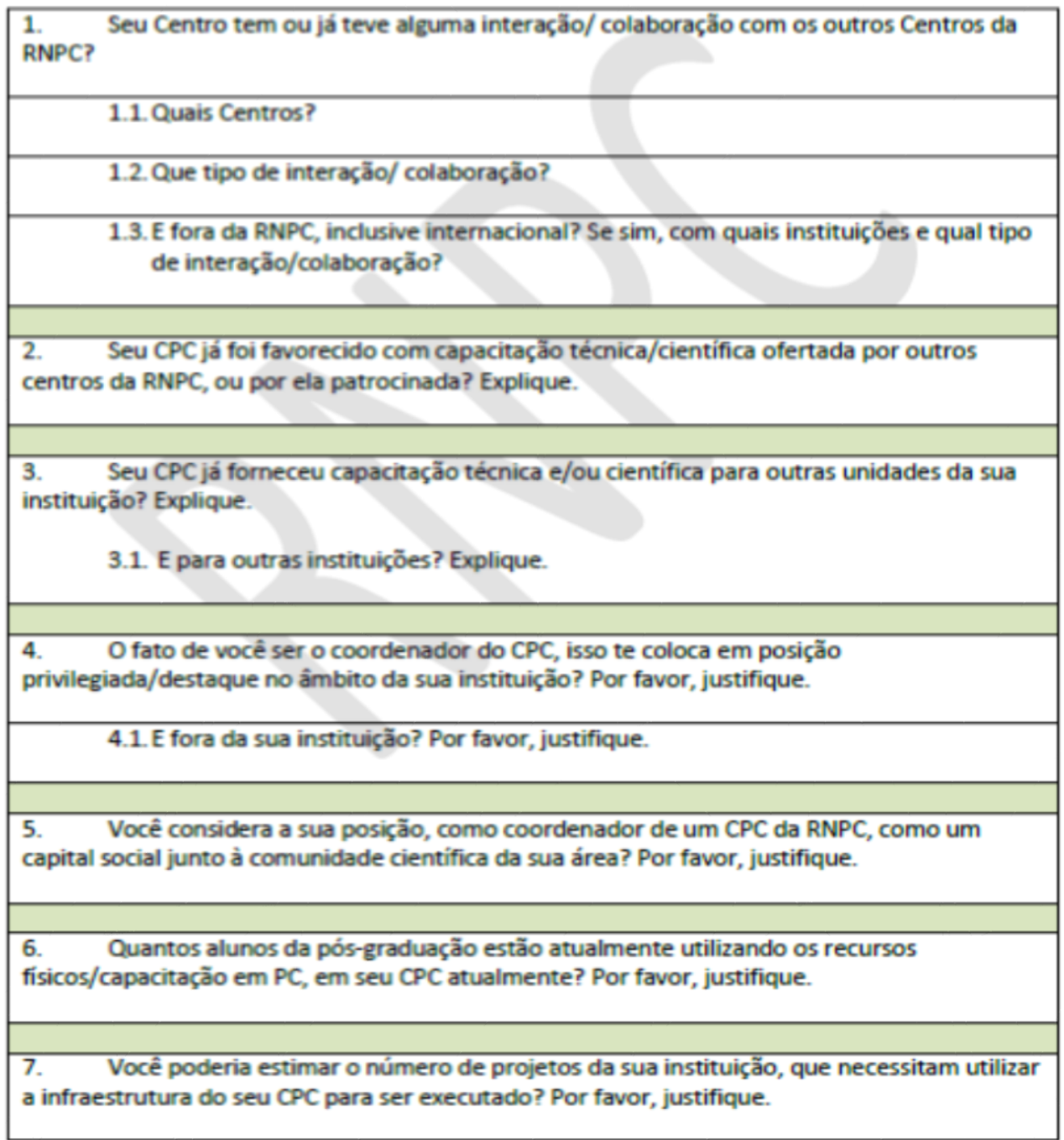




\section{Cont. Apêndice 2.}

\section{Poderia mensurar o número de teses de doutorado ou dissertações de mestrado que foram favorecidas pelo conhecimento e infraestrutura que o seu CPC detém? Por favor, justifique.}

9. Preencha o quadro a seguir, com relação à capacidade da Estrutura Física do seu CPC (Satisfatoriamente, Parcialmente, Não Possui), para a realização de ensaios clínicos nas diversas fases:

\begin{tabular}{|l|l|l|}
\hline Fases & Estrutura Fisica & Como Colaborador ou Coordenador? \\
\hline Fase I & & \\
\hline Fase II & & \\
\hline Fase III & & \\
\hline Fase IV & & \\
\hline Observacional & & \\
\hline
\end{tabular}

9.1. Se possuir Parcialmente ou Nảo Possuir, por favor, justifique:

10. Preencha o quadro a seguir com relaçào à Capacidade Científica do seu CPC (Satisfatoriamente, Parcialmente, Não Possui), para a realização de ensaios clínicos nas diversas fases:

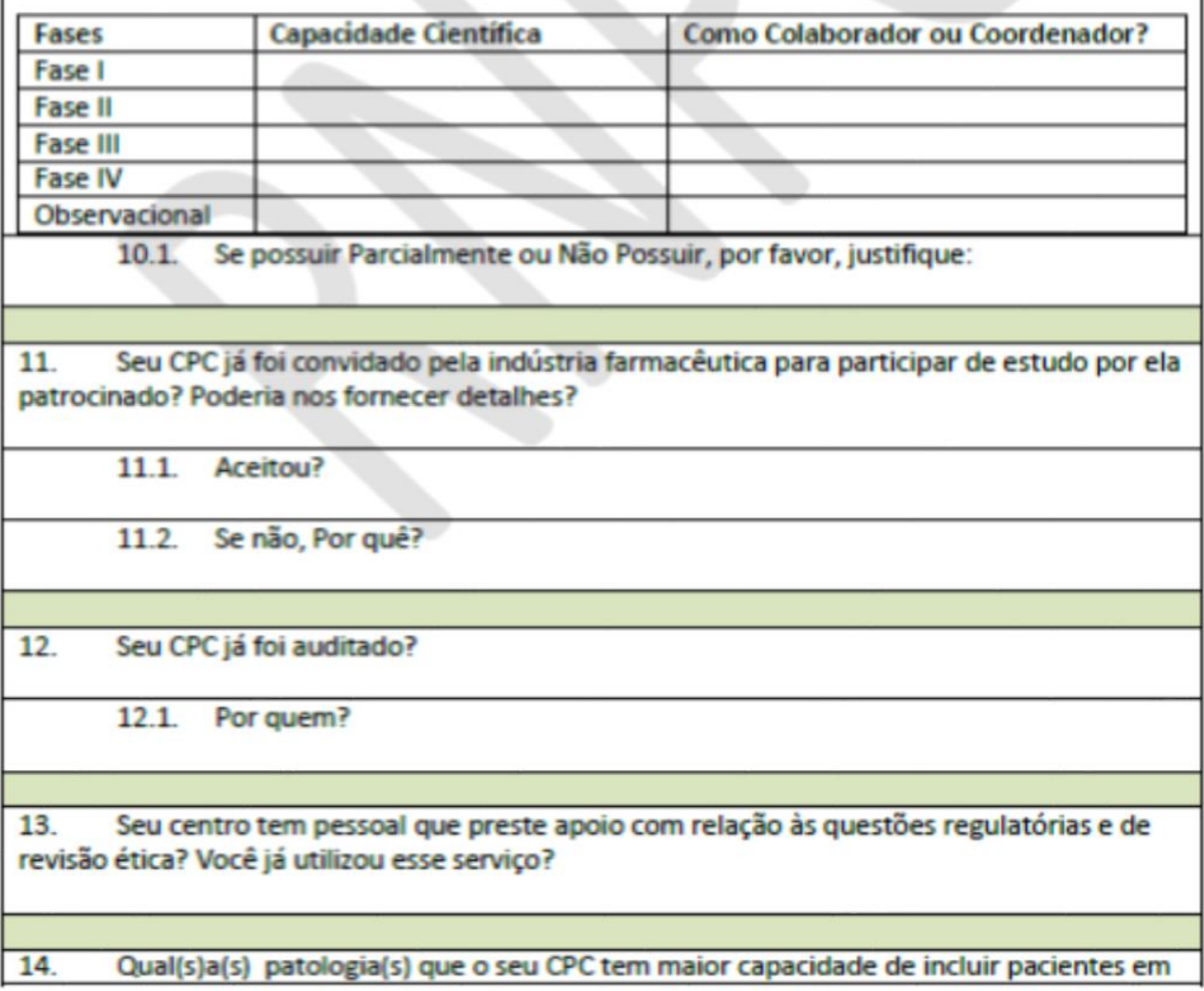




\section{Cont. Apêndice 2.}

\section{um estudo clínico?}

15. Seu CPC já teve projetos financiados por outras fontes, que não o Ministério da Saúde?

16. Você tem divulgado a RNPC e o seu CPC em encontros cientificos? Por favor, justifique.

17. Vocế tem citado o nome da RNPC nas publicaçōes geradas a partir da utilização do seu CPC? Por favor, justifique.

18. Você tem orientado os pós-graduandos que utilizam as instalações ou que são capacitados no CPC, sobre a necessidade de citar o nome da Rede nos produtos gerados?

19. Por favor, preencha o quadro a seguir com relação aos profissionais que estão diretamente ligados ao seu CPC:

\begin{tabular}{|l|l|l|l|l|}
\hline Especialidade & Quantidade & $\begin{array}{l}\text { Nivel de } \\
\text { Formação }\end{array}$ & Formação em PC & Gênero \\
\hline Médico & & & & \\
\hline Enfermeiro & & & & \\
\hline Farmacêutico & & & & \\
\hline Nutricionista & & & & \\
\hline Estatistico & & & & \\
\hline Epidemiologista & & & & \\
\hline Biólogo & & & & \\
\hline Administrador & & & & \\
\hline Economista & & & & \\
\hline $\begin{array}{l}\text { Coordenador } \\
\text { de Pesquisa } \\
\text { Clinica }\end{array}$ & & & & \\
\hline Outros & & & & \\
\hline
\end{tabular}

20. Houve incremento de publicações dos membros do seu CPC a partir da RNPC?

21. Gostaria de fazer alguma sugestão sobre a gestão da RNPC?

FONTE: Elaboração própria 


\section{APÊNDICE 3 - Roteiro de entrevistas}

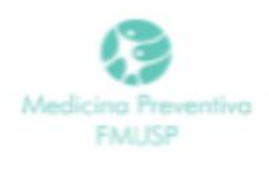

\section{EAfratinin MEDICINA ROTEIRO DE ENTREVISTA

\section{A. SOBRE O CONCEITO DE REDE DE PESQUISA.}

1. Para você, como se define o trabalho em rede e quais os aspectos essenciais de uma rede de pesquisa?

2. No seu ponto de vista, em que aspectos, conceitualmente falando, o trabalho em rede traz vantagens em relação ao trabalho fora dela?

3. Na medida em que reúne grupos de pesquisa (ou pesquisadores individuais) de instituições diferentes, o trabalho em rede pode enfraquecer uma perspectiva institucional do trabalho de pesquisa. Em outras palavras, a hegemonia do trabalho em rede pode significar uma "desregulamentação" ou "flexibilização" de regras e modos que governam instituições (universidades, institutos de pesquisa, etc.). Qual a sua opinião sobre esse comentário?

\section{B. SOBRE A EXPERIÊNCIA CONCRETA DE TRABALHAR EM REDE.}

4. Quando se associou à Rede?

5. Como tomou conhecimento da existência da Rede?

6. Qual o impacto do trabalho em rede na sua performanece (ou na de seu grupo), nos seguintes aspectos:
a. produção bibliográfica?
b. depósito de patentes ou outras formas de proteção à propriedade intelectual?
c. informação cientifica ou técnica?
d. orientação de estudantes ou pós-docs?
e. levantamento de recursos financeiros para pesquisa?
f. infraestrutura para seu laboratório?
g. relações internacionais?
h. quem se apropria dos ganhos de produtividade, a rede como um todo ou alguns individuos? Como isso ê aferido? 


\section{Cont. Apêndice 3.}

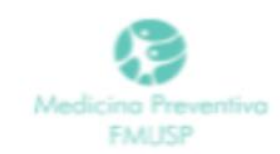

\section{intininin \\ MEDICINA}

प्रP

\section{SOBRE A GESTÃO DA REDE.}

7. No que se refere às relações entre os grupos participantes, quais as principais dificuldades enfrentadas por você no trabalho em rede?

8. Como você define o fluxo de comunicação na rede: seu grupo com os demais da mesma rede e seu grupo com as agências de fomento e vice-versa.

9. No que se refere ao fomento e organização da rede, como você avalia o papel das seguintes instituições:
a. Ministério da Saúde?
b. Ministério da Ciência, Tecnologia e Inovação?
c. CNPq?
d. FINEP?
f. BNDES?
g. Fundações estaduais de apoio à pesquisa?
h. Sistema CEP/CONEP?
i. Hospitais participantes de projetos de pesquisa da rede?
j. CRO participantes de projetos de pesquisa da rede?

10. Como você avalia as regras de operação na rede (escolha de coordenação; processo decisório; critérios de compartilhamento etc).

\section{SOBRE O FLUXO E O VOLUME DE RECURSOS FINANCEIROS PARA A REDE.}

11. Qual a ordem de grandeza dos recursos financeiros captados pelo seu grupo durante o tempo em que vem participando da rede (de todas as fontes, não exclusivamente dos editais destinados especificamente à rede).
a. menos de RS 100 mil.
b. de RS 101 mil a 500 mil.
c. de RS 501 mil a 1 milhão.
d. de RS 1,1 milhão a 5 milhões.
e. de RS 5,1 milhões a 10 milhões.
f. acima de RS 10 milhões. 


\section{Cont. Apêndice 3.}

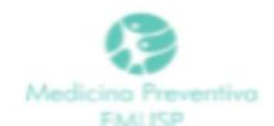

\section{intifingen \\ MEDICINA \\ TSP]}

12. Qual a ordem de grandeza dos recursos financeiros captados pelo seu grupo durante 0 tempo em que vem participando da rede (exclusivamente dos editais destinados especificamente à rede).
a. menos de RS 100 mil.
b. de RS 101 mil a 500 mil.
c. de RS 501 mil a 1 milhão.
d. de RS 1,1 milhão a 5 milhões.

13. Na sua opinião, o volume de recursos financeiros para a rede (em particular para o seu grupo) foi adequado ou inadequado? Poderia justificar?

12. Na sua opinião, os mecanismos de fluxo financeiro para a rede (em particular para o seu grupo de pesquisa) foi adequado ou inadequado? Poderia justificar?

\section{E. SOBRE O FUTURO DAS REDES.}

14. Na sua opinião, qual o futuro da rede da qual seu grupo participa?

15. Poderia fornecer sugestões para o aperfeiçoamento da rede da qual seu grupo participa?

16. Como você avalia a rede que participa? Comente:

FONTE: Elaboração própria 
APÊNDICE 4 - Produção extraída dos Currículos Lattes dos coordenadores das Unidades de Pesquisas Clínicas da Rede Nacional de Pesquisa Clínica.

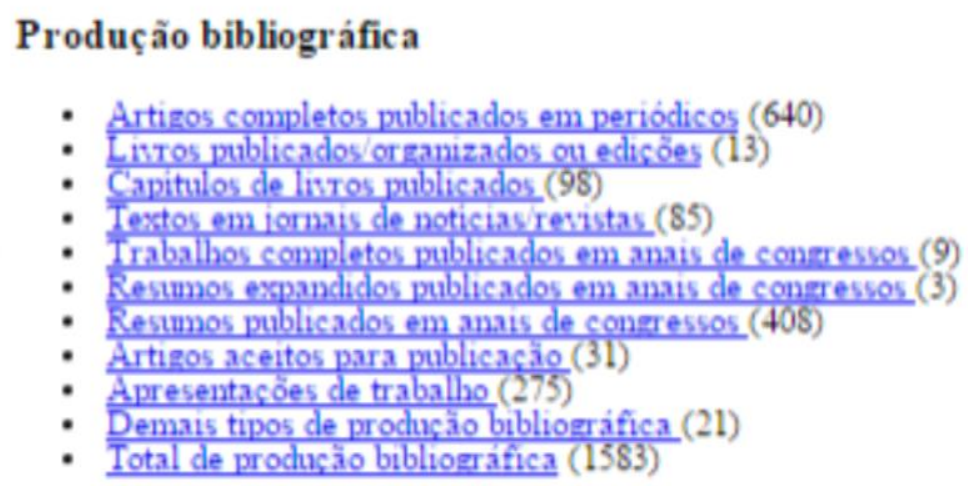

- Antizos completos publicados em periódicos (640)

- Livtos publicados or zamizados ou edicōes (13)

- Capitulos de livtos publicados (98)

- Textos ema iornais de noticias revistas (85)

- Traballos completos publicados em amais de coneressos (9)

- Resumos expandidos publicados em amais de coneresios (3)

- Resumos publicados em amais de coneressos (408)

- Artizos aceitos para publicaçao (31)

- Apresentaçóes de traballoo (275)

- Demais tipos de produçào bibliográfica (21)

- Iotal de producão bibliografica (1583)

\section{Produção técnica}

- Prochutos tecnológicos (18)

- Irabalhos técnicos (73)

- Demais tipos de produção técnica (43)

- Total de produção técnica (134)

\section{Produção artistica}

- Total de prochucão artistica (1)

\section{Orientações}

- Orientações em andamento

- Supervisão de pós-doutorado (14)

- Tese de doutorado (60)

- Dissertacĩo de mestrado (62)

- Traballho de conclusăo de curso de maduacăo (5)

- Iniciacio cientifica (27)

- Orientacoóes de outra matureza (6)

- Iotal de orientacóes em andamento (174)

- Supervisōes e orientaçōes concluidas

- Supervisão de pós-doutorado (9)

- Tese de doutorado (47)

- Dissertaciao de mestrado (\$1)

- Iraballho de conclusão de curso de graduação (26)

- Iniciação cientifica (61)

- Orientaçōes de outra natureza (19)

- Iotal de orientaçóes concluidas (243)

\section{Projetos de pesquisa}

- Total de projetos de pescuisa (215)

\section{Prêmios e títulos}

- Total de prêmios e titulos (62)

FONTE: Gerado automaticamente por scriptLattes V8.09 por Jesús P. MenaChalco e Roberto M. Cesar-Jr. 
APÊNDICE 5 - Grupos de Pesquisa Clínica, extraídos do Diretório dos Grupos de Pesquisa da Plataforma Lattes

\begin{tabular}{|c|c|c|c|c|c|}
\hline \multicolumn{6}{|c|}{ Consulta Parametrizada - Grupos de Pesquisas em Ensaios Clínicos } \\
\hline INSTITUIÇÄO & GRUPO & LÍDER & \begin{tabular}{|c|} 
ÁREA \\
PREDOMINANTE
\end{tabular} & ESPECIALIDADE & REGIÄO \\
\hline $\begin{array}{l}\text { Escola Superior de Ciências da } \\
\text { Saúde }\end{array}$ & Terapia Nutricional e Câncer & $\begin{array}{l}\text { Maria Rita Carvalho Garbi } \\
\text { Novaes }\end{array}$ & Ciências da Saúde & Nutrição & $\mathrm{co}$ \\
\hline FK Biotecnologia & $\begin{array}{l}\text { Desenvolvimento de instrumentos para ensaios } \\
\text { clínicos e de pesquisa }\end{array}$ & Fernando Thomé Kreutz & Engenharias & $\begin{array}{l}\text { Engenharia } \\
\text { Elétrica }\end{array}$ & s \\
\hline \begin{tabular}{|l} 
Fundação de Medicina Tropical \\
Doutor Heitor Vieira Dourado
\end{tabular} & $\begin{array}{l}\text { Centro Intemacional de Pesquisa Clínica em } \\
\text { Malária }\end{array}$ & Wuelton Marcelo Monteiro & Ciências da Saúde & Medicina & $\mathrm{N}$ \\
\hline \begin{tabular}{|l} 
Fundação de Medicina Tropical \\
Doutor Heitor Vieira Dourado
\end{tabular} & $\begin{array}{l}\text { Núcleo de Investigaçäo de Dermatoses Infecciosas } \\
\text { e Tropicais- NIDIT }\end{array}$ & Fabio Francesconi do Valle & Ciências da Saúde & Medicina & $\mathrm{N}$ \\
\hline $\begin{array}{l}\text { Fundaçä̃o Hospitalar do Estado de } \\
\text { Minas Gerais }\end{array}$ & $\begin{array}{l}\text { Núcleo de Ensino e Pesquisa do Hospital Galba } \\
\text { Velloso }\end{array}$ & Fernando Madalena Volpe & Ciências da Saúde & Medicina & SE \\
\hline Fundaçäo Oswaldo Cruz & Doenças endemicas & Cristine Vieira do Bonfim & Ciências da Saúde & Saúde Coletiva & SE \\
\hline Fundaçäo Oswaldo Cruz & $\begin{array}{l}\text { Epidemiologia clínica aplicada ao desenvolvimento } \\
\text { de instrumentos de apoio à decisäo médica }\end{array}$ & Sonia Regina Lambert Passos & Ciências da Saúde & Saúde Coletiva & SE \\
\hline Fundação Oswaldo Cruz & Epidemiologia e Vigilância em Saúde & Gerson Oiveira Penna & Ciências da Saúde & Saúde Coletiva & SE \\
\hline Fundaçäo Oswaldo Cruz & Epidemiologia Psiquiátrica & $\begin{array}{l}\text { Evandro da Silva Freire } \\
\text { Coutinho }\end{array}$ & Ciências da Saúde & Saúde Coletiva & SE \\
\hline
\end{tabular}

\begin{tabular}{|c|c|c|c|c|c|}
\hline Fundação Oswaldo Cruz & Grupo de Endemias Virais da Amazónia & $\begin{array}{l}\text { Deusilene Souza Vieira } \\
\text { Dallacqua }\end{array}$ & Ciências da Saúde & Medicina & SE \\
\hline Fundação Oswaldo Cruz & $\begin{array}{l}\text { Grupo de Pesquisa Clínica e Epidemiológica em } \\
\text { HIVIAIDS }\end{array}$ & $\begin{array}{l}\text { Beatriz Gilda Jegerhorn } \\
\text { Grinsztejn }\end{array}$ & Ciências da Saúde & Medicina & SE \\
\hline Fundação Oswaldo Cruz & Grupo de Pesquisa em Doenças Febris Agudas & Patrícia Brasil & Ciências da Saúde & Medicina & SE \\
\hline Fundação Oswaldo Cruz & Imunobiologia da Esquistossomose & Cristina Toscano Fonseca & \begin{tabular}{|l} 
Ciências \\
Biológicas
\end{tabular} & Imunologia & SE \\
\hline Fundação Oswaldo Cruz & Laboratório de Imuno-regulação LIMI & Manoel Barral Netto & \begin{tabular}{|l} 
Ciências \\
Biológicas
\end{tabular} & Imunologia & SE \\
\hline Fundação Oswaldo Cruz & Núcleo de Pesquisa em Leishmaniose & Aloísio Falqueto & \begin{tabular}{|l} 
Ciências \\
Biológicas
\end{tabular} & Parasitologia & SE \\
\hline Fundação Oswaldo Cruz & Pesquisa Clínica em Saúde da Criança & Maria Elisabeth Lopes Moreira & Ciências da Saúde & Medicina & SE \\
\hline Fundação Oswaldo Cruz & Pesquisa Clinica em tuberculose e HIV & Valeria Cavalcanti Rolla & Ciências da Saúde & Medicina & SE \\
\hline Fundação Oswaldo Cruz & $\begin{array}{l}\text { Programa de Pesquisa Translacional em Doença } \\
\text { de Chagas (Fio-Chagas) }\end{array}$ & $\begin{array}{l}\text { Rubem Figueiredo Sadok } \\
\text { Menna Barreto }\end{array}$ & Ciências da Saúde & Medicina & SE \\
\hline Fundação Oswaldo Cruz & Quimioterapia Anti-Parasitária e Anti-Tumoral & Carlos Gustavo Regis da Silva & \begin{tabular}{|l} 
Ciências \\
Biológicas
\end{tabular} & Parasitologia & SE \\
\hline $\begin{array}{l}\text { Hospital de Clínicas de Porto } \\
\text { Alegre }\end{array}$ & $\begin{array}{l}\text { Aspectos } \infty \text { gnitivos e comportamentais associados } \\
\text { ao envelhecimento e a disfunçóes neurobiológicas }\end{array}$ & $\begin{array}{l}\text { Marcia Lorena Fagundes } \\
\text { Chaves }\end{array}$ & Ciências da Saúde & Medicina & $s$ \\
\hline
\end{tabular}




\section{Cont. Apêndice 5.}

\begin{tabular}{|c|c|c|c|c|c|}
\hline $\begin{array}{l}\text { Hospital de Clínicas de Porto } \\
\text { Alegre }\end{array}$ & $\begin{array}{l}\text { Epidemiologia de Doenças Infecciosas e Infeccōes } \\
\text { Hospitalares }\end{array}$ & $\begin{array}{l}\text { Ricardo de Souza } \\
\text { Kuchenbecker }\end{array}$ & Ciências da Saúde & Saúde Coletiva & S \\
\hline $\begin{array}{l}\text { Hospital de Clínicas de Porto } \\
\text { Alegre }\end{array}$ & $\begin{array}{l}\text { Farmacologia Clínica e Avaliação e Gestäo de } \\
\text { Tecnologias em Saúde }\end{array}$ & Paulo Dornelles Picon & Ciências da Saúde & Medicina & S \\
\hline $\begin{array}{l}\text { Hospital de Clínicas de Porto } \\
\text { Alegre }\end{array}$ & $\begin{array}{l}\text { Grupo de Estudos de Doenças da Mulher Ligadas } \\
\text { à Emergência }\end{array}$ & Ricardo Francalacci Savaris & Ciências da Saúde & Medicina & S \\
\hline $\begin{array}{l}\text { Hospital de Clínicas de Porto } \\
\text { Alegre }\end{array}$ & $\begin{array}{l}\text { Southem Surgical Oncology Research Group } \\
\text { [SSORG] }\end{array}$ & Luis Fernando Moreira & Ciências da Saúde & Medicina & S \\
\hline Instituto Adolfo Lutz & Virus Entéricos. & $\begin{array}{l}\text { Maria do Carmo Sampaio } \\
\text { Tavares Timenetsky }\end{array}$ & \begin{tabular}{|l} 
Ciências \\
Biológicas
\end{tabular} & Microbiologia & SE \\
\hline Instituto Butantan & $\begin{array}{l}\text { Proteínas de venenos e salivas animais envolvidas } \\
\text { em coagulação, fibrinólise e proliferação celular: }\end{array}$ & $\begin{array}{l}\text { Ana Marisa Chudzinski } \\
\text { Tavassi }\end{array}$ & \begin{tabular}{|l} 
Ciências \\
Biológicas
\end{tabular} & Bioquímica & SE \\
\hline $\begin{array}{l}\text { Instituto de Cardiologia do Rio } \\
\text { Grande do Sul }\end{array}$ & $\begin{array}{l}\text { Grupo de Pesquisa em Prevenção Cardiovascular } \\
\text { na Infância e Adolescência - PREVINA }\end{array}$ & Lucia Campos Pellanda & Ciências da Saúde & Medicina & S \\
\hline $\begin{array}{l}\text { Instituto de Ensino e Pesquisa da } \\
\text { Santa Casa de Belo Horizonte }\end{array}$ & Biofísica e Farmacologia Molecular da dor & Célio José de Castro Júnior & \begin{tabular}{|l} 
Ciências \\
Biológicas
\end{tabular} & Farmacologia & SE \\
\hline Instituto Evandro Chagas & $\begin{array}{l}\text { Doenças negligenciadas e pesquisa clínico- } \\
\text { epidemiológica aplicada na Amazônia }\end{array}$ & $\begin{array}{l}\text { Francisco Lúzio de Paula } \\
\text { Ramos }\end{array}$ & Ciências da Saúde & Medicina & SE \\
\hline Instituto Federal do Ceará - Reitoria & Biotecnologia \& Nanotecnologia & Marco Antonio Botelho Soares & Ciências da Saúde & Saúde Coletiva & NE \\
\hline $\begin{array}{l}\text { Pontificia Universidade Católica do } \\
\text { Paraná }\end{array}$ & Grupo de Estudos em Terapia Celular - GETEC & Paulo Roberto Slud Brofman & Ciências da Saúde & Medicina & S \\
\hline
\end{tabular}

\begin{tabular}{|c|c|c|c|c|c|}
\hline $\begin{array}{l}\text { Pontificia Universidade Católica do } \\
\text { Paraná }\end{array}$ & Patologia Geral e Comparada & $\begin{array}{l}\text { Pedro Vicente Michelotto } \\
\text { Júnior }\end{array}$ & Ciências Agrárias & $\begin{array}{l}\text { Medicina } \\
\text { Veterinária }\end{array}$ & S \\
\hline $\begin{array}{l}\text { Pontificia Universidade Católica do } \\
\text { Rio Grande do Sul }\end{array}$ & Pesquisa em Nefrologia (PGCMCS/IPB) & $\begin{array}{l}\text { Bartira Erćlia Pinheiro da } \\
\text { Costa }\end{array}$ & Ciências da Saúde & Medicina & s \\
\hline $\begin{array}{l}\text { Universidade Bandeirante de Säo } \\
\text { Paulo }\end{array}$ & $\begin{array}{l}\text { Avaliaçäo Biológica elou Molecular da Atividade de } \\
\text { Substấncias Bioativas }\end{array}$ & $\begin{array}{l}\text { Marcia Regina Machado dos } \\
\text { Santos }\end{array}$ & Ciências da Saúde & Famácia & SE \\
\hline $\begin{array}{l}\text { Universidade Camilo Castelo } \\
\text { Branco }\end{array}$ & P\&D em Medicina Translacional & Ovidiu Constantin Baltatu & Engenharias & $\begin{array}{l}\text { Engenharia } \\
\text { Biomédica }\end{array}$ & SE \\
\hline Universidade Cidade de Säo Paulo & $\begin{array}{l}\text { Agentes eletrofísicos na modulação da dor, reparo } \\
\text { tecidual e produçäo de contraçäo muscular }\end{array}$ & Richard Eloin Liebano & Ciências da Saúde & \begin{tabular}{|l} 
Fisioterapia e \\
Terapia \\
Ocupacional
\end{tabular} & SE \\
\hline Universidade Cidade de Säo Paulo & Grupo de pesquisa em dor lombar & $\begin{array}{l}\text { Luciola da Cunha Menezes } \\
\text { Costa }\end{array}$ & Ciências da Saúde & $\begin{array}{l}\text { Fisioterapia e } \\
\text { Terapia } \\
\text { Ocupacional }\end{array}$ & SE \\
\hline Universidade de Brasília & Medicina Tropical & Cleudson Nery de Castro & Ciências da Saúde & Medicina & $\mathrm{CO}$ \\
\hline Universidade de Caxias do Sul & $\begin{array}{l}\text { Grupo de Pesquisa em HIVIAIDS e Patologias } \\
\text { Associadas }\end{array}$ & Rosa Dea Sperhacke & Ciências da Saúde & Medicina & s \\
\hline Universidade de Pernambuco & Epidemioclínica & $\begin{array}{l}\text { Arnaldo de França Caldas } \\
\text { Junior }\end{array}$ & Ciências da Saúde & Odontologia & NE \\
\hline Universidade de Ribeirão Preto & $\begin{array}{l}\text { Bioquímica e Farmacologia de Produtos } \\
\text { Biotecnológicos }\end{array}$ & Renê de Oliveira Beleboni & \begin{tabular}{|l} 
Ciências \\
Biológicas
\end{tabular} & Bioquímica & SE \\
\hline Universidade de Säo Paulo & Bioinformática e Informática Médica & Ariane Machado Lima & $\begin{array}{l}\text { Ciências Exatas e } \\
\text { da Tenra }\end{array}$ & $\begin{array}{l}\text { Ciência da } \\
\text { Computaçãa }\end{array}$ & SE \\
\hline
\end{tabular}




\section{Cont. Apêndice 5.}

\begin{tabular}{|c|c|c|c|c|c|}
\hline Universidade de São Paulo & Clínica Integrada e Terapêutica & Maria Aparecida Borsatti & Ciências da Saúde & Odontologia & SE \\
\hline Universidade de São Paulo & Doença Sistèmica e o œraçäo & Daniela Calderaro & Ciências da Saúde & Medicina & SE \\
\hline Universidade de São Paulo & Fluência, Funções da Face e Disfagia & Fernanda Chiarion Sassi & Ciências da Saúde & Fonoaudiologia & SE \\
\hline Universidade de São Paulo & iii - Instituto de Investigaçäo em Imunologia & Jorge Elias Kalil Filho & Ciências da Saúde & Medicina & SE \\
\hline Universidade de São Paulo & $\begin{array}{l}\text { Laboratório de Imunologia Clínica e Alergia da } \\
\text { FMUSP }\end{array}$ & Jorge Elias Kali Filho & Ciências da Saúde & Medicina & SE \\
\hline Universidade de São Paulo & Núcleo de Epidemiologia-NEPI & Lenise Mondini & Ciências da Saúde & Saúde Coletiva & SE \\
\hline Universidade de São Paulo & $\begin{array}{l}\text { Pesquisa Clínica e Tecnológica em Reabilitação } \\
\text { Oral }\end{array}$ & Raphael Freitas de Souza & Ciências da Saúde & Odontologia & SE \\
\hline Universidade de São Paulo & Programa de Transtomo Bipolar (PROMAN) & Beny Lafer & Ciências da Saúde & Medicina & SE \\
\hline Universidade de São Paulo & Propriedades Funcionais de Alimentos & José Alfredo Gomes Arêas & Ciências Agrárias & \begin{tabular}{|l} 
Ciência e \\
Tecnologia de \\
Alimentos
\end{tabular} & SE \\
\hline Universidade de São Paulo & Terapia Gênica & Eugenia Costanzi-Strauss & \begin{tabular}{|l} 
Ciências \\
Biológicas
\end{tabular} & Bioquímica & SE \\
\hline $\begin{array}{l}\text { Universidade do Estado do Rio de } \\
\text { Janeiro }\end{array}$ & Gestação em doenças reumáticas e tromboflias & Roger Abramino Levy & Ciências da Saúde & Medicina & SE \\
\hline
\end{tabular}

\begin{tabular}{|c|c|c|c|c|c|}
\hline Universidade do Sagrado Coração & $\begin{array}{l}\text { Controle Genético das Células-Tronco } \\
\text { Mesenquimais Humanas Cultivadas e a Utilizaçäo }\end{array}$ & Ricardo Ribeiro dos Santos & Ciências da Saúde & Medicina & NE \\
\hline $\begin{array}{l}\text { Universidade Estadual de } \\
\text { Campinas }\end{array}$ & Saúde matema e perinatal & Eliana Amaral & Ciências da Saúde & Medicina & SE \\
\hline Universidade Estadual de Londrina & Bioética e saúde & $\begin{array}{l}\text { Ester Massae Okamoto Dalla } \\
\text { Costa }\end{array}$ & Ciências Humanas & Filosofia & S \\
\hline Universidade Estadual de Londrina & Núcleo de Estudos de Farmacoepidemiologia & $\begin{array}{l}\text { Ester Massae Okamoto Dalla } \\
\text { Costa }\end{array}$ & Ciências da Saúde & Famácia & S \\
\hline $\begin{array}{l}\text { Universidade Estadual Paulista } \\
\text { Júlio de Mesquita Filho }\end{array}$ & Analise de Sobrevivência e Epidemiologia & Liciana Vaz de Arruda Silveira & $\begin{array}{l}\text { Ciências Exatas e } \\
\text { da Terra }\end{array}$ & $\begin{array}{l}\text { Probabilidade e } \\
\text { Estatistica }\end{array}$ & SE \\
\hline $\begin{array}{l}\text { Universidade Estadual Paulista } \\
\text { Júlio de Mesquita Filho }\end{array}$ & $\begin{array}{l}\text { Biomecánica, Biofisica e Bioquímica dos } \\
\text { Biomateriais }\end{array}$ & Aimée Maria Guiotti & Ciências da Saúde & Odontologia & SE \\
\hline $\begin{array}{l}\text { Universidade Estadual Paulista } \\
\text { Júlio de Mesquita Filho }\end{array}$ & $\begin{array}{l}\text { Estudos Multicêntricos em Reumatologia } \\
\text { Pediátrica }\end{array}$ & Cláudia Saad Magalhäes & Ciências da Saúde & Medicina & SE \\
\hline $\begin{array}{l}\text { Universidade Estadual Paulista } \\
\text { Júlio de Mesquita Filho }\end{array}$ & $\begin{array}{l}\text { Morfofisiologia comparada do processo de reparo e } \\
\text { cicatrização }\end{array}$ & Flávio Ruas de Moraes & Ciências Agrárias & $\begin{array}{l}\text { Medicina } \\
\text { Veterinária }\end{array}$ & SE \\
\hline $\begin{array}{l}\text { Universidade Estadual Paulista } \\
\text { Júlio de Mesquita Filho }\end{array}$ & Novas Tecnologias e Materiais em Ortodontia & Luiz Gonzaga Gandini Júnior & Ciências da Saúde & Odontologia & SE \\
\hline $\begin{array}{l}\text { Universidade Estadual Paulista } \\
\text { Júlio de Mesquita Filho }\end{array}$ & $\begin{array}{l}\text { Pesquisa e Desenvolvimento de Produtos, } \\
\text { Técnicas, Bio e Nanomateriais para Odontologia }\end{array}$ & $\begin{array}{l}\text { Osmir Batista de Oliveira } \\
\text { Junior }\end{array}$ & Ciências da Saúde & Odontologia & SE \\
\hline $\begin{array}{l}\text { Universidade Estadual Paulista } \\
\text { Júlio de Mesquita Filho }\end{array}$ & $\begin{array}{l}\text { Unidade de Medicina Baseada em Evidências da } \\
\text { UNESP }\end{array}$ & Regina EI Dib & Ciências da Saúde & Medicina & SE \\
\hline
\end{tabular}




\section{Cont. Apêndice 5.}

\begin{tabular}{|c|c|c|c|c|c|}
\hline Universidade Federal da Bahia & $\begin{array}{l}\text { Bioengenharia Tecidual: Desenvolvimento de } \\
\text { Biomateriais e Terapéuticas Regenerativas }\end{array}$ & Fabiana Paim Rosa & Ciências da Saúde & Odontologia & NE \\
\hline Universidade Federal da Bahia & Centro de Pesquisa Fima Lifshitz & Hugo da Costa Ribeiro Junior & Ciências da Saúde & Nutrição & NE \\
\hline Universidade Federal da Bahia & $\begin{array}{l}\text { Grupo de Pesquisa em Doenças Infecciosas e } \\
\text { Retrovirologia }\end{array}$ & Roberto José da Silva Badaró & Ciências da Saúde & Medicina & $\mathrm{NE}$ \\
\hline Universidade Federal da Bahia & Vida & Mônica Neves Aguiar da Silva & $\begin{array}{l}\text { Ciências Sociais } \\
\text { Aplicadas }\end{array}$ & Direito & $\mathrm{NE}$ \\
\hline Universidade Federal da Paraíba & Ciências Odontológicas & Paulo Rogério Ferreti Bonan & Ciências da Saúde & Odontologia & NE \\
\hline Universidade Federal da Paraíba & Desenvolvimento E Ensaios de Medicamentos & Rui Oliveira Macedo & Ciências da Saúde & Fammácia & NE \\
\hline Universidade Federal da Paraíba & $\begin{array}{l}\text { Grupo de Estudos e Pesquisa em Tratamento de } \\
\text { Feridas }\end{array}$ & Marta Miriam Lopes Costa & Ciências da Saúde & Enfermagem & $\mathrm{NE}$ \\
\hline Universidade Federal da Paraíba & $\begin{array}{l}\text { Grupo de Estudos PsicoNeuroEndócrinos e Clínico } \\
\text { Metabólicos (GEPEC) }\end{array}$ & $\begin{array}{l}\text { Eutília Andrade Medeiros } \\
\text { Freire }\end{array}$ & Ciências da Saúde & Medicina & NE \\
\hline Universidade Federal da Paraiba & $\begin{array}{l}\text { Grupo de Pesquisa em Odontopediatria e Clínica } \\
\text { Integrada }\end{array}$ & Ana Maria Gondim Valença & Ciências da Saúde & Odontologia & $\mathrm{NE}$ \\
\hline Universidade Federal da Paraíba & Plantas Medicinais e Tóxicas & $\begin{array}{l}\text { Margareth de Fátima Formiga } \\
\text { Melo Diniz }\end{array}$ & Ciências da Saúde & Fammácia & $\mathrm{NE}$ \\
\hline Universidade Federal de Alagoas & Morfologia Aplicada e Saúde & Fabiano Timbó Barbosa & Ciências da Saúde & Medicina & NE \\
\hline
\end{tabular}

\begin{tabular}{|c|c|c|c|c|c|}
\hline Universidade Federal de Alagoas & $\begin{array}{l}\text { Núcleo de Pesquisa e Inovaçäo Tecnológica em } \\
\text { Tratamento de Feridas }\end{array}$ & Maria Lysete de Assis Bastos & Ciências da Saúde & Enfermagem & NE \\
\hline Universidade Federal de Goiás & Toxicologia e Farmacologia Celular & Marize Campos Valadares & Ciências da Saúde & Fammácia & $\mathrm{CO}$ \\
\hline $\begin{array}{l}\text { Universidade Federal de Juiz de } \\
\text { Fora }\end{array}$ & Reproduçäo Humana & Martha de Oliveira Guena & Ciências da Saúde & Medicina & SE \\
\hline $\begin{array}{l}\text { Universidade Federal de Mato } \\
\text { Grosso do Sul }\end{array}$ & $\begin{array}{l}\text { Genética Molecular de Microrganismos e } \\
\text { VegetalBiotecnologia (GMMV/Biotec) }\end{array}$ & Odanir Garcia Guerra & \begin{tabular}{|l} 
Ciências \\
Biológicas
\end{tabular} & Genética & SE \\
\hline $\begin{array}{l}\text { Universidade Federal de Minas } \\
\text { Gerais }\end{array}$ & $\begin{array}{l}\text { Biotecnologia aplicada ao desenvolvimento e teste } \\
\text { de imunobiológicos }\end{array}$ & Rodolfo Cordeiro Giunchetti & \begin{tabular}{|l} 
Ciências \\
Biológicas
\end{tabular} & Parasitologia & SE \\
\hline $\begin{array}{l}\text { Universidade Federal de Minas } \\
\text { Gerais }\end{array}$ & Grupo de Pesquisa em Micobacterioses & Wania da Silva Carvalho & Ciências da Saúde & Medicina & SE \\
\hline Universidade Federal de Pelotas & Saúde bucal baseada em evidências & Flavio Fernando Demarco & Ciências da Saúde & Odontologia & S \\
\hline $\begin{array}{l}\text { Universidade Federal de } \\
\text { Pernambuco }\end{array}$ & $\begin{array}{l}\text { Centro de Pesquisas em Alergia e Imunologia } \\
\text { Clínica }\end{array}$ & José Ângelo Rizzo & Ciências da Saúde & Medicina & NE \\
\hline $\begin{array}{l}\text { Universidade Federal de } \\
\text { Pernambuco }\end{array}$ & $\begin{array}{l}\text { Design de fármacos para o combate de doenças } \\
\text { negligenciadas }\end{array}$ & Janaína Versiani dos Anjos & $\begin{array}{l}\text { Ciências Exatas e } \\
\text { da Terra }\end{array}$ & Química & NE \\
\hline $\begin{array}{l}\text { Universidade Federal de } \\
\text { Pernambuco }\end{array}$ & Etnofamacologia Aplicada & Rafael Matos Ximenes & \begin{tabular}{|l} 
Ciências \\
Biológicas
\end{tabular} & Farmacologia & NE \\
\hline $\begin{array}{l}\text { Universidade Federal de } \\
\text { Pernambuco }\end{array}$ & $\begin{array}{l}\text { Sistemas de liberação controlada de fármacos e } \\
\text { vacinas:Nanotecnologia Farmacéutica }\end{array}$ & Gilles Ponchel & Ciências da Saúde & Fammácia & $\mathrm{NE}$ \\
\hline
\end{tabular}




\section{Cont. Apêndice 5.}

\begin{tabular}{|c|c|c|c|c|c|}
\hline $\begin{array}{l}\text { Universidade Federal de Santa } \\
\text { Catarina }\end{array}$ & Células Tronco e Regeneração Tecidual & Andrea Goncalves Trentin & \begin{tabular}{|l} 
Ciências \\
Biológicas
\end{tabular} & Morfologia & s \\
\hline $\begin{array}{l}\text { Universidade Federal de Santa } \\
\text { Catarina }\end{array}$ & $\begin{array}{l}\text { CPIG - Centro de Pesquisa de Infecção em } \\
\text { Ginecologia }\end{array}$ & Edison Natal Fedrizzi & Ciências da Saúde & Medicina & s \\
\hline $\begin{array}{l}\text { Universidade Federal de Santa } \\
\text { Catarina }\end{array}$ & Farmacologia dos Antidepressivos & $\begin{array}{l}\text { Thereza Christina Monteiro de } \\
\text { Lima }\end{array}$ & \begin{tabular}{|l} 
Ciências \\
Biológicas
\end{tabular} & Famnacologia & s \\
\hline $\begin{array}{l}\text { Universidade Federal de Santa } \\
\text { Catarina }\end{array}$ & $\begin{array}{l}\text { Grupo de Estudos de Odontologia em Saúde } \\
\text { Coletiva }\end{array}$ & $\begin{array}{l}\text { Karen Glazer de Anselmo } \\
\text { Peres }\end{array}$ & Ciências da Saúde & Odontologia & s \\
\hline $\begin{array}{l}\text { Universidade Federal de Santa } \\
\text { Catarina }\end{array}$ & $\begin{array}{l}\text { Grupo de Pesquisa Translacional em Medicina } \\
\text { Tradicional Chinesa/Acupuntura }\end{array}$ & $\begin{array}{l}\text { Adair Roberto Soares dos } \\
\text { Santos }\end{array}$ & Ciências da Saúde & Medicina & s \\
\hline $\begin{array}{l}\text { Universidade Federal de Santa } \\
\text { Catarina }\end{array}$ & Imunologia das infeç̧öes microbianas e vacinas & Andre Luiz Barbosa Bafica & \begin{tabular}{|l} 
Ciências \\
Biológicas
\end{tabular} & Imunologia & s \\
\hline Universidade Federal de São Paulo & Distúrbios do Sono & Gilmar Fernandes do Prado & Ciências da Saúde & Medicina & SE \\
\hline Universidade Federal de São Paulo & $\begin{array}{l}\text { Efetividade das Intervençöes Terapêuticas e } \\
\text { Diagnósticas em Cirurgia Ortopédica e }\end{array}$ & Joao Carlos Belloti & Ciências da Saúde & Medicina & SE \\
\hline Universidade Federal de São Paulo & $\begin{array}{l}\text { Eventos de regeneraçäo no sistema } \\
\text { musculoesquelético }\end{array}$ & Flavio Faloppa & Ciências da Saúde & Medicina & SE \\
\hline Universidade Federal de São Paulo & Prática Baseada em Evidências & Maria Stella Peccin da Silva & Ciências da Saúde & $\begin{array}{l}\text { Fisioterapia e } \\
\text { Terapia } \\
\text { Ocupacional }\end{array}$ & SE \\
\hline Universidade Federal de São Paulo & $\begin{array}{l}\text { Qualidade e Gestão em Pesquisa na Área } \\
\text { Cirúrgica }\end{array}$ & Lydia Masako Ferreira & Ciências da Saúde & Medicina & SE \\
\hline
\end{tabular}

\begin{tabular}{|c|c|c|c|c|c|}
\hline Universidade Federal de São Paulo & Videocirurgia & $\begin{array}{l}\text { Joao Luiz Moreira Coutinho de } \\
\text { Azevedo }\end{array}$ & Ciências da Saúde & Medicina & SE \\
\hline Universidade Federal de Sergipe & $\begin{array}{l}\text { Aspectos Clínicos e Biomecânicos na Reabilitação } \\
\text { Oral }\end{array}$ & André Luís Faria e Silva & Ciências da Saúde & Odontologia & $\mathrm{NE}$ \\
\hline Universidade Federal de Sergipe & $\begin{array}{l}\text { Laboratório Multidisciplinar de Pesquisa em } \\
\text { Reabilitaçăo Funcional - LMPRF }\end{array}$ & Sibele de Andrade Melo Knaut & Ciências da Saúde & $\begin{array}{l}\text { Fisioterapia e } \\
\text { Terapia } \\
\text { Ocupacional }\end{array}$ & $\mathrm{NE}$ \\
\hline Universidade Federal de Sergipe & $\begin{array}{l}\text { LCMEP Laboratório de Controle Motor e Equilibrio } \\
\text { Postural }\end{array}$ & Miburge Bolivar Gois Junior & Ciências da Saúde & $\begin{array}{l}\text { Fisioterapia e } \\
\text { Terapia } \\
\text { Ocupacional }\end{array}$ & NE \\
\hline $\begin{array}{l}\text { Universidade Federal de } \\
\text { Uberlândia }\end{array}$ & Ánima & Eliane Maria de Carvalho & Ciências da Saúde & $\begin{array}{l}\text { Fisioterapia e } \\
\text { Terapia } \\
\text { Ocupacional }\end{array}$ & SE \\
\hline $\begin{array}{l}\text { Universidade Federal de } \\
\text { Uberländia }\end{array}$ & Biomecánica Aplicada à Odontologia Restauradora & Carlos José Soares & Ciências da Saúde & Odontologia & SE \\
\hline Universidade Federal do Ceará & Grupo de Pesquisa Translacional em Psiquiatia & Andre Ferrer Carvalho & Ciências da Saúde & Medicina & $\mathrm{NE}$ \\
\hline Universidade Federal do Ceará & $\begin{array}{l}\text { Grupo de Prevenção ao Uso Indevido de } \\
\text { Medicamentos }\end{array}$ & Paulo Sergio Dourado Arrais & Ciências da Saúde & Famnácia & NE \\
\hline Universidade Federal do Ceará & Laboratório Escola Prof. Luiz Capelo & Armenio Aguiar dos Santos & $\begin{array}{l}\text { Cièncias } \\
\text { Biológicas }\end{array}$ & Fisiologia & $\mathrm{NE}$ \\
\hline Universidade Federal do Ceará & $\begin{array}{l}\text { UNIFAC - Pesquisa pré-clínica e Clínica de } \\
\text { Fármacos e Medicamentos }\end{array}$ & $\begin{array}{l}\text { Manoel Odorico de Moraes } \\
\text { Filho }\end{array}$ & Ciências da Saúde & Medicina & $\mathrm{NE}$ \\
\hline $\begin{array}{l}\text { Universidade Federal do Espíito } \\
\text { Santo }\end{array}$ & Neuropsicofarmacologia & $\begin{array}{l}\text { Ester Miyuki Nakamura } \\
\text { Palacios }\end{array}$ & \begin{tabular}{|l} 
Ciências \\
Biológicas
\end{tabular} & Famacologia & SE \\
\hline
\end{tabular}




\section{Cont. Apêndice 5.}

\begin{tabular}{|c|c|c|c|c|c|}
\hline $\begin{array}{l}\text { Universidade Federal do } \\
\text { Recóncavo da Bahia }\end{array}$ & Grupo de Materiais Fotônicos & $\begin{array}{l}\text { Jorge Fernando Silva de } \\
\text { Menezes }\end{array}$ & $\begin{array}{l}\text { Ciências Exatas e } \\
\text { da Terra }\end{array}$ & Química & $\mathrm{NE}$ \\
\hline $\begin{array}{l}\text { Universidade Federal do Rio de } \\
\text { Janeiro }\end{array}$ & Mauro Schechter & Mauro Schechter & Ciências da Saúde & Medicina & SE \\
\hline $\begin{array}{l}\text { Universidade Federal do Rio de } \\
\text { Janeiro }\end{array}$ & Pesquisa Clinica em Pneumologia e Tisiologia & Marcus Barreto Conde & Ciências da Saúde & Medicina & SE \\
\hline $\begin{array}{l}\text { Universidade Federal do Rio } \\
\text { Grande do Norte }\end{array}$ & $\begin{array}{l}\text { Pesquisa científica em Dentistica e Materiais } \\
\text { Dentários }\end{array}$ & Boniek Castillo Dutra Borges & Ciências da Saúde & Odontologia & $\mathrm{NE}$ \\
\hline $\begin{array}{l}\text { Universidade Federal do Rio } \\
\text { Grande do Norte }\end{array}$ & PESQUISA CLÍNICA EM CIRURGIA & Irami Araújo Filho & Ciências da Saúde & Medicina & $\mathrm{NE}$ \\
\hline $\begin{array}{l}\text { Universidade Federal do Rio } \\
\text { Grande do Norte }\end{array}$ & $\begin{array}{l}\text { Radiobiologia Experimental e Ensaios } \\
\text { Farmacológicos e Toxicológicos }\end{array}$ & Louisianny Guerra da Rocha & \begin{tabular}{|l} 
Ciências \\
Biológicas
\end{tabular} & Famacologia & $\mathrm{NE}$ \\
\hline $\begin{array}{l}\text { Universidade Federal do Rio } \\
\text { Grande do Sul }\end{array}$ & $\begin{array}{l}\text { Avaliaçäo, Desenvolvimento e Implementação de } \\
\text { Terapias para Doenças }\end{array}$ & $\begin{array}{l}\text { Ida Vanessa Doederlein } \\
\text { Schwartz }\end{array}$ & \begin{tabular}{|l} 
Ciências \\
Biológicas
\end{tabular} & Genética & S \\
\hline $\begin{array}{l}\text { Universidade Federal do Rio } \\
\text { Grande do Sul }\end{array}$ & Genética Aplicada à Medicina & Moacir Wajner & \begin{tabular}{|l} 
Ciências \\
Biológicas
\end{tabular} & Genética & S \\
\hline $\begin{array}{l}\text { Universidade Federal do Rio } \\
\text { Grande do Sul }\end{array}$ & Neurogenética & Laura Bannach Jardim & Ciências da Saúde & Medicina & S \\
\hline $\begin{array}{l}\text { Universidade Federal do Rio } \\
\text { Grande do Sul }\end{array}$ & $\begin{array}{l}\text { Neuroprogressäo em transtomos psiquiátricos } \\
\text { severos }\end{array}$ & Clarissa Severino Gama & Ciências da Saúde & Medicina & S \\
\hline $\begin{array}{l}\text { Universidade Federal do Rio } \\
\text { Grande do Sul }\end{array}$ & $\begin{array}{l}\text { Variáveis clínicas, laboratoriais e de imagem em } \\
\text { Neurocirurgia }\end{array}$ & Marco Antonio Stefani & Ciências da Saúde & Medicina & S \\
\hline
\end{tabular}

\begin{tabular}{|c|c|c|c|c|c|}
\hline Universidade Federal Fluminense & Fisiopatologia das interaçóes linfocitánias & $\begin{array}{l}\text { Rita de Cássia dos Santos } \\
\text { Vasconcellos }\end{array}$ & $\begin{array}{l}\text { Ciências } \\
\text { Biologgicas }\end{array}$ & Imunologia & SE \\
\hline Universidade Federal Fluminense & Pesquisa pré-clinica e clínica de biomateriais & Jose Mauro Granjeiro & Ciências da Saúde & Odontologia & SE \\
\hline $\begin{array}{l}\text { Universidade Federal Rural do Rio } \\
\text { de Janeiro }\end{array}$ & Estatistica Aplicada & Marcelo Jangarelli & $\begin{array}{l}\text { Ciênncias Exatas e } \\
\text { da Terra }\end{array}$ & $\begin{array}{l}\text { Probabilidade e } \\
\text { Estatistica }\end{array}$ & SE \\
\hline $\begin{array}{l}\text { Universidade José do Rosário } \\
\text { Vellano }\end{array}$ & $\begin{array}{l}\text { Ensaios Farmacológicos, Carcinogénicos, } \\
\text { Mutagếnicos e Teratogêninicos de Produtos }\end{array}$ & $\begin{array}{l}\text { Marcelo Fabiano Gomes } \\
\text { Boniollo }\end{array}$ & $\begin{array}{l}\text { Ciências } \\
\text { Biológicas }\end{array}$ & Famacologia & SE \\
\hline $\begin{array}{l}\text { Universidade Metodista de } \\
\text { Piracicaba }\end{array}$ & Cièncias Famacêuticas & $\begin{array}{l}\text { Fátima Cristiane Lopes } \\
\text { Goularte Farhat }\end{array}$ & Ciências da Saúde & Fammácia & SE \\
\hline $\begin{array}{l}\text { Universidade Regional do Noroeste } \\
\text { do Estado do Rio Grande do Sul }\end{array}$ & Grupo de Pesquisa em Fisiologia - GPeF & Thiago Gomes Heck & \begin{tabular}{|l} 
Ciências \\
Biológicas
\end{tabular} & Fisiologia & S \\
\hline
\end{tabular}

FONTE: Diretório dos Grupos de Pesquisas - Plataforma Lattes, com adaptações próprias. 
APÊNDICE 6 - Matriz de colaboração entre as Unidades de Pesquisas Clínicas.

\begin{tabular}{|c|c|c|c|c|c|c|c|c|c|c|c|c|c|c|c|c|c|c|c|c|c|c|c|c|c|c|c|c|c|}
\hline & & & & & & & & & & & & & & & & & & & & & & & & & & & & & \\
\hline$\overline{1}$ & \begin{tabular}{|l|l|l}
1 & 1
\end{tabular} & & \begin{tabular}{|l|}
1 \\
\end{tabular} & 1 & 10 & 0 & & 1 & 0 & 0 & 0 & 0 & 1 & 0 & 0 & \begin{tabular}{|l|}
0 \\
\end{tabular} & 0 & 0 & 1 & 0 & 0 & \begin{tabular}{|l|}
0 \\
\end{tabular} & 0 & 0 & 1 & 0 & 0 & 0 & 0 \\
\hline 2 & \begin{tabular}{|l|l|l|} 
& 1 \\
\end{tabular} & 10 & 0 & 0 & 10 & 0 & & 1 & 0 & 0 & 0 & 0 & 0 & 0 & 0 & 0 & 0 & 10 & 0 & 0 & 0 & 0 & 0 & 0 & 0 & 0 & 0 & 0 & 0 \\
\hline 3 & $\begin{array}{lll}0 & 0\end{array}$ & $\begin{array}{ll}0 & 1\end{array}$ & 0 & 0 & 10 & 0 & & 0 & 0 & 0 & 0 & 0 & 0 & 0 & 0 & 0 & 0 & 0 & 0 & 0 & 0 & 0 & 0 & 0 & 0 & 0 & 0 & 0 & 0 \\
\hline$\overline{4}$ & \begin{tabular}{l|l|l|l|l}
1 & \\
\end{tabular} & & 1 & 0. & 10 & 0 & & 1 & 0 & 0 & 0 & 0 & 0 & 0 & 0 & 0 & 0 & 0 & 1 & 0 & 0 & 0 & 0 & 0 & 0 & 0 & 0 & 0 & 0 \\
\hline 5 & \begin{tabular}{l|l|l}
10 & 0 \\
\end{tabular} & & 0 & $\begin{array}{ll}1 \\
\end{array}$ & 10 & 0 & & 1 & 0 & 0 & 0 & 1 & 0 & 1 & 0 & 0 & 0 & 0 & 1 & 0 & 0 & 0 & 1 & 1 & 1 & 0 & 0 & 0 & 0 \\
\hline 6 & \begin{tabular}{|l|l|l|l|} 
& 1 \\
\end{tabular} & $\begin{array}{lll}1 & 1\end{array}$ & 1 & 1. & 11 & 1 & & 1 & 1 & 1 & 1 & 1 & 1 & 1 & 1 & 1 & 1 & 1 & 1 & 1 & 1 & 1 & 1 & 1 & 1 & 1 & 1 & 1 & 1 \\
\hline 7 & \begin{tabular}{l|l}
0 & 0 \\
\end{tabular} & 00 & 0 & 0. & 1 & 0 & & 0 & 0 & 0 & 0 & 0 & 0 & 0 & 0 & 0 & 0 & 0 & 0 & 0 & 0 & 0 & 0 & 0 & 0 & 0 & 0 & 0 & 0 \\
\hline 8 & $\begin{array}{lll}0 & 0 \\
\end{array}$ & 00 & 0 & 0. & 10 & 1 & & 1 & 0 & 0 & 0 & 0 & 0 & 0 & 0 & 0 & 0 & 0 & 0 & 0 & 0 & 0 & 0 & 0 & 0 & 0 & 0 & 0 & 0 \\
\hline 9 & \begin{tabular}{l|l|l}
10 & 0 \\
\end{tabular} & 00 & 1 & 0. & 1 & 1 & & 1 & 0 & 0 & 0 & 0 & 0 & 0 & 0 & 0 & 0 & 0 & 1 & 1 & 0 & 0 & 1 & 0 & 0 & 0 & 0 & 0 & 0 \\
\hline 10 & \begin{tabular}{|l|l}
1 & 1 \\
\end{tabular} & 10 & 1 & 1. & 10 & 1 & & 1 & 1 & 1 & 1 & 0 & 0 & 0 & 0 & 1 & 1 & 1 & 1 & 1 & 1 & 1 & 0 & 1 & 1 & 1 & 1 & 0 & 1 \\
\hline 11 & $\begin{array}{llll}0 & 0\end{array}$ & & 0 & 0. & 10 & 0 & & 1 & 1 & 0 & 0 & 0 & 0 & 0 & 0 & 0 & 0 & 0 & 0 & 0 & 0 & 0 & 0 & 0 & 0 & 0 & 0 & 0 & 0 \\
\hline 12 & $\begin{array}{llll}0 & 0 \\
\end{array}$ & & 0 & 0. & 10 & 0 & & 1 & 0 & 1 & 1 & 0 & 0 & 0 & 1 & 0 & 0 & 0 & 1 & 0 & 0 & 0 & 0 & 0 & 1 & 0 & 0 & 0 & 0 \\
\hline 13 & $\begin{array}{lllll}0 & 0 \\
\end{array}$ & & 0 & 0. & 10 & 0 & & 1 & 0 & 1 & 1 & 0 & 0 & 0 & 0 & 0 & 0 & 0 & 0 & 0 & 0 & 0 & 0 & 0 & 0 & 0 & 0 & 0 & 0 \\
\hline 14 & $\begin{array}{lllll}0 & 0 \\
\end{array}$ & & 0 & 1. & 10 & 0 & & 0 & 0 & 0 & 0 & 1 & 0 & 0 & 0 & 0 & 0 & 0 & 1 & 0 & 0 & 0 & 0 & 0 & 0 & 0 & 0 & 0 & 0 \\
\hline 15 & \begin{tabular}{l|ll}
1 & 0
\end{tabular} & & 0 & 0 & 10 & 0 & & 0 & 0 & 0 & 0 & 0 & 1 & 0 & 0 & 0 & 0 & 0 & 0 & 0 & 0 & 0 & 0 & 0 & 0 & 0 & 0 & 0 & 0 \\
\hline \begin{tabular}{|l|}
16 \\
\end{tabular} & 00 & & 0 & 1 & 10 & 0 & & 0 & 0 & 0 & 0 & 0 & 0 & 1 & 0 & 0 & 0 & 0 & 0 & 0 & 0 & 0 & 0 & 0 & 0 & 0 & 0 & 0 & 0 \\
\hline \begin{tabular}{|l|}
17 \\
\end{tabular} & 00 & & 0 & 0 & 10 & 0 & & 0 & 0 & 1 & 0 & 0 & 0 & 0 & 1 & 0 & 0 & 0 & 0 & 0 & 0 & 0 & 0 & 0 & 0 & 0 & 0 & 0 & 0 \\
\hline \begin{tabular}{|l|}
18 \\
\end{tabular} & \begin{tabular}{l|l}
0 & 0
\end{tabular} & & 0 & 0 & 10 & 0 & & 1 & 0 & 0 & 0 & 0 & 0 & 0 & 0 & 1 & 0 & 0 & 0 & 0 & 0 & 0 & 0 & 0 & 0 & 0 & 0 & 0 & 0 \\
\hline \begin{tabular}{|l|}
19 \\
\end{tabular} & 00 & 00 & 0 & 0 & 10 & 0 & & 1 & $\overline{0}$ & 0 & 0 & 0 & 0 & 0 & 0 & 0 & 1 & 0 & 0 & 0 & 0 & 0 & 0 & 0 & 0 & 0 & 0 & 0 & 0 \\
\hline 20 & \begin{tabular}{l|l}
0 & 0 \\
\end{tabular} & 00 & 0 & 0 & 10 & 0 & & 1 & 0 & 0 & 0 & 0 & 0 & 0 & 0 & 0 & 0 & 1 & 0 & 0 & 0 & 0 & 0 & 0 & 0 & 0 & 0 & 0 & 0 \\
\hline 21 & \begin{tabular}{l|ll}
1 & 0 \\
\end{tabular} & 00 & \begin{tabular}{|l|}
1 \\
\end{tabular} & 1 & 10 & 0 & & 1 & $\overline{0}$ & 1 & 0 & 1 & 0 & 0 & 0 & 0 & 0 & 0 & 1 & 1 & 0 & 1 & 0 & 0 & & 0 & 0 & 0 & 1 \\
\hline 22 & \begin{tabular}{l|l}
0 & 0 \\
\end{tabular} & 00 & 0 & 0. & 10 & 0 & & 1 & $\overline{0}$ & 0 & 0 & 0 & 0 & 0 & 0 & 0 & 0 & 0 & 1 & 1 & 0 & 0 & 0 & 0 & 0 & 0 & 0 & 0 & 0 \\
\hline 23 & \begin{tabular}{l|ll}
0 & 0 \\
\end{tabular} & 00 & 0 & 0. & 10 & 0 & & 1 & $\overline{0}$ & 0 & 0 & 0 & 0 & 0 & 0 & 0 & 0 & 0 & 0 & 0 & 1 & 0 & 0 & 0 & 0 & 0 & 0 & 0 & 0 \\
\hline \begin{tabular}{|l|}
24 \\
\end{tabular} & $\begin{array}{lll}0 & 0 \\
\end{array}$ & 00 & 0 & 0. & 10 & 0 & & 1 & 0 & 0 & 0 & 0 & 0 & 0 & 0 & 0 & 0 & 0 & 1 & 0 & 0 & 1 & 0 & 0 & 0 & 0 & 0 & 0 & 0 \\
\hline 25 & \begin{tabular}{l|l}
0 & 0 \\
\end{tabular} & 00 & 0 & 1 & 10 & 0 & & 0 & $\overline{0}$ & 0 & 0 & 0 & 0 & 0 & 0 & 0 & 0 & 0 & 0 & 0 & 0 & 0 & \begin{tabular}{l|l|} 
\\
\end{tabular} & 0 & 0 & 0 & 0 & 0 & 0 \\
\hline \begin{tabular}{|l|}
26 \\
\end{tabular} & $\begin{array}{lll}0 & 0\end{array}$ & 00 & 0 & 1 & 10 & 0 & & 1 & $\overline{0}$ & 0 & 0 & 0 & 0 & 0 & 0 & 10 & 0 & 0 & 0 & 0 & 0 & 0 & 0 & 1 & 0 & 0 & 0 & 0 & 0 \\
\hline 27 & \begin{tabular}{l|l|l}
10 & 0 \\
\end{tabular} & 00 & 0 & 1 & 10 & 0 & & 1 & 0 & 1 & 0 & 0 & 0 & 0 & 0 & 0 & 0 & 0 & 1 & 0 & 0 & 0 & 0 & 0 & 1 & 0 & 1 & 0 & 0 \\
\hline 28 & $\begin{array}{lll}0 & 0 \\
\end{array}$ & 00 & 0 & 0. & 10 & 0 & & 1 & 0 & 0 & 0 & 0 & 0 & 0 & 0 & 0 & 0 & 0 & 0 & 0 & 0 & 0 & 0 & 0 & 0 & 1 & 0 & 0 & 0 \\
\hline 29 & $\begin{array}{lll}0 & 0\end{array}$ & 00 & 0 & 0. & 10 & 0 & 0 & \begin{tabular}{l|l}
1 \\
\end{tabular} & 0 & 0 & 0 & 0 & 0 & 0 & 0 & 0 & 0 & 0 & 0 & 0 & 0 & 0 & 0 & 0 & 1 & 0 & 1 & 0 & 0 \\
\hline 30 & $\begin{array}{lll}0 & 0\end{array}$ & 00 & 0 & 0. & 10 & 0 & 0 & 0 & 0 & 0 & 0 & 0 & 0 & 0 & 0 & $\begin{array}{ll}0 \\
\end{array}$ & 0 & 0 & 0 & 0 & 0 & 0 & 0 & 0 & 0 & 0 & 0 & 1 & 0 \\
\hline & & & & & & & & & & & & & & & & & & & & & & & & & & & & & \\
\hline
\end{tabular}

1. FIOCRUZ

2. FMTA

3. $\mathrm{HC} / \mathrm{HJBB}$

4. HUAP/UFF

5. $\mathrm{HC} / \mathrm{UFG}$

6. HC/UFMG

7. HC/UNICAMP

8. HC/UNIFESP

9. $\mathrm{HC} / \mathrm{USP}$

10. HCPA

11. HG/UPE

12. $\mathrm{HGF}$

13. HM/UFC

14. HU/UEM

15. HSR

16. HU/UFBA

17. HU/UFC

18. HU/UFMA

19. HU/UFRJ

20. HU/UFRN

21. HU/UNESP

22. HU/UNISUL

23. HU/USP

24. HUB/UnB

25. HU-USP/RP

26. IC-FUC/RS

27. IMIP

28. INC

29. INCA

30. INTO

31. PUC/RS

Fonte: Elaboração própria a partir das entrevistas e análise dos questionários. 
ANEXOS 
ANEXO 1 - Parecer cosubstanciado do Comitê de Ética em Pesquisas da Faculdade de Medicina da USP, via Plataforma Brasil.

\section{FACULDADE DE MEDICINA DA UNIVERSIDADE DE SÃO PAULO - FMUSP}

\section{PARECER CONSUBSTANCIADO DO CEP}

\section{DADOS DO PROJETO DE PESQUISA}

Título da Pesquisa: A Gestão de Redes de Pesquisa Científica, Tecnológica e de Inovação em Saúde no Brasil

Pesquisador: Moisés Goldbaum

Área Temática:

Versão: 1

CAAE: 15899213.0 .0000 .0065

Instituição Proponente: Faculdade de Medicina da Universidade de São Paulo

Patrocinador Principal: Financiamento Próprio

\section{DADOS DO PARECER}

Número do Parecer: 295.904

Data da Relatoria: 29/05/2013

Apresentação do Projeto:

Trata-se de um projeto de doutorado no qual é feito um estudo exploratório sobre Redes de pesquisa em ciência e tecnologia na área da saúde e um estudo de caso. O projeto está apresentado de forma correta, com objetivos bem definidos, seção de Materiais e Métodos com descrição detalhada, seção de resultados esperados e bibliografia adequada.

Objetivo da Pesquisa:

O objetivo da pesquisa, "compreender as estruturas, mecanismos e processos que influenciam na organização, conformação e efetivação de redes de ciência, tecnologia e inovação em saúde, buscando identificar condicionantes de processos, e indicadores de monitoramento e avaliação, visando potencializar o fomento e a gestão dessas redes no cenário brasileiro" é muito amplo e pouco específico, mas é aceitável para um estudo exploratório de caso.

Avaliação dos Riscos e Beneficios:

Trata-se de estudo teórico e de obtenção de informações técnicas através e questionários, de modo que não apresenta qualquer risco.

Comentários e Considerações sobre a Pesquisa:

Dado o tamanho do investimento que o Ministério da Saúde vem fazendo nas redes de pesquisa em ciência e tecnologia em sua área, um projeto que visa identificar sua efetividade e sua

Endereço: DOUTOR ARNALDO 455
$\begin{aligned} & \text { Bairro: PACAEMBU } \\ & \text { UF: SP } \quad \text { Município: SAO PAULO }\end{aligned}$
$\begin{aligned} & \text { Telefone: } \\ & \text { (11)3061- } 9004\end{aligned}$


Cont. Anexo 1.

\section{FACULDADE DE MEDICINA DA UNIVERSIDADE DE SÃO PAULO - FMUSP}

Contnuaçăo do Parecer. 295.904

eficiência é necessário e bem vindo.

Considerações sobre os Termos de apresentação obrigatória:

É apresentado o TCLE, que é bastante claro e, embora não seja apresentado o questionário, é apresentada a metodologia para a sua elaboração após a revisão da literatura e um piloto a ser realizado com alguns dos pesquisadores envolvidos na rede escolhida para o estudo de caso.

Recomendações:

Não há.

Conclusões ou Pendências e Lista de Inadequações:

Não há inadequações. O projeto deve ser aprovado.

Situação do Parecer:

Aprovado

Necessita Apreciação da CONEP:

Não

Consideraçôes Finais a critério do CEP:

Aprovado

SAO PAULO, 06 de Junho de 2013

Assinador por:

Paulo Euripedes Marchiori

(Coordenador)

Endereço: DOUTOR ARNALDO 455
$\begin{aligned} & \text { Bairro: PACAEMBU } \\ & \text { UF: SP }\end{aligned} \quad$ Municipio: SAO PAULO
$\begin{aligned} & \text { Telefone: } \\ & \text { (11)3061-9004 }\end{aligned}$


ANEXO 2 - Aprovação do Comitê de Ética com número de protocolo da pesquisa.

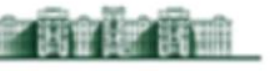 \\ MEDICINA \\ [TS \\ COMITÊ DE ÉTICA EM PESQUISA}

\section{APROVAÇÃO}

O Comitê de Ética em Pesquisa da Faculdade de Medicina da Universidade de São Paulo, em sessão de 29/05/2013, APROVOU o Protocolo de Pesquisa n 199/13 intitulado: "A GESTÃO DE REDES DE PESQUISA CIENTÍFICA, TECNOLÓGICA E DE INOVAÇÃO EM SAÚDE NO BRASIL” apresentado pelo Departamento de MEDICINA PREVENTIVA

Cabe ao pesquisador elaborar e apresentar ao CEPFMUSP, os relatórios parciais e final sobre a pesquisa (Resolução do Conselho Nacional de Saúde $n^{\circ}$ 196, de 10/10/1996, inciso IX.2, letra "c").

Pesquisador (a) Responsável: Moisés Goldbaum

Pesquisador (a) Executante: Marge tenório

CEP-FMUSP, o7 de Junho de 2013.

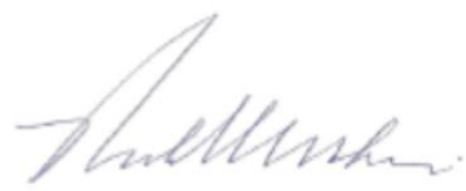

Prof. Dr. Paulo Eurípedes Marchiori

Vice-Coordenador

Comitê de Ética em Pesquisa 
ANEXO 3 - Autorização de acesso aos dados pelo Departamento de Ciência e Tecnologia - Decit do Ministério da Saúde.

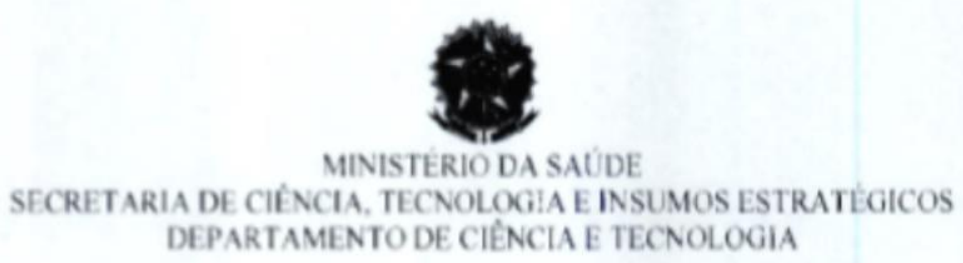

AUTORIZAÇÃO

Autorizo Marge Tenório, discente do Programa de Medicina Preventiva da Universidade de São Paulo (USP), sob orientação do Prof. Dr. Moisés Goldbaum, acesso aos dados da Rede Nacional de Terapia Celular e da Rede Nacional de Pesquisa Clínica, para o desenvolvimento do seu projeto de doutorado intitulado: "A Gestão de Redes de Pesquisa Cientifica, Tecnológica e de Inovação em Saùde no Brasil":

Brasilia, 16 de abril de 2013.

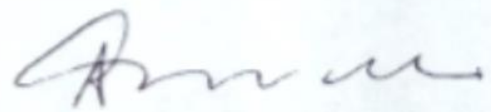

ANTONIO CARLOS CAMPOS DE CARVALHO

Diretor do Departamento de Ciência e Tecnologia

whas caries Corpos de Cantaiko

Diretor do Depahamento de

ciancia e Tecnokogia 
ANEXO 4 - Autorização de acesso aos dados pelo Conselho Nacional de desenvolvimento Científico e Tecnológico - CNPq.

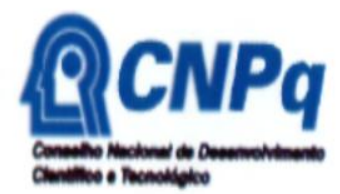

Ministério da Ciência, Tecnologia e Inovaçáo

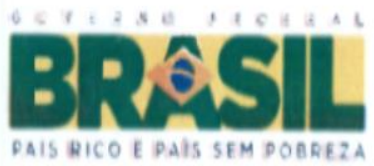

AUTORIZAÇÃo

Autorizo Marge Tenório, discente do Programa de Medicina Preventiva da Universidade de Sào Paulo (USP), sob orientaçào do Prof. Dr. Moisés Goldbaum, acesso aos projetos concluidos, relatórios, atas de reuniòes e demais documentos referentes às Redes de Terapia Celular e de Pesquisa Clínica, para o desenvolvimento do seu projeto de doutorado intitulado: "A Gestào de Redes de Pesquisa Cientifica, Tecnológica e de Inovação em Sauide no Brasil".

Brasilia, 04 de abril de 2013.

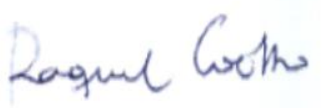

$$
\begin{gathered}
\text { Rauquel de Andrade Lime Coutho } \\
\text { Coordenadon Geral do Programa de } \\
\text { Pesquisa em Saide } \\
\text { PO 233/2007 }
\end{gathered}
$$


REFERÊNCIAS 


\section{REFERÊNCIAS ${ }^{\mathrm{i}}$}

ACEDO, Francisco J.; BARROSO, Carmen; CASANUEVA, Cristobal; GALÁN, José

L. Co-Authorship in Management and Organizational Studies: An Empirical and Network Analysis. Journal of Management Studies. 2006; 43(5): 957-983.

ACERO, Luciana; KLEIN, Helena E. Ciência e colaboração científica: as publicações em pesquisa e terapia celular no Brasil. Parcerias Estratégicas. 2013; 18(37): 49-70.

ADAMIL, Eliana R.; CHEMIN, Márcia R.C.; FRANÇA, Beatriz H. S. Aspectos éticos e bioéticos da pesquisa clínica no Brasil. Estud Biol. 2014; 36: SE07.

AGÊNCIA NACIONAL DE VIGILÂNCIA SANITÁRIA (Anvisa). Resolução da Diretoria Colegiada - RDC n ${ }^{\circ}$ 9, de 20 de fevereiro de 2015. [Citado 12 abr 2016]. Disponível em: http://portal.anvisa.gov.br/wps/wcm/connect/c3dc820047823081b0a7fbfe096a5d32/r dc0009_20_02_2015.pdf?MOD=AJPERES

AGÊNCIA NACIONAL DE VIGILÂNCIA SANITÁRIA (Anvisa). Sistema de Notificação em vigilância Sanitária - Notivisa. [Citado 16 abr 2016]. Disponível em: http://redesentinela-anvisa.blogspot.com.br/p/sobre-rede-sentinela.html 
ALBUQUERQUE, Mariana V. O enfoque regional na política de saúde brasileira (2001-2011): diretrizes nacionais e o processo de regionalização nos estados brasileiros. Tese (doutorado). São Paulo: Faculdade de Medicina da Universidade de São Paulo; 2013.

ALCADIPANI, Rafael; TURETA, César. Teoria ator-rede e análise organizacional; contribuições e possibilidades de pesquisa no Brasil. Organizações \& Sociedade. 2009; 16 (51): 647-664.

ALMEIDA-ANDRADE, Priscila. Avaliação da Política Nacional de Ciência, Tecnologia e Inovação em Saúde: contribuições para a pesquisa \& desenvolvimento em biotecnologia em saúde (2004 - 2014). Tese (doutorado). Brasília: Universidade de Brasília; 2015.

BALANCIERI, Renato et al. A análise de redes de colaboração científica sob as novas tecnologias de informação e comunicação: um estudo na Plataforma Lattes. Ciência da Informação. 2005; 34(1): 64-77.

BARDIN, Laurence. Análise de conteúdo. São Paulo: Edições 70. 2011, 229 p.

BARRETO, Maurício L. O conhecimento científico e tecnológico como evidência para políticas e atividades regulatórias em saúde. Ciência \& Saúde Coletiva. 2004; 9(2): 329-338. 
BAXTER, Pamela; JACK, Suzan. Qualitative case study methodology: study design and implementatio for novice researchers. The Qualitative Report. 2008; 13: 544-559.

BEAVER, Donald; ROSEN, Richard. Studies in Scientific Collaboration: Part I. The professional origins of scientific co-authorship. Scientometrics. 1978; 1: 65-84.

BOTELHO, Antonio José J.; ALVES, Alex S. As lacunas de inovação em Saúde no Brasil: entre a produção de ciência e tecnologia na saúde. In: Costa, Lais S; Bahia, Ligia; Gadelha, Carlos Augusto G. (Org.) Saúde, Desenvolvimento e Inovação. CEPESC, Rio de Janeiro. 2015; 1: 279-309.

BRASIL. Presidência da República. Constituição da República Federativa do Brasil 1988. [Citado 10 dez 2015]. Disponível em: http://www.planalto.gov.br/ccivil_03/constituicao/ConstituicaoCompilado.htm

BRASIL. Ministério da Saúde. Conselho Nacional de Saúde. Resolução No. 196 de 10 de outubro de 1996, Brasília: 1996. [Citado 12 dez 2015]. Disponível em: http://conselho.saude.gov.br/comissao/Conep/resolucao.html

BRASIL. Anais da II Conferência Nacional de Ciência, Tecnologia e Inovação em Saúde. Brasília: Ed. Ministério da Saúde. 2005, 272 p.

BRASIL. Ministério da Saúde. Saúde no Brasil: Contribuições para a Agenda de Prioridades de Pesquisa. Brasília: Ed. Ministério da Saúde, 2006, 304 p. 
BRASIL. Ministério da Saúde, Secretaria de Ciência, Tecnologia e Insumos Estratégicos. Relatório de Gestão 2005 do Departamento de Ciência e Tecnologia. Brasília: Ed. Ministério da Saúde. 2007a, 273 p.

BRASIL. Ministério da Saúde, Secretaria de Ciência, Tecnologia e Insumos Estratégicos. Relatório de Gestão 2006 do Departamento de Ciência e Tecnologia. Brasília: Ed. Ministério da Saúde. 2007b, 267 p.

BRASIL. Ministério da Saúde. Secretaria de Ciência, Tecnologia e Insumos Estratégicos. Departamento de Ciência e Tecnologia. Política Nacional de Ciência, Tecnologia e Inovação em Saúde. Brasília: Ed. Ministério da Saúde. 2008, 44 p.

BRASIL. Ministério da Saúde, Secretaria de Ciência, Tecnologia e Insumos Estratégicos. Departamento de Ciência e Tecnologia. Proposta para ampliação da Rede Nacional de Pesquisa Clínica. 2009. [Citado 12 dez 2015]. Disponível em: http://www.portal.saude.gov.br/portal/arquivos/pdf/ampliação_RNPC.pdf

BRASIL. Ministério da Saúde, Secretaria de Ciência, Tecnologia e Insumos Estratégicos. Departamento de Ciência e Tecnologia. Rede Nacional de Pesquisa Clínica do Brasil: respostas e redução da dependência estrangeira. Rev. Saúde Pública. 2010a; 44(3): 575-578. 
BRASIL. Ministério da Saúde, Secretaria de Ciência, Tecnologia e Insumos Estratégicos. Departamento de Ciência e Tecnologia. Rede Nacional de Pesquisa Clínica: Brasília, Ed. Ministério da Saúde. 2010b, 108 p.

BRASIL. Ministério da Saúde. Secretaria de Ciência, Tecnologia e Insumos Estratégicos. Departamento de Ciência e Tecnologia. Agenda Nacional de Prioridades de Pesquisa em Saúde. Brasília: Ed. Ministério da Saúde. 2011a, 68 p.

BRASIL. Ministério da Saúde. Secretaria de Ciência, Tecnologia e Insumos Estratégicos. Departamento de Ciência e Tecnologia. Política Nacional de Gestão de Tecnologia em Saúde. Brasília: Ed. Ministério da Saúde. 2011b, 48 p.

BRASIL. Ministério do Desenvolvimento, Indústria e Comércio. Plano Brasil Maior 2011/2014. 2011c [Citado 04 abr 2016]. Disponível em: http://www.brasilmaior.mdic.gov.br/wp-content/uploads/2011/08/apresentacao_completa_final.pdf

BRASIL. Ministério da Saúde. Conselho Nacional de Saúde. Resolução N ${ }^{o} .466$ de 12 de dezembro de 2012. Brasília: 2012. [Citado 12 dez 2015]. Disponível em: http://conselho.saude.gov.br/resolucoes/2012/Reso466.pdf

BRASIL. Ministério da Saúde. Portaria $N^{o}$ 137, de 24 de janeiro de 2014. Dispõe sobre as Redes Nacionais de Pesquisa em Saúde. Brasília: 2014. [Citado 05 jan 2016]. Disponível em: http://bvsms.saude.gov.br/bvs/saudelegis/gm/2014/prt0137_24_01_2014.html 
BRASIL. Portal Brasil. Países dos BRICS discutem população e desenvolvimento. 2015. [Citado 16 abr 2016]. Disponível em http://www.brasil.gov.br/governo/2015/02/paises-dos-brics-discutem-populacao-edesenvolvimento

CAMARGO, Fausto; VERSCHOORE, Jorge; PADILHA, Livia. A dinâmica estrutural da gestão interorganizacional: o papel do gestor sob a perspectiva da análise de redes sociais. Base. 2013; 10(1): 43-54.

CARAMORI, Carlos A. Institucionalização da Pesquisa Clínica na Faculdade de Medicina de Botucatu UNESP: Pesquisa Clínica, Ensino Médico, Desenvolvimento, Inovação. 2013; [Citado 13 dez 2015] Disponível em: https://books.google.com.br/books/about/Institucionaliza\%C3\%A7\%C3\%A3o_da_P esquisa_Cl\%C3\%ADni.html?hl=pt-BR\&id=K2dbBAAAQBAJ

CARVALHO, Emília Campos de et al. Da produção à utilização de resultados de pesquisa na prática assistencial: uma experiência em consolidação. Rev. bras. enferm. 2010; 63(5): 853-858.

CASSIOLATO, José Eduardo; LASTRES, Helena M. M. Sistemas de inovação e desenvolvimento: as implicações de política. São Paulo Perspec. 2005; 19(1): 34-45.

CASTELLS, Manuel. A sociedade em rede - a era da informação: economia, sociedade e cultura. Paz e Terra. 1999; 1: 17-49. 
CAVALCANTE, Luiz R. Desigualdades regionais em Ciência, Tecnologia e Inovação (CT\&I) no Brasil: uma análise de sua evolução recente. Rio de Janeiro: Instituto de Pesquisa Econômica Aplicada - IPEA, Texto para discussão (1574), 2011.

CONDESSA, Mirta B. A política atual para a regulação de medicamentos no Brasil. [Citado 12 abr 2016] Disponível em: http://www.unieuro.edu.br/sitenovo/revistas/downloads/farmacia/cenarium_02_01.pdf

CONSELHO NACIONAL DE DESENVOLVIMENTO CIENTÍFICO E TECNOLÓGICO (CNPq). Plataforma Lattes. [Citado 12 dez 2015a]. Disponível em: http://buscatextual.cnpq.br/buscatextual/busca

CONSELHO NACIONAL DE DESENVOLVIMENTO CIENTÍFICO E TECNOLÓGICO (CNPq). Diretório dos Grupos de Pesquisas. [Citado 12 dez 2015b]. Disponível em: http://dgp.cnpq.br/dgp/faces/consulta/consulta_parametrizada.jsf

CORLEY, Elizabeth A.; BOARDMAN Craig; BOZEMAN, Barry. Design and the management of multi-institutional research collaborations: Theoretical implications from two case studies. Research Policy. 2006; 35: 975 - 993.

COSTA, Karen S. Acesso e uso de medicamentos: inquéritos de saúde como estratégia de avaliação. Tese (doutorado). Campinas: Faculdade de Ciências Médicas da Universidade Estadual de Campinas; 2014. 
COSTA, Lais S; GADELHA, Carlos A.G; MALDONADO, José. A perspectiva territorial da inovação em saúde: a necessidade de um novo enfoque. Rev. Saúde Pública. 2012; 46(1): 59-67.

COSTA, Laís Silveira. Análise da dinâmica de geração de inovação em saúde: a perspectiva dos serviços e do território. Tese (doutorado). Rio de Janeiro: Escola Nacional de Saúde Pública, Fiocruz; 2013.

DA COSTA LEITE, Iuri et al. Carga de doença no Brasil e suas regiões, 2008. Cad. Saúde Pública. 2015; 31(7): 1551-1564.

DAINESI, Sônia M.; GOLDBAUM, Moisés. Pesquisa clínica como estratégia de desenvolvimento em saúde. . Rev Assoc Med Bras. 2012; 58(1): 2-6.

DAL POZ, Maria Ester S. Redes de inovação em biotecnologia: genômica e direitos de propriedade intelectual. Tese (doutorado). Campinas: Universidade Estadual de Campinas; 2006.

DE SOLLA Price; DEREK J.; BEAVER, Donald. Collaboration in an invisible college. American. Psychologist. 1966; 21(11): 1011-1018.

DEBORAH, Zarin A. et al. The ClinicalTrials.gov Results Database - Update and Key Issues. N Engl J Med. 2011; 364: 852-860. 
DEMOTES-MAINARD, J.; KUBIAK, C. A European perspective-the European clinical research infrastructures network. Annals of oncology. 2011; 22, (Suppl 7): vii44-vii49.

ELIAS, Flávia T. S. A importância da Avaliação de Tecnologias para o Sistema Único de Saúde. BIS, Bol. Inst. Saúde. 2013; 14(2): 143-150.

ETZKOWITZ, Henry.; LEYDESDORFF, Loet. The dynamics of innovation: from national systems and 'Mode 2' to a triple helix of university-industry-government relations. Research Policy. 2000; 29: 823-833.

FINANCIADORA DE ESTUDOS E PROJETOS (Finep). Implantação de Unidades de Pesquisa Clínica 2005. [Citado 13 dez 2015]. Disponível em: http://www.finep.gov.br/chamadas-publicas/chamadapublica/481

FLEURY, Sonia T. Redes de políticas: novos desafios para a gestão pública. Revista Administração em Diálogo-RAD. 2008; 7(1).

FLEURY, Sonia; TEIXEIRA, Sonia Maria Fleury. Gestão de redes: a estratégia de regionalização da política de saúde. Rio de Janeiro: FGV Editora. 2011, 204 p.

FONTANELLA, Bruno J.B. et al. Amostragem por saturação em pesquisas qualitativas em saúde: contribuições teóricas. Cad. Saúde Pública. 2008; 24: 17-27. 
GADELHA, Carlos Augusto. G. et al. O complexo industrial da saúde no Brasil: dinâmica de inovação e implicações para o Sistema nacional de inovação em saúde. Revista Brasileira de Inovação. 2013; 12(2): 251-282.

GADELHA, Carlos Augusto. G.; COSTA, Lais S.; BAHIA, Ligia. Reflexões sobre saúde na agenda conteporânea do desenvolvimento. In: COSTA, Lais S; BAHIA, Ligia; GADELHA, Carlos Augusto G. (Org.) Saúde, Desenvolvimento e Inovação. Rio de Janeiro: 2015a; 2: 43-69.

GADELHA, Carlos Augusto. G.; VARGAS, Marcos A.; MALDONADO, José; COSTA, Laís S. Complexo econômico-industrial da saúde. In: Saúde Desenvolvimento e Inovação. COSTA, Laís, S.; BAHIA, Ligia; GADELHA, Carlos A. G. Rio de Janeiro: CEPESC-IMS/UERJ - Fiocruz - IESC/UFRJ. 2015b; 2: 41-63.

GARCIA, Marcelo O. O processo de transferência de tecnologia em universidades mineiras pela ótica da teoria ator-rede. Dissertação (Mestrado). Viçosa: Universidade Federal de Viçosa; 2015.

GIBBONS, Michael. et. al. The New Production of Knowledge: The Dynamics of Science and Research in Contemporary Societies. London: Sage. 2011, 179 p.

GOLDBAUM, Moisés; SERRUYA, Suzanne. O Ministério da Saúde e a política de ciência, tecnologia e inovação em saúde. Cad. Saúde Pública. 2006; 22(3): 470-471. 
GOLDSMITH, Stephen; EGGERS,William D. Governança em rede: o novo formato do setor público. Brasília/São Paulo: ENAP/ UNESP. 2006, 259 p.

GONZALES, Zuleika Köhler; BAUM, Carlos. Desdobrando a Teoria Ator-Rede: reagregando o social no trabalho de Bruno Latour. Revista Polis e Psique. 2013; 3(1): 142.

GUIMARÃES, Reinaldo; VIANNA, Cid Manso M. "Ciência e tecnologia em saúde: tendências mundiais, diagnóstico global e estado da arte no Brasil." Anais da I Conferência Nacional de Ciência e Tecnologia em Saúde. Brasília, 1994: 115-236.

GUIMARAES, Reinaldo. Pesquisa no Brasil: a reforma tardia. Perspec. 2002; 16(4): 41-47.

GUIMARAES, Reinaldo et al. Defining and implementing a National Policy for Science, Technology, and Innovation in Health: lessons from the Brazilian experience. Cad. Saúde Pública. 2006; 22(9): 1775-1794.

GUIMARÃES, Reinaldo. Desafios da pós-graduação em saúde humana no Brasil. Rev. Saúde Pública. 2011; 45(1): 1-13.

GUIMARÃES, Reinaldo. Pesquisa Translacional: uma interpretação. Cienc Saude Coletiva. $2013 ; 18(6): 1731-44$. 
HADDAD, Eduardo A.; MENA-CHALCO, Jesús P.; SIDONE, Otávio J.G. Scholarly Collaboration in Regional Science in Developing Countries The Case of the Brazilian REAL Network. International Regional Science Review. 2015: 0160017615614898.

INSTITUTO BRASILEIRO DE GEOGRAFIA E ESTATÍSTICA (IBGE). [Citado 19 abr 2016]. Disponível em: http://www.ibge.gov.br/paisesat/main_frameset.php

IOZZI, Fabiola L. Ciência, Tecnologia e Inovação no Brasil: Panorama atual das políticas federais para Saúde. In: VIANA, Ana Luiza d'A; IBAÑES, Nelson; BOUSQUAT, Aylene. (Org). Saúde desenvolvimento, ciência, tecnologia e Inovação. São Paulo: Hucitec-Cealag. 2012: 150-173.

JOHNSON, J. David. Gestão de redes de conhecimento. São Paulo: Ed. SENAC. 2011,440 p.

KUBIAK C. et al. Common definition for categories of clinical research: a prerequisite for a survey on regulatory requirements by the European Clinical Research Infrastructures Network (ECRIN). Trials 2009; 10 (1): 95.

LASTRES, Maria Helena M.; CASSIOLATO, José Eduardo. Inovação e sistemas de inovação: relevância para a área de saúde. RECIIS - Revista Eletrônica de Comunicação, Informação e Inovação em Saúde. 2007; 1(1): 153-162. 
LATOUR, Bruno. Reagregando o social: uma introdução à teoria do ator-rede. Salvador: Edufba. 2012, 400 p.

LEYDESDORFF, Loet; ETZKOWITZ, Henry. Emergence of a triple helix of university-industry-government relations. Science and Public Policy. 1996; 23:279286.

LIMA, Suzana Maria. V.; DE CASTRO, Antônio Maria. G.; BORGES-ANDRADE, Jairo Eduardo; DE CARVALHO, José Ruy P. Inovação e gestão tecnológica em organizações de P\&D: um modelo integrador. Cadernos de Ciência \& Tecnologia, Brasília. 2004; 21(1): 83-103.

LONG, Janet C.; CUNNINGHAM, Frances C.; BRAITHWAITE, Jeffrey. Bridges, brokers and boundary spanners in collaborative networks: a systematic review. $B M C$ health services research. 2013; 13(1): 1.

MAIA, Paulo Ricardo S. et al. Bases conceituais para uma estratégia de gestão: o caso da Rede Nacional de Bancos de Leite Humano. Cad. saúde pública. 2004; 20(6): 17001708.

MAROTTI, Marcelo. Quais são os objetivos clínicos que determinam a eficácia dos tratamentos em oncologia? Rev. Assoc. Med. Bras. 2007; 53 (6): 477-478. 
MARQUES, Eduardo C. Redes sociais e instituições na construção do estado e da sua permeabilidade. Revista Brasileira de Ciências Sociais. 1999; 14(41): 45-67.

MARQUES, Eduardo C. Os mecanismos relacionais. Revista Brasileira de Ciências Sociais. 2007a; 22(64): 157-161.

MARQUES, E. Redes sociais, segregação e pobreza em São Paulo. Tese (Livre docência). São Paulo: Faculdade de Filosofia, Letras e Ciências Humanas, Universidade de São Paulo, 2007b.

MARTINS, Wagner J.; ARTMANN, Elizabete; RIVERA Francisco J.U. Gestão comunicativa para redes cooperativas de ciência, tecnologia e inovação em saúde. Rev. de Saúde Pública. 2012; 46(Spe): 51-58.

MARTINS, Wagner de Jesus. Gestão estratégica das redes cooperativas de ciência, tecnologia e inovação em saúde: um modelo para o desenvolvimento socioeconômico e a sustentabilidade do SUS. Tese (doutorado). Rio de Janeiro: Escola Nacional de Saúde Pública, Fiocruz; 2013.

MELO, Maria A.C.; AGOSTINHO, Marcia C.E. Gestão Adaptativa: uma proposta para o gerenciamento de Redes de inovação. Revista de administração contemporânea. 2007; 11(2): 93-111. 
MENA-CHALCO, Jesus P; CESAR-JR. Roberto M. scriptLattes: An open-source knowledge extraction system from the Lattes Platform. Journal of the Brazilian Computer Society. 2009; 15(4): 31-39.

MENA-CHALCO, Jesús P. et al. Brazilian bibliometric coauthorship networks. Journal of the Association for Information Science and Technology. 2014; 65: 14241445.

MENDES, Eugênio V. Revisão bibliográfica sobre redes de atenção à saúde. Secretaria de Estado de Saúde de Minas Gerais, 2007. [Citado 02 mar 2016] Disponível em: http://portalses.saude.sc.gov.br/index.php?option=com_docman\&task=doc_downloa $\mathrm{d} \&$ gid $=4241 \&$ Itemid $=82$

MENDES, Eugênio V. As redes de atenção à saúde. Ciência \& Saúde Coletiva. 2010; 15(5): 2297-2305.

METTEN, Antoine, COSTA, Lais; GADELHA, Carlos Augusto G.; MARDONADO, José. A introdução do complexo econômico industrial da saúde na agenda de desenvolvimento: uma análise a partir do modelo de fluxos múltiplos de Kingdon. Revista de Administração Pública. 2015; 49 (4): 915-936.

MINAYO, Maria Cecília S. Pesquisa social: teoria, método e criatividade. Rio de Janeiro: Ed. Vozes, 2010. 
MORAES, M. A ciência como rede de atores: ressonâncias filosóficas. História, Ciência e Saúde - Manguinhos. 2004; 11(2): 321-33.

MULLINS, Nicholas.C. et al. Group structure of co-citation clusters: a comparativestudy. American. Sociological Review. 1977; 42(4): 552-562.

NATIONAL INSTITUTE OF HEALTH (NIH). [Citado 20 abr 2016]. Disponível em: http://grants.nih.gov/grants/glossary.htm\#ClinicalTrial

NISHIOKA, Sergio A.; Sá, Paula Frassinete G. A. Agência Nacional de Vigilância Sanitária e a pesquisa clínica no Brasil. Rev Assoc Med Bras. 2006; 52(1): 60-2.

NODARI, Cristine H. et al. Configuração das práticas de inovação na atenção primária à saúde: estudo de caso. Ciência \& Saúde Coletiva. 2015; 20: 3073-3086.

PALMEIRA FILHO, Pedro L. et al. O desafio do financiamento à inovação farmacêutica no Brasil: a experiência do BNDES Profarma. Revista do BNDES Setorial. 2012; 37: 67-90.

PAULA, Ana P. et al. Clinical investigations for SUS, the brazilian public health system. São Paulo Med J. 2012; 130(3): 179-86. 
PINHO, Renata G.; PAIVA, Vitor P.; BORGES André L.; PIERONI João Paulo et al. Ensaios clínicos no Brasil: competitividade internacional e desafios. BNDES Setorial 2012; 36: 45-84.

QUENTAL, Cristiane; GADELHA, Carlos Augusto G.; FIALHO, Beatriz C. O papel dos institutos públicos de pesquisa na inovação farmacêutica. Rev. de Adm. Publica. 2001; 35(5): 135-161.

QUENTAL, Cristiane; SALLES FILHO, Sérgio. Ensaios clínicos: capacitação nacional para avaliação de medicamentos e vacinas. Rev. bras. Epidemiol. 2006; 9(4): 408-424.

QUENTAL, Cristiane. Infraestrutura científica e tecnológica para apoio ao CEIS Seguimento biofarmacêutico. In: FIOCRUZ et al. (Org.). A Saúde no Brasil em 2030: prospecção estratégica do sistema de saúde brasileiro. Desenvolvimento produtivo e complexo da saúde. Rio de Janeiro: Ed. Fiocruz, 2013: 159 - 192.

RAPINI, Márcia Siqueira. Interação universidade-empresa no Brasil: evidências do Diretório dos Grupos de Pesquisa do CNPq. Estud. Econ. 2007; 37(1): 211-233.

RODAN, Simon; GALUNIC, Charles. More than network structure: how knowledge heterogeneity influences managerial performance and innovativeness. Strategic Management Journal. 2004; 25(6): 541-562. 
ROSSONI, Luciano; HOCAYEN-DA-SILVA, Antonio João; JÚNIOR, Israel F. Estrutura de relacionamento entre instituições de pesquisa do campo de Ciência de Tecnologia no Brasil. RAE-Rev de Adm Empresas. 2008; 48(4): 34-48.

SCHUMPETER, Joseph A. Development. In: Journal of Economic Literature. 2005; 43: 108-120.

SILVA, Ricardo E. Aspectos Éticos, Legais e Tendências no Desenvolvimento de Ensaios Clínicos no Brasil. Dissertação (Mestrado). Brasília: Universidade de Brasília; 2013.

SILVA, Rondineli M.; CAETANO, Rosangela. Um exame dos fluxos financeiros do Ministério da Saúde em pesquisa e desenvolvimento (2003-2005), segundo a Agenda Nacional de Prioridades de Pesquisa em Saúde. Cad. Saúde Pública. 2011; 27(4): 687700.

THE CLINICALTRIALS. [Citado 28 abr 2016]. Disponível em: https://clinicaltrials.gov/

TORRES-FREIRE, Carlos; GOLGHER, Denise; CALLIL, Victor. Biotecnologia em saúde humana no Brasil: produção científica e pesquisa e desenvolvimento. Novos estud. - CEBRAP. 2014; 98: 69-93. 
TURETA, César; ALCADIPANI, Rafael. O objeto objeto na análise organizacional: a teoria ator-rede como método de análise da participação dos não-humanos no processo organizativo. Cadernos EBAPE. 2009; 7(1): 50-70.

UNESCO Science Report: towards 2030. 2015. [Citado 26 abr 2016] Disponível em: http://unesdoc.unesco.org/images/0023/002354/235406e.pdf

VALE, Gláucia Maria V.; AMÂNCIO, Robson; DE LIMA, Juvêncio B. criação e gestão de redes: uma estratégia competitiva para empresas e regiões. RAUP. 2006; 41(2): 136-146.

VARDA, Danielle M.; RETRUM, Jessica H.; An Exploratory Analysis of Network Characteristics and Quality of Interactions among Public Health Collaboratives. Journal of public health research. 2012; 1(2): 170-176.

VARGAS, Marco Antonio et al. Indústrias de Base Química e a Biotecnologia Voltadas para a Saúde no Brasil: panorama atual e perspectivas para 2030. In: Fiocruz. A saúde no Brasil em 2030 - prospecção estratégica do sistema de saúde brasileiro: desenvolvimento produtivo e complexo da saúde. Rio de Janeiro: Fiocruz/Ipea/Ministério da Saúde/Secretaria de Assuntos Estratégicos da Presidência da República. 2013; 5: 31-78.

VARGAS, Marco Antonio; RIBEIRO, Leonardo C; PAIVA, Leonardo; GADELHA, Carlos Augusto. G.A inovação nos seguimentos químicos e biotecnológicos da saúde: 
nichos estratégicos e lacunas. In: COSTA, Lais S; BAHIA, Ligia; GADELHA, Carlos Augusto G. (Org.) Saúde, Desenvolvimento e Inovação. Rio de Janeiro: CEPESC. $2015 ; 2: 105-138$.

VELHO, Léa. Redes regionais de cooperação em C\&T e o Mercosul. In: Parcerias Estratégicas. Brasília: IPEA. 2001; 10: 59-71.

VIANA, Ana Luiza d'Ávila; ELIAS, Paulo E. M. Saúde e Desenvolvimento. Ciência e Saúde Coletiva. 2007; 12, (Supl.)1765-1777.

VIANA, Ana Luiza d'Ávila; IOZZI, Fabiola L.; ALBUQUERQUE, Mariana V.; BOUSQUAT, Aylene. Saúde, desenvolvimento e inovação tecnológica: nova perspectiva de abordagem e de investigação. São Paulo: Lua Nova Editora. 2011; 83(1): 41-77.

VIANA, Ana Luiza d'Ávila; IBAÑES, Nelson; BOUSQUAT, Aylene. (Org). Saúde desenvolvimento, ciência, tecnologia e Inovação. São Paulo: Hucitec-Cealag: 2012; 931.

VIANA, Ana Luiza d'Ávila; SILVA, Hudson P.; IOZZI, Fabiola L.; ALBUQUERQUE, Mariana V. et al. Políticas públicas para o desenvolvimento em saúde no Brasil. In: ANDRADE, L.O.M. et al. (Org). Conhecimento e inovação em Saúde: experiência do Brasil e Canadá. Campinas: Saberes Editora. 2012a: 29-65. 
VIANA, Ana Luiza d'Ávila; SILVA, Hudson P. Relação Estado, mercado e sociedade no Brasil: arranjos assistenciais e produtivos na saúde. In: VIANA, Ana Luiza d'Ávila; IBAÑES, Nelson; BOUSQUAT, Aylene. (Org). Saúde desenvolvimento, ciência, tecnologia e Inovação. São Paulo, Hucitec-Cealag. 2012b: 105-129.

VIANA, Ana Luiza d'Ávila; DA FONSECA, Ana Maria Medeiros. Estado de crise: dimensões política e social da crise atual no Brasil e no exterior. Bem comum, esfera pública e ética como sentido e nexos da universalidade. Revista Continentes. 2016; 1(7): 106-120.

VIANNA, Cid Manso M.; KROPF, Marcelo; RODRIGUES, Marcus Paulo S; MOSEGUI, Gabriela B. Interesses produtivos e sociais da saúde no âmbito do sistema nacional de inovação: uma análise da experiência do Instituto Nacional de Traumatologia e Ortopedia. In: COSTA, Lais S; BAHIA, Ligia; GADELHA, Carlos Augusto G. (Org.) Saúde, Desenvolvimento e Inovação. Rio de Janeiro: CEPESC, 2015; 1: 173-201.

VIEIRA, Sônia; HOSSNE, William S. Metodologia científica para a área da saúde. Rio de Janeiro: Elsevier Brasil, 2015, 179 p.

YIN, Robert K. Estudo de Caso: Planejamento e Métodos. Porto Alegre: Bookman, 2005. 
YOUTIE, Jan; LIBAERS, Dirk; BOZEMAN, Barry. Institutionalization of university research centers: the case of the National Cooperative Program in Infertility Research. Technovation. 2006; 26(9): 1055-1063.

ZAGO, Marco Antonio. A pesquisa clínica no Brasil. Ciência \& Saúde Coletiva 2004; 9(2): 363-374.

\footnotetext{
${ }^{\mathrm{i}}$ De acordo com:

Adaptado de International Committee of Medical Journals Editors (Vancouver). Universidade de São Paulo. Faculdade de Medicina. Serviço de Biblioteca e Documentação. Guia de apresentação de dissertações, teses e monografias da FMUSP. Elaborado por Anneliese Carneiro da Cunha, Maria Julia A.L. Freddi, Maria F. Crestana, Marinalva de S. Aragão, Suely C. Cardoso, Valéria Vilhena. 3a ed. São Paulo: Divisão de Biblioteca e Documentação; 2011. Abreviaturas dos títulos dos periódicos de acordo com List of Journals Indexed in Index Medicus.
} 